\title{
AGNP Consensus Guidelines for Therapeutic Drug Monitoring in Psychiatry: Update 2011
}

Authors

Affiliations

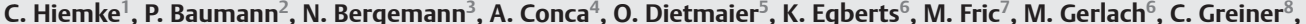
G. Gründer ${ }^{9}$, E. Haen ${ }^{10}$, U. Havemann-Reinecke ${ }^{11}$, E. Jaquenoud Sirot ${ }^{12}$, H. Kirchherr ${ }^{13}$, G. Laux ${ }^{7}$, U. C. Lutz ${ }^{14}$, T. Messer ${ }^{15}$, M. J. Müller ${ }^{16}$, B. Pfuhlmann ${ }^{17}$, B. Rambeck ${ }^{18}$, P. Riederer ${ }^{17}$, B. Schoppek ${ }^{19}$, J. Stingl ${ }^{20}$, M. Uhr ${ }^{21}$, S. Ulrich ${ }^{22}$, R. Waschgler ${ }^{23}$, G. Zernig ${ }^{24}$

Affiliation addresses are listed at the end of the article
Key words

- consensus guidelines

- drug analysis

- pharmacokinetics

- psychotropic drugs

- reference ranges

- therapeutic drug monitoring

- therapeutic window
Bibliography

DOI http://dx.doi.org/

10.1055/s-0031-1286287

Pharmacopsychiatry 2011; 44: 195-235

(c) Georg Thieme Verlag KG Stuttgart · New York

ISSN 0176-3679

Correspondence

\section{Hiemke, PhD, Univ.-Prof.}

Department of Psychiatry and Psychotherapy

University Medical Center,

Mainz

D-55101 Mainz

Germany

Tel.: +49/6131/177 131

Fax: $+49 / 6131 / 176789$

hiemke@uni-mainz.de

\section{Abstract \\ $\nabla$}

Therapeutic drug monitoring (TDM), i.e., the quantification of serum or plasma concentrations of medications for dose optimization, has proven a valuable tool for the patient-matched psychopharmacotherapy. Uncertain drug adherence, suboptimal tolerability, non-response at therapeutic doses, or pharmacokinetic drug-drug interactions are typical situations when measurement of medication concentrations is helpful. Patient populations that may predominantly benefit from TDM in psychiatry are children, pregnant women, elderly patients, individuals with intelligence disabilities, forensic patients, patients with known or suspected genetically determined pharmacokinetic abnormalities or individuals with pharmacokinetically relevant comorbidities. However, the potential benefits of TDM for optimization of pharmacotherapy can only be obtained if the method is adequately integrated into the clinical treatment process. To promote an appropriate use of TDM, the TDM expert group of the Arbeitsgemeinschaft für Neuropsychopharmakologie und Pharmakopsychiatrie (AGNP) issued guidelines for TDM in psychiatry in 2004. Since then, knowledge has advanced significantly, and new psychopharma-

\section{Introduction}

$\nabla$

In psychiatry, around 130 drugs are now available which have been detected and developed during the last 60 years [54]. These drugs are effective and essential for the treatment of many psychiatric disorders and symptoms. Despite enormous medical and economic benefits, however, therapeutic outcomes are still far from satisfactory for many patients $[5,6,396,661]$. Therefore, after having focused clinical research on the development of new drugs during more cologic agents have been introduced that are also candidates for TDM. Therefore the TDM consensus guidelines were updated and extended to 128 neuropsychiatric drugs. 4 levels of recommendation for using TDM were defined ranging from "strongly recommended" to "potentially useful". Evidence-based "therapeutic reference ranges" and "dose related reference ranges" were elaborated after an extensive literature search and a structured internal review process. A "laboratory alert level" was introduced, i.e., a plasma level at or above which the laboratory should immediately inform the treating physician. Supportive information such as cytochrome P450 substrateand inhibitor properties of medications, normal ranges of ratios of concentrations of drug metabolite to parent drug and recommendations for the interpretative services are given. Recommendations when to combine TDM with pharmacogenetic tests are also provided. Following the guidelines will help to improve the outcomes of psychopharmacotherapy of many patients especially in case of pharmacokinetic problems. Thereby, one should never forget that TDM is an interdisciplinary task that sometimes requires the respectful discussion of apparently discrepant data so that, ultimately, the patient can profit from such a joint effort.

than 5 decades [521,522], growing evidence suggests that improving the way the available medications are administered may bring substantial benefit to patients [45]. Evidence-based guidelines for optimum treatment have been published during the last decade $[23,46,101,204,205,221,234$, 254, 276, 284, 582, 585,748].

A valuable tool for tailoring the dosage of the prescribed medication(s) to the individual characteristics of a patient is therapeutic drug monitoring (TDM). The major reason to use TDM for the guidance of psychopharmacotherapy is the 
considerable interindividual variability in the pharmacokinetic properties of the patient $[524,526]$. At the very same dose, a more than 20-fold interindividual variation in the medication's steady state concentration in the body may result, as patients differ in their ability to absorb, distribute, metabolize and excrete drugs due to concurrent disease, age, concomitant medication or genetic peculiarities [61,94,310,311,334,335,374]. Different formulations of the same medication may also influence the degree and temporal pattern of absorption and, hence, medication concentrations in the body. TDM uses the quantification of drug concentrations in blood plasma or serum to titrate the dose of individual patients so that a drug concentration associated with highest possible probability of response and tolerability and a low risk of toxicity can be obtained. Moreover, TDM has the possible and widely unexploited potential to improve cost-effectiveness of psychopharmacotherapy $[527,660]$. For a considerable number of psychopharmacologic compounds, the quantification of the medications' plasma concentration has become clinical routine for dose adjustment. Clear evidence of the benefits of TDM has been given for tricyclic antidepressants, a number of old and new antipsychotic drugs and for conventional mood stabilizing drugs $[51,459,505]$. For lithium, TDM has become a standard of care due to its narrow therapeutic range [133,395].

The benefits of TDM regarding the optimization of pharmacotherapy, however, can only be obtained if the method is adequately integrated into the clinical treatment process. Current TDM use in psychiatric care is obviously suboptimal $[134,700,742]$. Similar to other medical disciplines, systematic studies have demonstrated that the inappropiate use of TDM is widespread. Inappropriate TDM testing wastes laboratory resources and also bears the risk that misleading results will adversely influence clinical decision making [122]. A study on the clinical use of TDM for tricyclic antidepressants in psychiatric university hospital settings showed that between 25 and $40 \%$ of the requests for TDM were inappropriate and the interpretation of the results led to about $20 \%$ of inappropriate therapeutic adjustments [700,742]. Other typical errors were absence of steady-state conditions and transcription errors on the request form [700,743]. Studies on TDM for antidepressant and mood stabilizing drugs further specified the information on the inappropriate use of TDM $[420,421]$.

Against this background, the TDM group of the Arbeitsgemeinschaft für Neuropsychopharmakologie und Pharmakopsychiatrie (AGNP) issued best practice guidelines for TDM in psychiatry in 2004 [51]. These guidelines were widely accepted by many laboratories and practicing clinicians. They have been cited more than 200 times in the literature and were translated into German [312] and French [50]. Moreover, they were summarized for depression [52]. The AGNP-TDM consensus guidelines have also been implemented in recent international guidelines on the treatment of mental diseases [582]. Since 2004, knowledge on TDM has advanced significantly. New psychotropic medications have been introduced which are also candidates for TDM. The TDM group of the AGNP therefore decided to prepare an updated version of their guidelines.

\section{Objectives of this Consensus Document}

This document addresses topics related to the theory and practice of TDM in psychiatry. The first part deals with theoretical aspects of monitoring drug plasma concentrations. The second part defines indications for TDM and gives reference drug plasma concentrations for dose optimization. The third part describes the best practice of the process of TDM, which starts with the request and ends with the clinical decision to either continue or change the pre-TDM pharmacotherapy.

Aiming to optimise the practice of TDM the following topics were addressed:

- definition of indications to utilize TDM in psychiatry

- definition of graded levels of recommendations to use TDM

- definition of therapeutic reference ranges ("therapeutic windows") and dose-related reference ranges that laboratories can quote and clinicians can use to guide the psychopharmacotherapy

- definition of alert levels for laboratories to warn the treating physician when plasma concentrations are considered to be too high and potentially harmful

- recommendations and help for interpretative services

- recommendations concerning the combination of TDM with pharmacogenetic tests

\section{Preparation of the Consensus Document \\ $\nabla$}

The updated consensus guidelines were prepared by the interdisciplinary TDM group of the AGNP consisting of clinical psychiatrists, pharmacologists, biochemists, pharmacists and chemists from academic and non academic hospitals and institutions of Germany, Switzerland, Austria and Italy, who have been involved for many years in the development and implementation of TDM for psychotropic medications in everyday clinical practice. The experts compiled information from the literature and worked out the present best practice guidelines aiming at promoting the appropriate use of TDM in psychiatry. Because TDM is widely used in daily clinical practice for antidepressant, antipsychotic and mood stabilizing drugs, these 3 pharmacologic classes are extensively represented in the present guidelines. Anxiolytic and hypnotic drugs, antidementia drugs, drugs for treatment of substance abuse related disorders and other psychotropic drugs are also candidates for TDM and are thus covered in the present guidelines. In special situations, the measurement of drug plasma concentrations can be helpful for any drug. Many patients are simultaneously treated for neurologic and psychiatric disorders. Therefore, the updated guidelines also contain information on anticonvulsant and antiparkinson drugs which are also more or less well established candidates for TDM $[481,499]$ and were thus extended from 65 psychiatric drugs in 2004 [51] to 128 neuropsychiatric drugs at present.

Data published in the AGNP consensus guidelines 2004 [51] and other guidelines and recommendations for TDM of primarily antidepressant and antipsychotic drugs $[317,400,488-490$, $504,505]$ were initially used as the basis for this update. An extensive literature search was conducted, primarily in MEDLINE, to identify TDM-related information for the surveyed 128 neuropsychiatric drugs. The search concentrated on reports on "optimum plasma concentrations", "dose related drug plasma concentrations", "cytochrome P450 substrate, inducer and inhibitor properties" and on "ratios of concentrations of drug metabolites to parent drugs". Relevant reports were also searched by hand in pharmacologic and clinical chemical journals dealing with TDM. Over 1000 articles were assessed and 
analysed. Extracted data on reference ranges were listed in tables by 7 authors ( $\mathrm{CH}, \mathrm{EH}, \mathrm{CG}, \mathrm{BR}, \mathrm{PR}, \mathrm{HK}$ ). Results of the literature search and analyses were sent out for review to 20 members of the TDM group with inclusion of a checklist how to extract and analyse the data. An internet based and passwordprotected platform was built up for the reviewers to have access to relevant articles. The reviewers' protocols and commentaries were distributed to all authors of these guidelines. Final decisions on data reported in this document were made during 2 consensus conferences and by e-mail communication. Consensus making also included definitions of reference ranges, alert levels and graded levels of recommendations to utilize TDM.

\section{Theoretical Aspects of TDM in Psychiatry}

$\nabla$

Pharmacokinetics, metabolism and pharmacogenetics of neuropsychiatric drugs

Most psychotropic drugs share a number of pharmacokinetic characteristics

- good absorption from the gastrointestinal tract within plasma concentrations reaching a maximum within $1-6 \mathrm{~h}$

- highly variable first-pass metabolism (systemic bioavailability ranging 5-90\%)

- fast distribution from plasma to the central nervous system with 2- to 40-fold higher levels in brain than in blood

- high apparent volume of distribution (about 10-50 L/kg)

- low trough plasma concentrations under steady-state (about $0.1-500 \mathrm{ng} / \mathrm{mL}$ for psychoactive drugs and up to $20 \mu \mathrm{g} / \mathrm{mL}$ for neurological drugs)

- slow elimination from plasma (half-life 12-36h) mainly by hepatic metabolism

- linear pharmacokinetics at therapeutic doses which has the consequence that doubling the daily dose will result in a doubling of the plasma level

- low renal excretion with small effect of renal insufficiency on the plasma concentrations of parent drug and active metabolites

- cytochrome P450 (CYP) and UDP-glucuronosyltranferases as major metabolic enzyme systems

There are, however, numerous exceptions. For example, venlafaxine, nefazodone, trazodone, tranylcypromine, moclobemide, quetiapine, rivastigmine and ziprasidone display short (about 2-10h) elimination half-lives, whereas aripiprazole and fluoxetine have long elimination half-lives ( $72 \mathrm{~h}$ for aripiprazole and 3-15 days for fluoxetine, taking into account its active metabolite norfluoxetine). Amisulpride, milnacipran, memantine, gabapentin, or sulpiride are not or only poorly metabolised in the liver but also mainly excreted renally. Paroxetine exhibits non-linear pharmacokinetics, due to the inhibition of its own metabolism by a metabolite which is irreversibly bound to the enzyme (mechanism based inhibition) resulting in its inactivation [69].

Many psychotropic drugs are used as racemic compounds, and their enantiomers differ markedly in their pharmacology, metabolism and pharmacokinetics [53,605]. So far however, methadone, methylphenidate and flupentixol are at present the only racemic psychotropic compounds for which TDM of the enantiomers has been introduced $[39,189]$. The active principles of racemic methadone and fluoxetine are (R)-methadone and cis-(Z)-flupentixol, respectively. For research projects and other special situations, stereoselective analysis should be considered, e.g., for citalopram, fluoxetine, reboxetine, venlafaxine, paliperidone or amitriptyline metabolites.
Most psychotropic drugs undergo phase-I metabolism by oxidative (e.g., hydroxylation, dealkylation, oxidation to N-oxides, S-oxidation to sulfoxides or sulfones), reductive (e.g., carbonyl reduction to secondary alcohols) or hydrolytic reactions, dealkylation, oxidation to $\mathrm{N}$-oxides, carbonyl reduction to secondary alcohols or S-oxidation to sulfoxides or sulfones. The phase-I reactions are predominantly catalysed by cytochrome P450 (CYP) enzymes which comprise more than 200 isoenzymes. The most important isoenzymes for psychotropic medications are CYP1A2, CYP2B6, CYP2D6, CYP2C9, CYP2C19 and CYP3A4/5 (๑ Table 1) [745-747]. In general, phase-I reactions introduce a polar functional group that enables a phase-II conjugation reaction with highly polar molecules such as glucuronic or sulphuric acid. For psychotropic compounds possessing functional groups in the parent compound, glucuronidation of a hydroxyl group (for example oxazepam or lorazepam) or an $\mathrm{N}-\mathrm{H}$ group (for example olanzapine) may represent the essential metabolic pathway. In addition, tertiary amine groups can be conjugated with the formation of quaternary ammonium glucuronides. Actually, phase II enzymes are poorly characterised with regard to substrate specificity, and there is much overlap between the isozymes regarding affinity for substrates [143]. Other enzymatic systems may also be involved, such as ketoaldehyde oxidases [43], which have been shown to reduce ziprasidone to its dihydro-derivative [58] or naltrexone to naltrexol [92], or MAO-A and MAO-B, which deaminate citalopram stereoselectively to an apparently inactive acidic metabolite [562].

Drugs are metabolised mainly in the liver and, to a minor degree, in extrahepatic tissues such as the intestinal mucosa or the brain $[59,238,444]$. Inter- and intra-individual differences in plasma concentrations of psychotropic drugs (i.e., the pharmacokinetic variability) are caused by different activities of drug-metabolising enzymes. The enzyme activity may decrease with age [374] and can be modified by renal and hepatic diseases. Gender differences have been reported for psychotropic drugs, but the findings are inconsistent and the clinical relevance is not clear [7-9,608].

For a number of psychoactive drugs, metabolites actively contribute to the overall clinical effect of the parent compound. For this reason, TDM must include the quantification of active metabolites, e.g., in the case of clomipramine (norclomipramine), doxepin (nordoxepin), fluoxetine (norfluoxetine) or risperidone (9-hydroxyrisperidone). For drugs like sertraline or clozapine, the clinical relevance of their metabolites norsertraline and norclozapine, respectively, is still a matter of debate. The analysis of pharmacologically inactive metabolites, however, may give useful information on the metabolic state of the patient or on his/her compliance $[105,569]$. $\odot$ Table 2 shows the "normal" ratios of concentrations of metabolites to parent drugs. Calculated ranges contain $68 \%$ of the ratios expected under standard dosages, i.e., ratios within the range of the mean $\pm 1 \mathrm{SD}$ assuming normal distribution. A ratio above or below the "normal ratio" ( $\bullet$ Table 2 ) can indicate problems of drug adherence [546] or metabolic abnormalities due to a genetic variation $[157,159,350,592]$ or a drug-drug interaction. Spina and coworkers [618] have shown this for the conversion of 2-hydroxydesipramine to desipramine. With regard to drug-drug interactions, ratios increase if the enzymatic conversion of the parent medication is induced by concurrent psychotropic or non-psychotropic medications or pharmacokinetically relevant activities such as smoking ( $\bullet$ Table 3 ). Other co-medications and food 
Table 1 Psychopharmacologic medications and enzymes involved in their metabolism.

\begin{tabular}{|c|c|c|}
\hline Drug (active metabolite) & Enzymes & Reference \\
\hline Acamprosate & not involved (not metabolized) & [578] \\
\hline Agomelatine & CYP1A2, CYP2C19 & [78] \\
\hline Amantadine & merely involved ( $90 \%$ excreted unmetabolized) & {$[24]$} \\
\hline Alprazolam & CYP3A4/5 & {$[17,496]$} \\
\hline Amisulpride & $\begin{array}{l}\text { merely involved (more than } 90 \% \text { is excreted } \\
\text { unmetabolized via the kidney) }\end{array}$ & [566] \\
\hline Amitriptyline and amitriptyline oxide (amitriptyline, nortriptyline) & CYP1A2, CYP2C9, CYP2C19, CYP2D6, CYP3A4 & {$[90,650,713]$} \\
\hline Aripiprazole (dehydroaripiprazole) & CYP2D6, CYP3A4 & {$[306,701]$} \\
\hline Asenapine & Glucuronosyltransferase and CYP1A2 & [707] \\
\hline Atomoxetine & CYP2D6 & [446] \\
\hline Benperidol & unclear & [589] \\
\hline Benserazide & hydroxylation, COMT & [347] \\
\hline Biperiden & hydroxylation & [628] \\
\hline Bromocriptine & CYP3A4 & [513] \\
\hline Bromperidol & CYP3A4 & {$[230,633,645,736]$} \\
\hline Brotizolam & CYP3A4 & [655] \\
\hline Buprenorphine (norbuprenorphine) & CYP2C8, CYP3A4 & {$[79,454]$} \\
\hline Bupropion (hydroxybupropion) & CYP2B6 & [309] \\
\hline Buspirone & CYP3A4 & [416] \\
\hline Cabergoline & hydrolysis, CYP3A4 & [167] \\
\hline Carbidopa & unknown metabolic pathways $1 / 3$ unmetabolized & [575] \\
\hline Carbamazepine, CBZ (CBZ-10,11-epoxide)* & CYP1A2, CYP2B6, CYP2C8, CYP3A4/5 & {$[360,497]$} \\
\hline Chlorpromazine & CYP1A2, CYP2D6 & {$[724]$} \\
\hline Citalopram & CYP2C19, CYP2D6, CYP3A4 & {$[97,227,739]$} \\
\hline Clomipramine (norclomipramine) & CYP1A2, CYP2C19, CYP2D6, CYP3A4 & [244] \\
\hline Clomethiazol & CYP2A6, CYP2B6, CYP3A4 & [116] \\
\hline Clozapine & CYP1A2, CYP2C19, CYP3A4 & {$[334,487]$} \\
\hline Desipramine & CYP2D6 & {$[244]$} \\
\hline Diazepam (nordazepam, oxazepam, temazepam) & CYP2B6, CYP2C19, CYP3A4 & {$[228,704]$} \\
\hline Dihydroergocryptine & CYP3A4 & {$[19,162]$} \\
\hline Diphenhydramine & CYP2D6 & [13] \\
\hline Disulfiram & CYP1A2, CYP2B6, CYP2E1, CYP3A4 & [412] \\
\hline Donepezil & CYP2D6, CYP3A4 & [681] \\
\hline Dothiepin = Dosulepin & CYP2C19, CYP2D6 & {$[740]$} \\
\hline Doxepin (nordoxepin) & CYP2C9, CYP2C19, CYP2D6 & {$[295,365]$} \\
\hline Duloxetine & CYP1A2, CYP2D6 & [405] \\
\hline Entacapone & Glucuronosyltransferase & [387] \\
\hline Escitalopram & CYP2C19, CYP2D6, CYP3A4 & {$[662,697]$} \\
\hline Fluoxetine (norfluoxetine) & CYP2B6, CYP2C9, CYP2C19, CYP2D6 & {$[404,588]$} \\
\hline Flupenthixol & CYP2D6 & {$[148,365]$} \\
\hline Fluphenazine & CYP2D6 & [746] \\
\hline Fluvoxamine & CYP2D6, CYP1A2 & {$[354,450]$} \\
\hline Galantamine & CYP2D6, CYP3A4 & [34] \\
\hline Gabapentin & unmetabolized renal excretion & [77] \\
\hline Haloperidol & CYP2D6, CYP3A4 & {$[93,645]$} \\
\hline Iloperidone & CYP2D6, CYP3A4 & [106] \\
\hline Imipramine (desipramine) & CYP1A2, CYP2C19, CYP2D6, CYP3A4 & {$[244,413]$} \\
\hline Lamotrigine & Glucuronosyltransferase, CYP2A6 & {$[121]$} \\
\hline Levodopa & Dopadecarboxylase, COMT, MAO & [575] \\
\hline Levomepromazine & CYP1A2, CYP2D6 & [36] \\
\hline Levomethadon & CYPC19, CYP2B6, CYP3A4, CYP2D6 & [145] \\
\hline Lisuride & CYP3A4, CYP2D6 & [539] \\
\hline Lithium & no metabolism, renal clearance & {$[256,619]$} \\
\hline Lorazepam & Glucuronosyltransferase & {$[164,196]$} \\
\hline Maprotiline & CYP2D6, CYP1A2 & {$[86]$} \\
\hline Melatonin & CYP1A2 & [296] \\
\hline Memantine & merely metabolized & [251] \\
\hline Methadone & CYP2B6, CYP2C19, CYP3A4, CYP2D6 & [145] \\
\hline Methylphenidate & Carboxylesterase 1 & [468] \\
\hline Mianserine & CYP2D6, CYP1A2, CYP3A4 & [379] \\
\hline Midazolam & CYP3A4 & [220] \\
\hline Milnacipran & no CYP related metabolism & {$[495,533]$} \\
\hline
\end{tabular}


Table 1 Continued.

\begin{tabular}{|c|c|c|}
\hline Drug (active metabolite) & Enzymes & Reference \\
\hline Mirtazapine & CYP3A4, CYP1A2, CYP2B6, CYP2D6 & {$[397,630]$} \\
\hline Moclobemide & CYP2C19, CYP2D6 & [255] \\
\hline Modafinil & Amide hydrolysis, CYP3A4 & {$[561]$} \\
\hline Naltrexone & Aldoketoreductase AKR1C4 & {$[92]$} \\
\hline Nortriptyline & CYP2D6 & {$[385,485,687]$} \\
\hline Olanzapine & $\begin{array}{l}\text { N-Glucuronosyltransferase, Flavin monoxigenase, } \\
\text { CYP1A2, CYP2D6 }\end{array}$ & [107] \\
\hline Opipramol & unclear & \\
\hline Paliperidone (=9-Hydroxyrisperidone) & $60 \%$ excreted unmetabolized, different pathways & {$[161]$} \\
\hline Paroxetine & CYP1A2, CYP2D6, CYP3A4 & {$[209,349,691]$} \\
\hline Perazine & CYP1A2, CYP2C19, CYP3A4, Flavin monoxigenase & {$[629,725]$} \\
\hline Pergolide & CYP3A4 & [731] \\
\hline Perphenazine & CYP1A2, CYP2C19, CYP2D6, CYP3A4 & {$[12,77,168,486]$} \\
\hline Pregabalin & unmetabolized renal excretion & {$[77]$} \\
\hline Piripedil & demethylation, p-hydroxylation, and $\mathrm{N}$-oxidation & [168] \\
\hline Pimozide & CYP1A2, CYP3A4 & {$[171]$} \\
\hline Pramipexole & not metabolized & {$[62]$} \\
\hline Promazine & CYP1A2, CYP2C19, CYP3A4 & [726] \\
\hline Promethazine & CYP2D6 & {$[465]$} \\
\hline Quetiapine & CYP3A4, CYP2D6 & [38] \\
\hline Rasagiline & CYP1A2 & [277] \\
\hline Reboxetine & CYP3A4 & {$[307,716]$} \\
\hline Risperidone (9-Hydroxyrisperidone) & CYP2D6, CYP3A4 & [732] \\
\hline Ropinirole & CYP1A2 & [357] \\
\hline Rotigotine & Glucuronosyltransferase, several other unknown pathways & [115] \\
\hline Selegiline & CYP2B6 & {$[60]$} \\
\hline Sertindole & CYP3A4, CYP2D6 & [729] \\
\hline Sertraline & CYP2B6, CYP2C19, CYP2C9, CYP2D6 & {$[482,705]$} \\
\hline Thioridazine & CYP1A2, CYP2C19, CYP2D6, CYP3A4 & {$[648,714]$} \\
\hline Tiapride & mainly not metabolized & {$[477]$} \\
\hline Tolcapone & Glucuronosyltransferase & [387] \\
\hline Trimipramine (nortrimipramine) & CYP2C19, CYP2D6, CYP2C9 & [187] \\
\hline Tranylcypromine & monoamine oxidase, unclear & [37] \\
\hline Trazodone & CYP3A4, CYP2D6 & {$[268,567]$} \\
\hline Valproic acid & $\begin{array}{l}\text { Glucuronosyltransferase, CYP2A6, CYP2B6, CYP2C9, } \\
\text { beta-oxidation }\end{array}$ & [641] \\
\hline Venlafaxine (O-desmethylvenlafaxine) & CYP2C19, CYP2D6, CYP3A4 & {$[217,434]$} \\
\hline Zaleplone & Aldehyde oxidase, CYP3A4 & [554] \\
\hline Ziprasidone & CYP3A4, Aldehyde oxidase & {$[58,519]$} \\
\hline Zolpidem & CYP1A2, CYP2C9, СYP3A4 & [698] \\
\hline Zopiclone & CYP2C8, CYP3A4 & {$[57,659]$} \\
\hline Zotepine & CYP1A2, CYP2D6, CYP3A4 & [596] \\
\hline Zuclopenthixol & CYP2D6 & [330] \\
\hline
\end{tabular}

Inhibition of enzymes indicated in bold will significantly increase the plasma concentrations of the drug, induction (CYP1A2, CYP3A4) will lead to decreased plasma concentrations (See Table 2). Prepared by $\mathrm{CH}$, reviewed and supplemented by EJS

which inhibit metabolic enzymes may decrease the ratio. $\bullet$ Table 3 summarizes drugs that are inhibitors or inducers of CYP enzymes and thus may lead to clinically relevant pharmacokinetic drugdrug interactions.

\section{Pharmacogenetic aspects}

The clinical importance of pharmacogenetic factors in the pharmacokinetics and pharmacodynamics of psychoptropic drugs is increasingly recognised $[156,199,457]$. Drug-metabolising enzymes, especially CYP isoenzymes, exhibit genetic variability [745-747]. When the frequency of a deviation in the alleles is at least $1 \%$ of the population, it is considered a genetic polymorphism. The number of active alleles in a gene determines how much of the enzyme is expressed (phenotype). Poor metabolisers (PM) lack functional alleles. Intermediate metabolisers (IM) are either genetically heterozygous, carrying an active and an inactive allele (or an allele with reduced activity) or have 2 alle- les with reduced activity. Extensive metabolisers (EM) are wildtype with 2 active alleles, and ultra-rapid metabolisers (UM) have an amplification of functional alleles [66]. Genetic polymorphisms of drug-metabolising enzymes may be clinically important, because unexpected adverse reactions and toxicity may occur in PM due to increased plasma concentrations and non-response may occur in UM due to subtherapeutic plasma concentrations [160]. Prodrugs are activated by metabolism such as codeine by CYP2D6 to morphine or clopidogrel by CYP2C19 to 2-oxoclopidogrel. PM patients will not be able to produce pharmacologically active metabolites. Other enzyme systems such as UDP-glucuronosyltransferases also display genetic polymorphism [155], but their clinical relevance in pharmacopsychiatry is unclear.

CYP genotyping methods are becoming more and more available, and guidelines have been published for their use in clinical practice [675]. The functional significance of many genotypes, 
Table 2 Ranges of metabolite-to-parent concentration ratios for psychopharmacologic medications. Reported ranges contain $68 \%$ of ratios determined under "normal" conditions in the blood of patients or healthy subjects.

\begin{tabular}{|c|c|c|c|}
\hline Drug & Metabolite & $\begin{array}{l}\text { Ratios of concentrations metabolite: } \\
\text { parent drug (Mean - SD - Mean +SD) }\end{array}$ & Reference \\
\hline Amitriptyline & Nortriptyline* & $0.2-1.8(n=83)$ & [545] \\
\hline Aripiprazole & Dehydroaripirazole( $\left.{ }^{*}\right)$ & $\begin{array}{l}0.3-0.5 \\
\text { PM of CYP2D6: } 0.2\end{array}$ & {$[306,368,452]$} \\
\hline Bromperidol & Reduced bromperidol & $0.11-0.51(n=31)$ & {$[609,633]$} \\
\hline Buprenorphine & Norbuprenorphine & $0.8-2.0(n=5)$ & [383] \\
\hline Bupropion & Hydroxybupropion & $\begin{array}{l}5-47(24 \mathrm{~h}, \mathrm{n}=9) \\
6-30(12 \mathrm{~h}, \mathrm{n}=9)\end{array}$ & {$[152,253,336]$} \\
\hline Buspirone & 6-Hydroxybuspirone & $25-53(n=20)$ & [178] \\
\hline Carbamazepine & Carbamazepine-10,11-epoxide & $0.07-0.25(n=14)$ & [338] \\
\hline Citalopram & N-Desmethylcitalopram & $0.31-0.60(n=2330)$ & [549] \\
\hline Clomipramine & Norclomipramine* & $0.8-2.6(n=115)$ & [545] \\
\hline Clozapine & Norclozapine( ${ }^{*}$ ) & $\begin{array}{l}\text { nonsmokers }(n=98) \\
0.5-0.6 \\
\text { smokers }(n=198) \\
0.4-0.7\end{array}$ & {$[140,308,500]$} \\
\hline Dothiepin & Nordothiepin & $0-1.4(n=50)$ & [325] \\
\hline Doxepin & Nordoxepin & $\begin{array}{l}0.6-1.6(n=12) \\
\text { PM CYP2C19: } 1.8(n=4) \\
\text { PM CYP2D6: } 0.8(n=6)\end{array}$ & {$[172,363]$} \\
\hline Escitalopram & N-Demethylescitalopram & $0.3-1.0(n=243)$ & [548] \\
\hline Fluoxetine & Norfluoxetine* & $0.7-1.9(n=334)$ & [545] \\
\hline Fluvoxamine & Fluvoxamino acid & $0-1.2(n=49)$ & [237] \\
\hline Haloperidol & Reduced haloperidol & mean 0.6 & [673] \\
\hline Imipramine & Desipramine & $\begin{array}{l}0.6-3.2(n=14) \\
\text { PM CYP2D6 } 4.1(n=2)\end{array}$ & {$[95,96,632]$} \\
\hline Maprotiline & Desmethylmaprotiline & $\begin{array}{l}1.1-3.7(n=76) \\
\text { PM CYP2D6 4.9 }\end{array}$ & [699] \\
\hline Mianserin & $\mathrm{N}$-Desmethylmianserin & $0.5-0.8(n=182)$ & [545] \\
\hline Mirtazapine & N-Desmethylmirtazapine & $0.2-1.2(n=100)$ & [591] \\
\hline Moclobemide & Moclobemide $\mathrm{N}$-oxide & $0.8-2.5(n=6)$ & [291] \\
\hline Olanzapine & N-Demethylolanzapine & $\begin{array}{l}\text { non smokers: } 0.1-0.3 \\
(n=76) \\
\text { smokers: } 0.2-0.4 \\
(n=69)\end{array}$ & [602] \\
\hline Perazine & Desmethylperazine & $1.1-3.3(n=27)$ & [91] \\
\hline Perphenazine & N-Dealkylperphenazine & $0.6-2.8(n=54)$ & [637] \\
\hline Quetiapine & Norquetiapine & $\begin{array}{l}0.1-3.8(n=25) \\
\text { (calculated for } 400 \mathrm{mg})\end{array}$ & [723] \\
\hline Reboxetine & O-Desethylreboxetine & $<0.1$ & [484] \\
\hline Risperidone & 9-Hydroxyrisperidone* & $\begin{array}{l}\text { EM or IM CYP2D6: } 1.5-10.0 \\
\text { PM CYP2D6: } \leq 1\end{array}$ & {$[159,677]$} \\
\hline Risperidone depot & 9-Hydroxyrisperidone* & EM: $1.2-4.3$ & [469] \\
\hline Sertindole & Dehydrosertindole & $\begin{array}{l}1.1-2.7(n=6) \\
1.0 \text { in PM of CYP2D6 }\end{array}$ & [729] \\
\hline Sertraline & Norsertraline & $1.7-3.4(n=348)$ & [546] \\
\hline Trazodone & m-Chlorophenylpiperazine (mCPP) & $0.04-0.22$ (total range) & [328] \\
\hline Trimipramine & Nortrimipramine* & $0-12.0(n=17)$ & [142] \\
\hline Venlafaxine & O-Desmethylvenlafaxine* & $\begin{array}{l}\text { EM or IM CYPD26: } 0.3-5.2 \\
\text { PM CYP2D6: } \leq 0.3 \\
\text { UM CYP2D6:>5.2 } \\
0.46-1.48\end{array}$ & [592] \\
\hline
\end{tabular}

*pharmacologically active metabolite, $\left({ }^{*}\right)$ active metabolite in vitro but unclear under in vivo conditions

When SD values of ranges of ratios (SD ratio) were not reported in the literature, SD ratios were calculated in accordance with Gaussian's law for the propagation of errors: SD ratio $=[($ SD parent drug $x$ mean metabolite $)+($ SD metabolite $x$ mean parent drug $)] /(\text { mean metabolite })^{2}$

Prepared by $\mathrm{CH}$, reviewed by Sonja Brünen, Christiane Knoth, Elnaz Ostad Haji and Viktoria Stieffenhofer

however, is unclear. For some enzymes, a genetic polymorphism is not clearly demonstrated despite the fact that they display a wide interindividual variability in their activity. Therefore it may be advantageous to use phenotyping methods with probe drugs such as caffeine for CYP1A2, omeprazole for CYP2C19, dextromethorphan for CYP2D6, or midazolam for CYP3A4/5 $[403,643]$. Phenotyping measures the metabolic situation of the patient at the moment of the test, and allows to follow its evolution. The measurement, however, may be influenced by environmental factors such as smoking or comedications $[201,601,749]$. The clear advantage of genotyping is that it represents a "trait marker" and that its result is not influenced by environmental factors. It can be carried out in any situation and its result has a lifetime value. 
Table 3 Inhibitors and inducers of enzymes involved in the metabolism of drug.

\begin{tabular}{|c|c|c|c|}
\hline Inhibiting drugs & Inhibited enzymes & Inducing drugs & Induced enzymes \\
\hline Amiodarone & CYP2C9, CYP2D6, CYP3A4 & Carbamazepine & CYP1A2, CYP2B6, CYP2C9, СYP3A4 \\
\hline Bupropion & CYP2D6 & Dexamethason & CYP2C9, CYP3A4 \\
\hline Bromocriptine & CYP3A4 & Efavirenz & CYP2B6, СYP3A4 \\
\hline Chinidine & CYP2D6 & Ethanol & CYP2E1 \\
\hline Cimetidin & CYP1A2, CYP2D6, CYP3A4 & Ginkgo biloba & CYP2C19 \\
\hline Ciprofloxacin & CYP1A2 & Isoniazide & CYP2E1 \\
\hline Clarithromycin & CYP3A4 & St. John's wort & CYP2C19, CYP3A4 \\
\hline Clopidogrel & CYP2B6 & Oxybutynin & CYP3A4 \\
\hline Disulfiram & CYP2E1 & Phenobarbital & CYP2C9, СYP2C19, СYP3A4 \\
\hline Duloxetine & CYP2D6 & Phenytoin & CYP2B6, СYP2C9, CYP2C19, CYP3A4 \\
\hline Enoxacin & CYP1A2 & Primidon & CYP2C9, СYP2C19, CYP3A4 \\
\hline Erythromycin & CYP3A4 & Smoke & CYP1A2 \\
\hline Esomeprazole & CYP2C19 & Rifabutin & CYP3A4 \\
\hline Felbamate & CYP2C19 & Rifampicin & CYP1A2, CYP2B6, CYP2C9, CYP2C19 \\
\hline Fluconazole & CYP2C19, CYP2C9, СYP3A4 & Ritonavir & CYP3A4, CYP2C9, CYP3A4 (high dose) \\
\hline Fluoxetine and norfluoxetine & CYP2D6, CYP2C19 & & \\
\hline Fluvoxamine & CYP1A2, CYP2C9, CYP2C19, CYP3A4 & & \\
\hline Indinavir & CYP3A4 & & \\
\hline Isoniazid & CYP1A2, CYP2A6, CYP2C19, CYP3A4 & & \\
\hline Itraconazol & CYP2B6, CYP3A4 & & \\
\hline Ketoconazol & CYP3A4 & & \\
\hline Levomepromazine & CYP2D6 & & \\
\hline Melperone & CYP2D6 & & \\
\hline Metoclopramide & CYP2D6 & & \\
\hline Metoprolol & CYP2D6 & & \\
\hline Miconazol & CYP2C9, CYP2C19 & & \\
\hline Mifepriston & CYP3A4 & & \\
\hline Moclobemide & CYP2C19, CYP2D6 & & \\
\hline Nelfinavir & CYP3A4 & & \\
\hline Norfloxacine & CYP1A2 & & \\
\hline Omeprazole & CYP2C19 & & \\
\hline Paroxetine & CYP2D6 & & \\
\hline Perazine & CYP1A2 & & \\
\hline Pergolide & CYP2D6 & & \\
\hline Perphenazin & CYP2D6 & & \\
\hline Propafenon & CYP1A2, CYP2D6 & & \\
\hline Propranolol & CYP2D6 & & \\
\hline Ritonavir & CYP2D6, CYP3A4 & & \\
\hline Saquinavir & CYP3А4, СYP2C9 & & \\
\hline Troleandomycin & CYP3A4 & & \\
\hline Valproate & CYP2C9 & & \\
\hline Verapamil & CYP3A4 & & \\
\hline Voriconazol & CYP2C9, СYP3A4 & & \\
\hline
\end{tabular}

Recent investigations indicate that the drug efflux transporter P-glycoprotein (P-gp) in the intestinal mucosa and blood-brainbarrier is also relevant for the pharmacokinetic variability of psychotropic medications [1]. This protein, a member of the ATP-cassette binding $(\mathrm{ABC})$ transporter protein family, is encoded by the multidrug resistance gene (MDR1; $A B C B 1)$. It displays a genetic polymorphism, but as yet, mainly genotyping but not phenotyping (e.g., with digoxin) is more commonly used $[129,183,210,389]$. Genetic polymorphism of P-gp may be of the same considerable clinical relevance as has been demonstrated for drug-metabolizing enzymes. For antidepressant drugs that are substrates of P-gp, a genotype dependent association of drug response was found [668,669]. Both plasma concentrations of quetiapine and its clinical effectiveness have been shown to depend on the P-gp genotype of patients suffering from schizophrenia [470]. With regard to the occurrence of wanted or unwanted clinical effects of psychoactive drugs, some first reports suggest the influence of the genetic polymorphism of P-gp [279,560]. However, further research is needed to evaluate the clinical relevance of the genetic polymorphisms of drug transporters.

\section{Dose and drug concentration in blood}

In most situations that use TDM for dose optimization, drugs are administered in a series of repeated doses to attain a steadystate concentration within a given therapeutic reference range. Steady-state is attained when the rate of medication input equals the rate of medication loss, i.e., approximately after 4 times the elimination half life. With multiple dosing, $94 \%$ of the steady state are achieved after 4 and $97 \%$ after 5 elimination half-lives. For more than $90 \%$ of all psychoactive medications, such a steady-state is reached within 1 week of maintenance 
Table 4 Total clearance $\left(\mathrm{Cl}_{\mathrm{t}}\right)$, bioavailability $(\mathrm{F})$, dosing intervals $(\mathrm{T})$ and factors $\left(\mathrm{C} / \mathrm{D}_{\text {low }}\right.$ and $\left.\mathrm{C} / \mathrm{D}_{\text {high }}\right)$ for calculation of dose-related plasma concentrations $(\mathrm{C} / \mathrm{D})$ for psychotropic drugs.

\begin{tabular}{|c|c|c|c|c|c|c|c|}
\hline Drug & n & $\begin{array}{l}\mathrm{Cl}_{\mathrm{t}}-\mathrm{SD}-\mathrm{Cl}_{\mathrm{t}}+\mathrm{SD} \\
{[\mathrm{mL} / \mathrm{min}]}\end{array}$ & $\mathbf{F}$ & $\mathbf{T}[\mathrm{h}]$ & $\begin{array}{l}C / D_{\text {low }} \\
{[\mathrm{ng} / \mathrm{mL} / \mathrm{mg}]}\end{array}$ & $\begin{array}{l}C / D_{\text {high }} \\
{[\mathrm{ng} / \mathrm{mL} / \mathrm{mg}]}\end{array}$ & Reference \\
\hline \multicolumn{8}{|l|}{ Antidepressant drugs } \\
\hline Amitriptyline & 8 & $198-373$ & 0.5 & 24 & 1.03 & 1.68 & {$[165]$} \\
\hline Amitriptyline oxide & 12 & $331-539$ & 0.8 & 24 & 0.93 & 1.75 & [384] \\
\hline Bupropion & 17 & $2500-11300$ & 1.0 & 24 & 0.06 & 0.28 & {$[665]$} \\
\hline Citalopram & 8 & $367-545$ & 0.8 & 24 & 1.02 & 1.51 & [616] \\
\hline Clomipramine & 9 & $583-933$ & 0.5 & 24 & 0.37 & 0.60 & [198] \\
\hline Desipramine & 12 & $1633-2333$ & 0.5 & 24 & 0.15 & 0.21 & [2] \\
\hline Desvenlafaxine & 7 & 233-396 & 1.0 & 24 & 1.75 & 2.98 & [520] \\
\hline Dothiepin = Dosulepin & 22 & $674-3960$ & 0.3 & 24 & 0.05 & 0.31 & [740] \\
\hline Doxepin & 85 & $769-2644$ & 1.0 & 24 & 0.18 & 0.27 & [100] \\
\hline Duloxetine & 12 & $610-1733$ & 0.5 & 24 & 0.20 & 0.57 & [600] \\
\hline Escitalopram & 24 & $360-960$ & 0.8 & 24 & 0.58 & 1.54 & [607] \\
\hline Fluoxetine & n. r. & $600-833$ & 0.7 & 24 & 0.60 & 0.83 & [18] \\
\hline Fluvoxamine & 6 & 807-1960 & 1.0 & 24 & 0.35 & 0.86 & [163] \\
\hline Imipramine & n. r. & $791-1029$ & 0.4 & 24 & 0.28 & 0.37 & [100] \\
\hline Maprotiline & 6 & $503-1747$ & 0.8 & 24 & 0.32 & 1.10 & [415] \\
\hline Mianserin & n. r. & $843-1948$ & 0.3 & 24 & 0.11 & 0.25 & [137] \\
\hline Mirtazapine & 10 & $455-945$ & 0.5 & 24 & 0.37 & 0.85 & [651] \\
\hline Nordoxepin & 85 & $504-2738$ & 1.0 & 24 & 0.25 & 1.38 & [445] \\
\hline Nortriptyline & n. r. & $300-1117$ & 0.5 & 24 & 0.31 & 1.16 & [664] \\
\hline Paroxetine & 30 & $1561-10856$ & 1.0 & 24 & 0.06 & 0.44 & [213] \\
\hline Reboxetine & n. r. & $22-51$ & 1.0 & 24 & 12.55 & 31.10 & [141] \\
\hline \multirow[t]{2}{*}{ Sertraline } & $11(\mathrm{~m})$ & $1313-2213(\mathrm{~m})$ & 1.0 & 24 & 0.31 & 0.53 & [565] \\
\hline & $11(\mathrm{f})$ & $793-2357(f)$ & 1.0 & 24 & 0.29 & 0.88 & \\
\hline Trazodone & 8 & $73-103$ & 1.0 & 24 & 6.72 & 9.47 & [473] \\
\hline Trimipramine & 12 & $898-1215$ & 0.40 & 24 & 0.23 & 0.31 & {$[165,364]$} \\
\hline Venlafaxine & 18 & $747-1540$ & 1.0 & 24 & 0.45 & 0.93 & [372] \\
\hline O-Desmethylvenlafaxine & & $315-618$ & 1.0 & 24 & 1.12 & 2.2 & \\
\hline \multicolumn{8}{|l|}{ Antipsychotic drugs } \\
\hline Amisulpride & 78 & $520-693$ & 0.5 & 24 & 0.50 & 0.67 & [566] \\
\hline Asenapine & n. r. & 867 & 0.35 & 24 & 0.28 & & [707] \\
\hline Aripiprazole & 6 & $47-70$ & 0.9 & 24 & 8.63 & 12.85 & [417] \\
\hline Benperidol & 14 & $1073-2240$ & 0.5 & 24 & 0.15 & 0.31 & [589] \\
\hline Bromperidol & 14 & $3570-7938$ & 1.0 & 24 & 0.09 & 0.19 & [390] \\
\hline Chlorpromazine & 11 & $1043-1510$ & 0.1 & 24 & 0.05 & 0.07 & [738] \\
\hline Chlorprothixene & 3 & $918-1448$ & 0.2 & 24 & 0.10 & 0.15 & [534] \\
\hline Clozapine & 16 & $258-728$ & 0.5 & 24 & 0.40 & 0.80 & {$[128,176,332]$} \\
\hline Flupentixol & 3 & $440-490$ & 0.6 & 24 & 0.78 & 0.87 & [348] \\
\hline Fluphenazine decanoate & 12 & $2380-3940$ & 1.0 & 24 & 0.18 & 0.29 & [197] \\
\hline Haloperidol & 6 & $420-680$ & 0.6 & 24 & 0.61 & 0.99 & [123] \\
\hline \multirow[t]{2}{*}{ Haloperidol decanoate } & & $420-680$ & 1.0 & 336 & 0.073 & 0.118 & [123] \\
\hline & & & & 672 & 0.036 & 0.059 & \\
\hline Melperone & 6 & $1484-2898$ & 0.6 & 24 & 0.14 & 0.28 & [83] \\
\hline Levomepromazine & 8 & $913-4737$ & 0.5 & 24 & 0.07 & 0.38 & [149] \\
\hline Olanzapine & 491 & $233-637$ & 0.8 & 24 & 0.87 & 2.38 & {$[67]$} \\
\hline Paliperidone & n. r. & $31-98$ & 0.3 & 24 & 1.99 & 6.31 & [161] \\
\hline Perphenazine & 8 & $1009-2566$ & 0.4 & 24 & 0.11 & 0.28 & [195] \\
\hline Pimozide & 7 & $21-553$ & 0.5 & 24 & 0.64 & 16.53 & [581] \\
\hline Quetiapine & 10 & $1146-2421$ & 1.0 & 24 & 0.13 & 0.21 & {$[7,435]$} \\
\hline Risperidone, oral & 8 & $91-171$ & 0.7 & 24 & $\begin{array}{l}3.50 \\
\text { active moiety }\end{array}$ & $\begin{array}{l}14.00 \\
\text { active moiety }\end{array}$ & [159] \\
\hline Risperidone, depot & n. r. & $91-171$ & 1.0 & 336 & $\begin{array}{l}0.29 \\
\text { active moiety }\end{array}$ & $\begin{array}{l}0.55 \\
\text { active moiety }\end{array}$ & [606] \\
\hline Sertindole & 6 & $133-600$ & 1.0 & 24 & 1.16 & 5.22 & [728] \\
\hline Supiride & 6 & $331-499$ & 0.25 & 24 & 0.35 & 0.52 & [717] \\
\hline Thiordazine & 11 & 404-982 & 0.60 & 24 & 0.42 & 1.03 & [117] \\
\hline Zotepine & 14 & $467-10267$ & 1.0 & 24 & 0.07 & 1.49 & [642] \\
\hline Ziprasidone & 12 & $303-397$ & 0.6 & 24 & 1.05 & 1.36 & SPC \\
\hline Zuclopenthixol & 8 & $867-2300$ & 0.4 & 24 & 0.13 & 0.35 & [337] \\
\hline
\end{tabular}


Table 4 Continued.

\begin{tabular}{|c|c|c|c|c|c|c|c|}
\hline Drug & $\mathbf{n}$ & $\begin{array}{l}\mathrm{Cl}_{\mathrm{t}}-\mathrm{SD}-\mathrm{Cl}_{\mathrm{t}}+\mathrm{SD} \\
{[\mathrm{mL} / \mathrm{min}]}\end{array}$ & $\mathbf{F}$ & $\mathrm{T}[\mathrm{h}]$ & $\begin{array}{l}C / D_{\text {low }} \\
{[\mathrm{ng} / \mathrm{mL} / \mathrm{mg}]}\end{array}$ & $\begin{array}{l}C / D_{\text {high }} \\
{[\mathrm{ng} / \mathrm{mL} / \mathrm{mg}]}\end{array}$ & Reference \\
\hline \multicolumn{8}{|c|}{ Anticonvulsant drugs Mood stabilizers } \\
\hline Carbamazepine & n.r. & $58-74$ & 1.0 & 24 & 9.40 & 11.93 & SPC \\
\hline Felbamate & 10 & $29.1-33.3$ & 1.0 & 24 & 20.85 & 23.86 & [556] \\
\hline Lamotrigine & 129 & $22-49$ & 1.0 & 24 & 14.09 & 31.28 & [118] \\
\hline Levetiracetam & 216 & $52-72$ & 1.0 & 24 & 9.65 & 13.35 & [535] \\
\hline Lithium & n. r. & $10-40$ & 1.0 & 24 & 17.36 & 69.44 & [706] \\
\hline Oxcarbazepine & 7 & $1703-5063$ & 1.0 & 24 & 0.14 & 0.41 & {$[319,694]$} \\
\hline Primidone & 8 & $30-47$ & 1.0 & 24 & 14.78 & 23.15 & [423] \\
\hline Topiramate & 6 & $21-31$ & 1.0 & 24 & 22.47 & 33.55 & [179] \\
\hline Valproic acid & 9 & $4.5-9.8$ & 1.0 & 24 & 71.23 & 154.32 & [682] \\
\hline \multicolumn{8}{|c|}{ Anxiolytic and hypnotic drugs } \\
\hline Alprazolam & 6 & $34-83$ & 0.8 & 24 & 6.73 & 16.53 & {$[496,604]$} \\
\hline Bromazepam & 10 & $50-91$ & 1.0 & 24 & 7.67 & 13.95 & [352] \\
\hline Brotizolam & 8 & $85-141$ & 0.7 & 24 & 4.93 & 8.17 & [341] \\
\hline Buspirone & 41 & $1260-2702$ & 0.04 & 24 & 0.01 & 0.02 & [41] \\
\hline Clonazepam & 9 & $63-90$ & 0.8 & 24 & 5.43 & 7.69 & [259] \\
\hline Diazepam & 48 & $10-43$ & 0.9 & 24 & 13.01 & 52.91 & [264] \\
\hline Lorazepam & 15 & $36-109$ & 0.8 & 24 & 5.98 & 17.93 & [266] \\
\hline \multirow[t]{2}{*}{ Oxazepam } & $18(\mathrm{~m})$ & $36-167$ & 0.8 & 24 & 3.33 & 15.22 & {$[260]$} \\
\hline & $20(w)$ & 29-109 & 0.8 & 24 & 5.12 & 18.90 & \\
\hline Triazolam & 13 & $326-584$ & 0.9 & 24 & 1.01 & 1.81 & [263] \\
\hline Zaleplon & 10 & $868-1330$ & 0.3 & 24 & 0.16 & 0.25 & [265] \\
\hline Zolpidem & 10 & $266-364$ & 0.67 & 24 & 1.02 & 2.14 & [265] \\
\hline Zopiclone & 10 & $250-883$ & 1 & 24 & 0.79 & 2.78 & [411] \\
\hline \multicolumn{8}{|c|}{ Antidementia drugs } \\
\hline Donepezil & 14 & $112-217$ & 1.0 & 24 & 3.20 & 6.20 & [463] \\
\hline Galantamine & 8 & $268-400$ & 1.0 & 24 & 1.74 & 2.59 & {$[744]$} \\
\hline Rivastigmine & 20 & $\begin{array}{l}\text { 29-64 } \\
\text { (patch) }\end{array}$ & 0.5 & 24 & 0.18 & 0.74 & [391] \\
\hline \multicolumn{8}{|c|}{ Drugs for treatment of substance related disorders } \\
\hline Acamprosate & 24 & $1741-4221$ & 1.0 & 24 & 0.16 & 0.40 & [287] \\
\hline Buprenorphin & & & & & & & no data available \\
\hline Bupropion & 17 & $2500-11300$ & 1.0 & 24 & 0.06 & 0.28 & [665] \\
\hline Methadone & 12 & $75-148$ & 0.95 & 24 & 4.46 & 8.80 & {$[474,727]$} \\
\hline Naltrexone & 453 & $2077-2590$ & 1.0 & 24 & 0.27 & 0.33 & [182] \\
\hline $6 \beta$-naltrexol & & $928-1242$ & & & 0.56 & 0.75 & \\
\hline Varenicline & 1878 & $170-176$ & 1.0 & 24 & 3.95 & 4.08 & [540] \\
\hline
\end{tabular}

SPC: Summary of product characteristics; n.r.: not reported; active moiety: risperidone plus 9-hydroxyrisperidone; n: number of individuals; SD: standard deviation Dose related ranges are obtained by multiplying $C / D_{\text {low }}$ and $C / D_{\text {high }}$ by the dose. Drugs listed in $\odot$ Table $\mathbf{5}$ were not included in this table, when clearance data were not available from the literature.

Prepared by EH and CG, reviewed and supplemented by $\mathrm{CH}$

dosing. The dose required to attain a steady-state concentration of a drug in plasma can be calculated if the dosing interval $(\tau)$, the clearance $(\mathrm{Cl})$ and the bioavailability (F) for the drug in a particular patient are known. The calculation is based on the direct correlation of the drug dose $\mathrm{D}_{\mathrm{e}}$ (constant dose per day at steady-state) to its blood concentration c, with the total clearance of the drug $\left(\mathrm{Cl}_{\mathrm{t}}\right)$ being the correlation coefficient:

\section{$D_{e}=D x F / \tau=c \times C l_{t}$}

Based on this information it is possible to calculate the dose-related plasma concentration of a drug that may be expected in blood specimens of patients under medication with a given dose [285]:

$$
\mathbf{c}=\mathrm{D}_{\mathrm{e}} / \mathrm{Cl}_{\mathrm{t}}
$$

For psychoactive medications, such data are available from studies in which drug concentrations were measured in plasma of healthy volunteers or patients treated with fixed doses. When the clearance is taken as arithmetic mean \pm standard deviation from clinical trials of the drug, a dose related reference range can be calculated [285].

\section{Definition}

The "dose-related reference range" reported in the present guidelines is calculated as a concentration range within that a drug concentration is expected according to pharmacokinetic studies in human blood specimens from subjects under medication with a given dose of the drug. It contains $68 \%$ of all the drug concentrations determined under normal conditions in the blood of a "normal" patient or subject, "normal" being defined by the population in the respective clinical trial. It usually consists of individuals 18-65 years of age without relevant comorbidity, comedication, and genetic abnormalities in drug metabolism.

- Table 4 lists factors for calculation of dose-related reference ranges for the most relevant psychoactive drugs. Dose-related reference ranges are calculated by multiplying $C / D_{\text {low }}$ and $C / D_{\text {high }}$ 
by the daily dose. One must be aware, however, that many patients encountered in the clinical context do not fulfil all the abovementioned conditions.

\section{Drug concentration in blood and brain}

The pharmacological activity of a psychotropic drug depends on its availability in the target organ, the brain. However, the latter is separated from the blood by 2 barriers, which have to be crossed by the drug, the blood-brain barrier (BBB) and the blood-cerebrospinal fluid barrier [154]. Most psychoactive drugs enter the brain due to their high lipid solubility by passive diffusion and thereby cross the barriers. The BBB is a physical barrier that separates circulating blood and the central nervous system, and it consists of endothelial cells around the capillaries joined together by tight junctions [154]. It efficiently restricts the exchange of solutes between the blood and the brain extracellular fluid. Functionally, it protects the brain against potentially harmful chemicals. As mentioned above, a number of psychoactive drugs, such as risperidone, aripiprazole or venlafaxine are substrates of P-gp [180,370,668]. As a consequence, brain to plasma concentration ratios vary widely for psychotropic drugs with similar physicochemical properties. Animal studies found ratios from 0.22 for risperidone [29] to 34 for fluphenazine [27]. In spite of highly variable ratios of brain to plasma concentrations of the different psychotropic drugs, animal studies have shown that steady-state plasma concentrations of psychoactive drugs correlate well with concentrations in brain, much better than doses. This has been shown for tricyclic antidepressants [249], trazodone [173], or olanzapine [28]. Drug concentrations in plasma can therefore be considered as a valid surrogate marker of concentrations in brain.

\section{Drug concentration in blood and target structure occupancy in brain}

Positron emission tomography (PET) enables analysis of central nervous receptor occupancy in vivo [207,274,275]. Antipsychotic drugs exert most of their therapeutic actions by blockade of dopamine D2-like receptors. Blockade of D2 receptors by antipsychotic drugs reduces the binding of radioactive PET ligands $[207,272,275]$. Using this approach and quantification of the displacement of dopamine receptor radioligands, it has been shown that plasma concentrations of antipsychotic drugs correlate well with receptor occupancy. In accordance with the high variability of drug concentrations in plasma under same doses it was found that receptor occupancy correlates better with plasma concentrations than with daily doses [313]. Optimal response was seen at $70-80 \%$ receptor occupancy, and $80 \%$ receptor occupancy was defined as the threshold for the occurrence of extrapyramidal side effects $[207,480]$. PET was also used to characterize in vivo serotonin transporter occupancy by SSRIs $[442,443]$. Using a serotonin transporter radioligand, plasma concentrations of citalopram, paroxetine, fluoxetine and sertraline were shown to correlate well with serotonin transporter occupancy. It was found that at least $80 \%$ occupancy should be attained for optimal clinical outcome [442,443]. PET studies have thus brought about highly relevant information for the determination of optimal plasma concentrations of a considerable number of psychotropic drugs which is reviewed in this special issue by Gründer and co-workers [274].

\section{"Therapeutic window" - therapeutic reference range} TDM is based on the assumption that there is a relationship between plasma concentrations and clinical effects (therapeutic improvement, side effects and adverse effects). It also assumes that there is a plasma concentration range of the drug which is characterized by maximal effectiveness and maximal safety, the so-called "therapeutic window". Studies on relations between plasma concentration and clinical improvement have supported this concept since the sixties for lithium, tricyclic antidepressants and classical antipsychotic drugs. Systematic reviews and meta-analyses that were based on adequately designed studies led to convincing evidence of a significant relationship between clinical outcomes and plasma concentrations for nortriptyline, imipramine and desipramine which are associated with a high probability of response [51]. For amitriptyline as a model compound, a meta-analysis of 45 studies has shown that various statistical approaches provided almost identical results [672,674]. For new antipsychotic drugs like aripiprazole [612], olanzapine [509] or risperidone [737] relationships between plasma concentration and clinical effectiveness have been reported.

For the "therapeutic window" there are many synonymous terms like "therapeutic reference range", "therapeutic range", "optimal plasma concentration", "effective plasma concentration", "target range”, "target concentration”, or "orienting therapeutic range", the term used in the first consensus [51]. The present consensus uses the term "therapeutic reference range" in accordance with the guidelines on TDM for antiepileptic drugs [499]. The "therapeutic reference range" was defined in this consensus guideline for neuropsychiatric drugs as follows:

\section{Definition}

The "therapeutic reference ranges" reported in this guideline ( $\bullet$ Table 5 ) define ranges of medication concentrations which specify a lower limit below which a drug induced therapeutic response is relatively unlikely to occur and an upper limit above which tolerability decreases or above which it is relatively unlikely that therapeutic improvement may be still enhanced. The therapeutic reference range is an orienting, population based range which may not necessarily be applicable to all patients. Individual patients may show optimal therapeutic response under a drug concentration that differs from the therapeutic reference range. Ultimately, psychopharmacotherapy can be best guided by identification of the patient's "individual therapeutic concentration".

The therapeutic reference ranges as recommended by the TDM group of the AGNP are given in 0 Table 5. They were evidencebased and derived from the literature by the structured review process described above. For only 15 neuropsychiatric drugs therapeutic reference ranges based on randomized clinical trials were found in the literature. For most drugs, reference ranges were obtained from studies with therapeutically effective doses. Therefore, there is a need for further studies to define therapeutic ranges.

The reference ranges listed in 0 Table $\mathbf{5}$ are generally those for the primary indication. A number of drugs, however, are recommended for several indications. For example, antidepressant drugs are also used for the treatment of anxiety states, and antipsychotic drugs are increasingly used to treat mania. Little information is available on optimum plasma concentrations in these situations. Exceptions are carbamazepine, lamotrigine and 


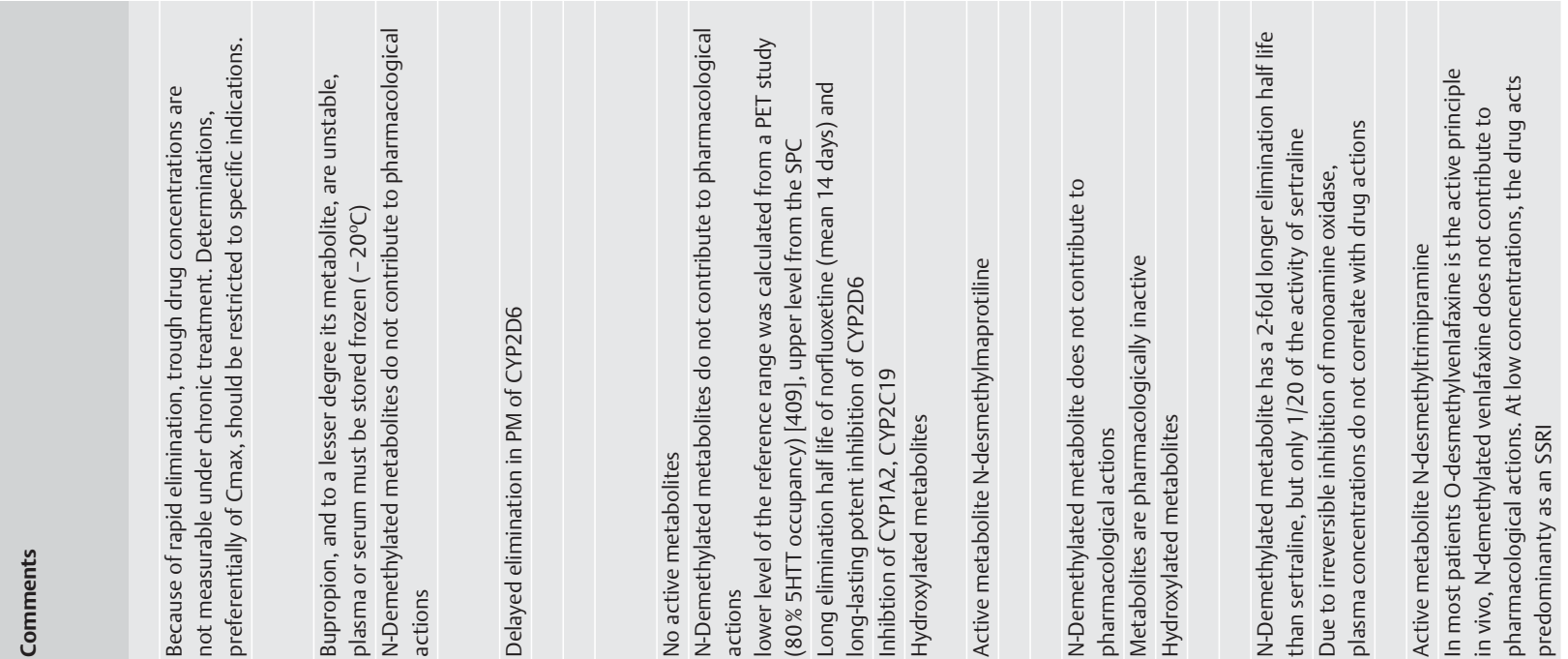

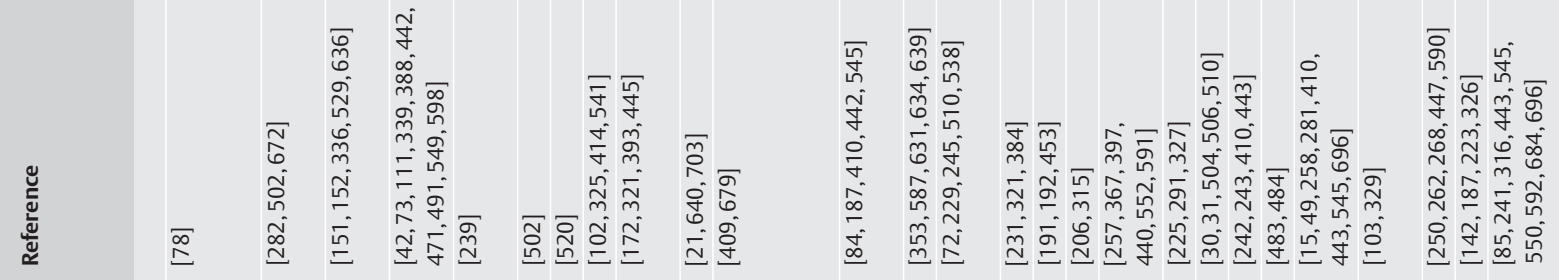

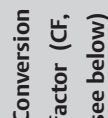

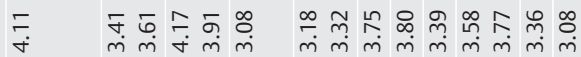

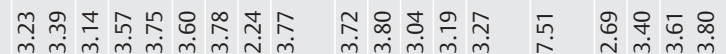

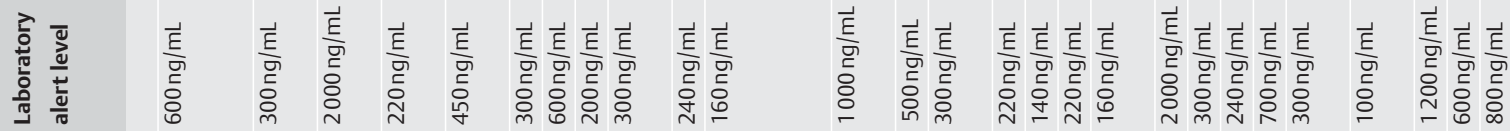

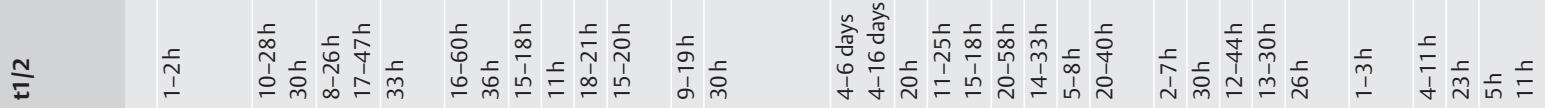

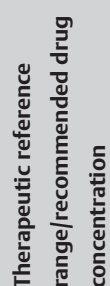

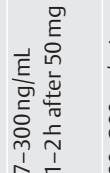

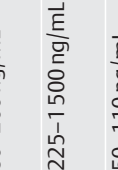

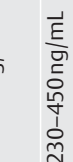

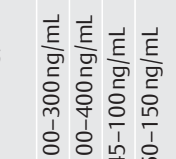

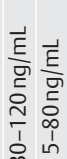

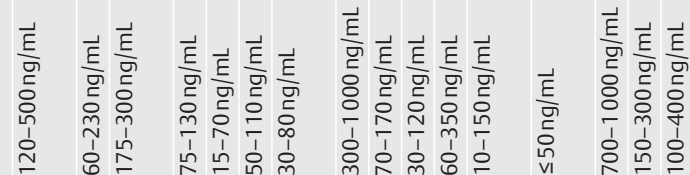

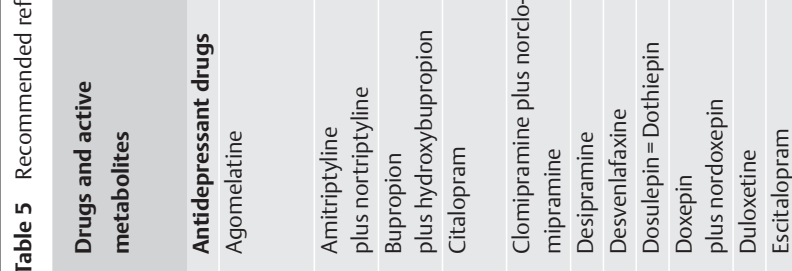

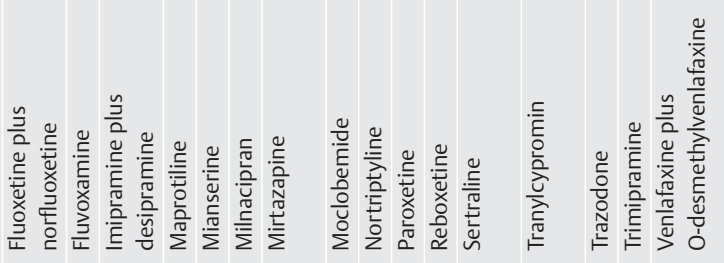




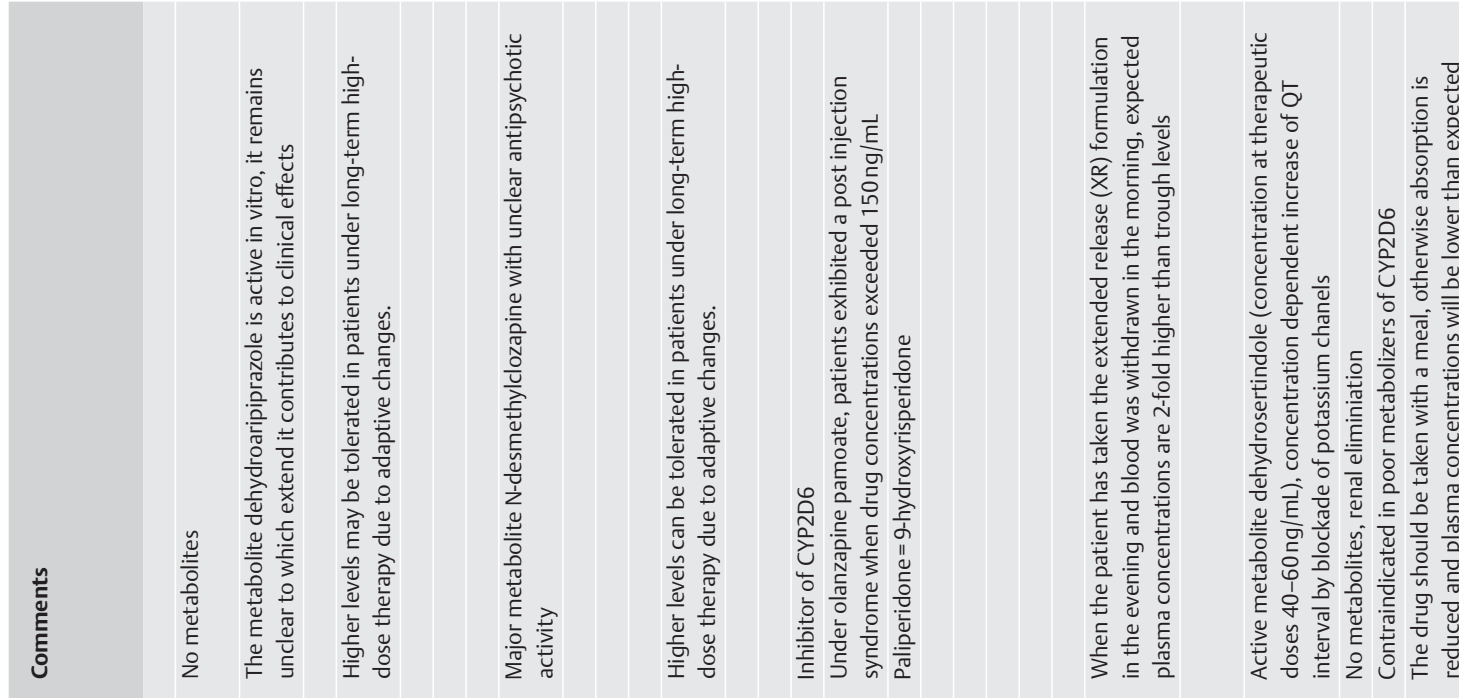

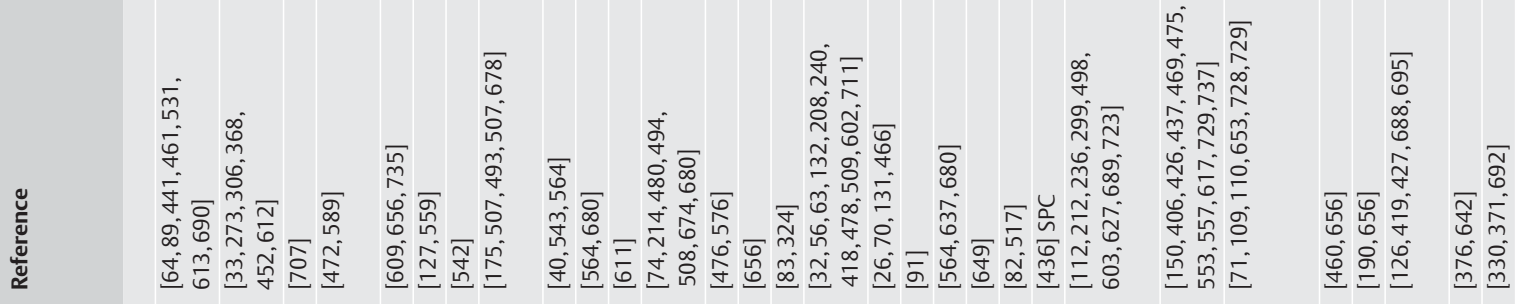

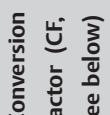

5

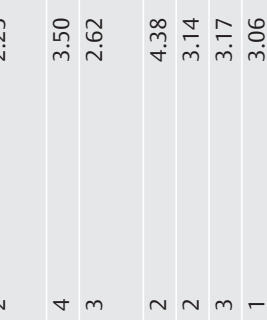

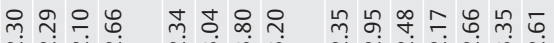

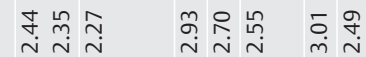

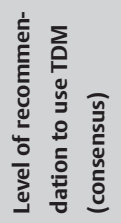

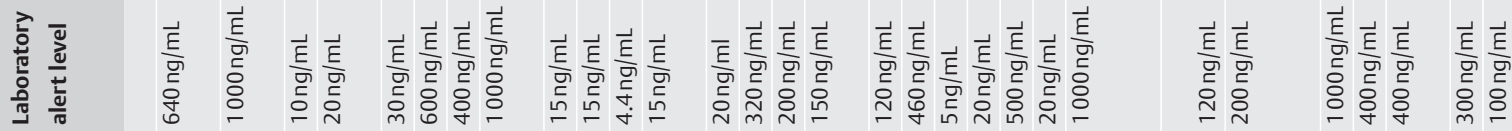

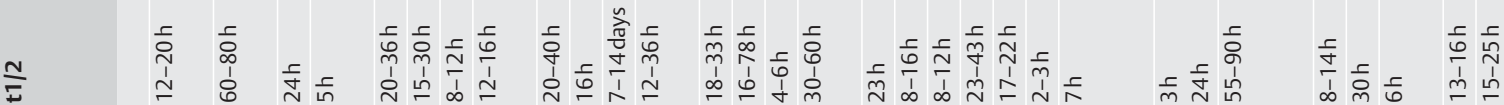

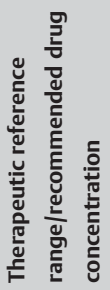

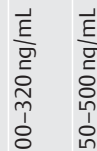

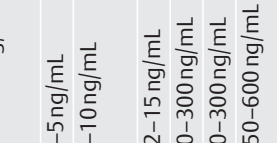

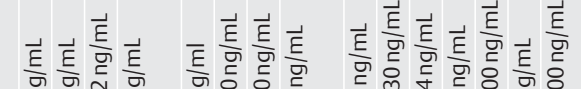

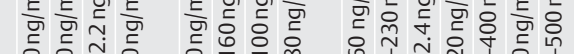

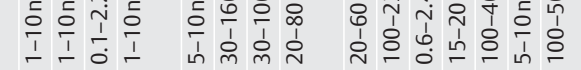

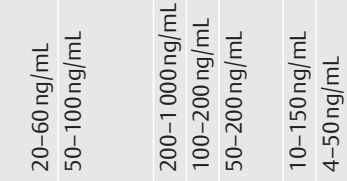

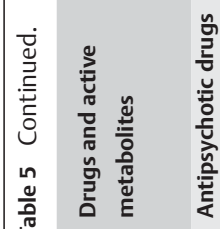

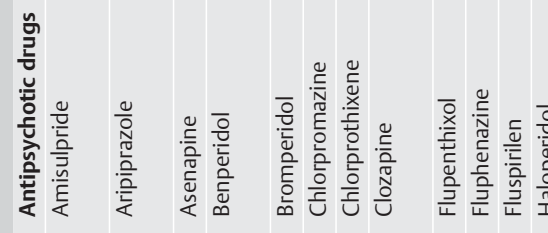

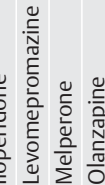

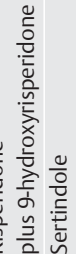

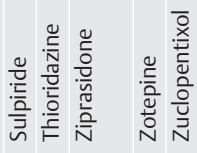



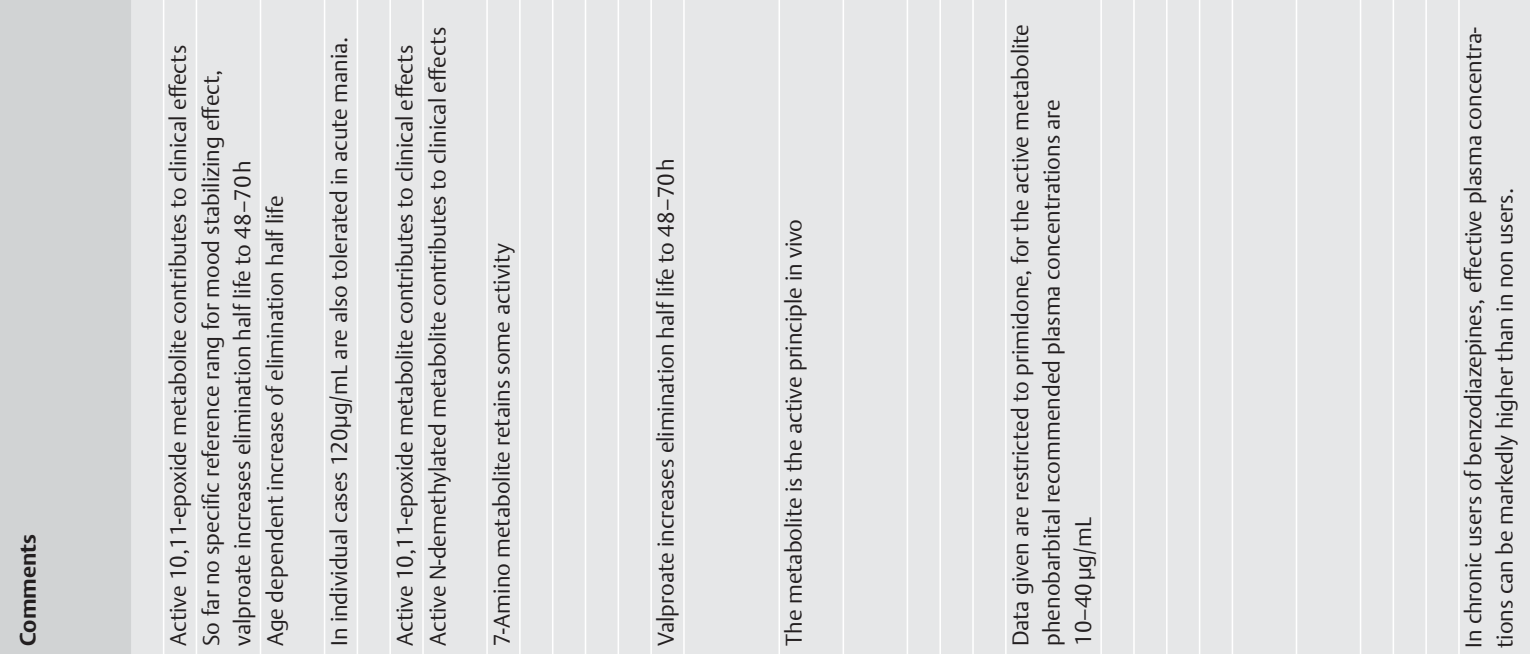

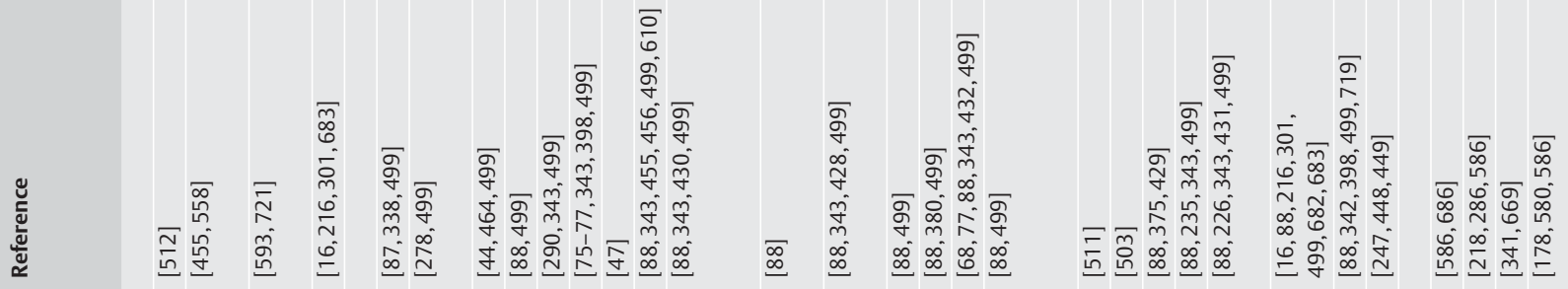

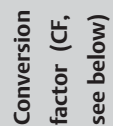

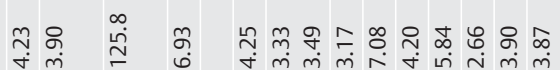

\section{总 䒿}

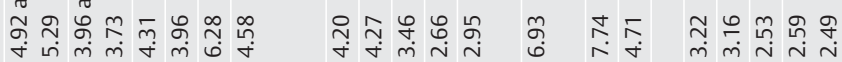

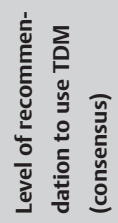

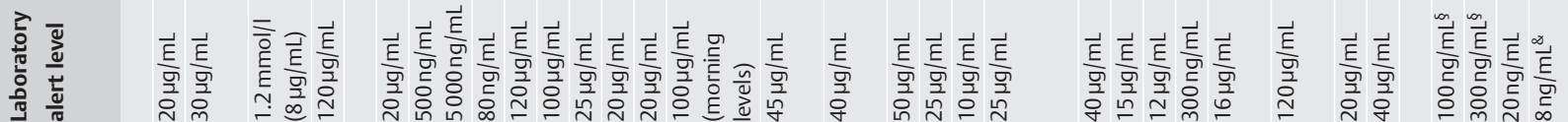

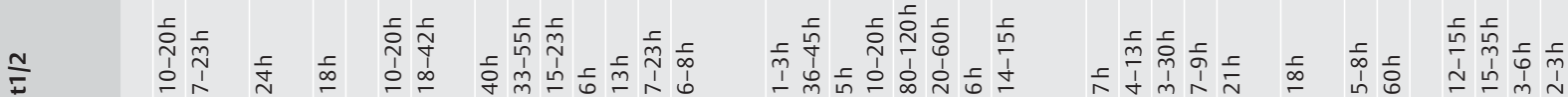

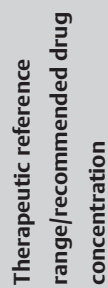

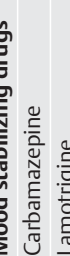

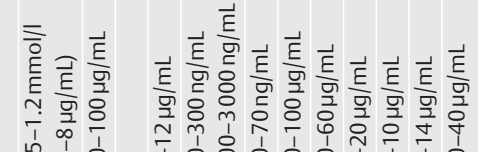

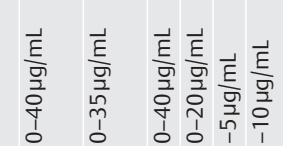

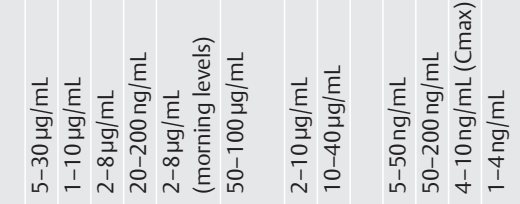

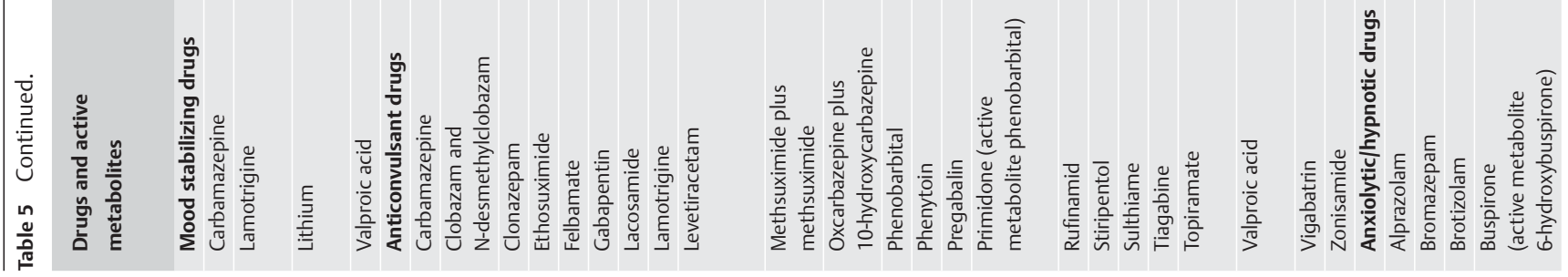




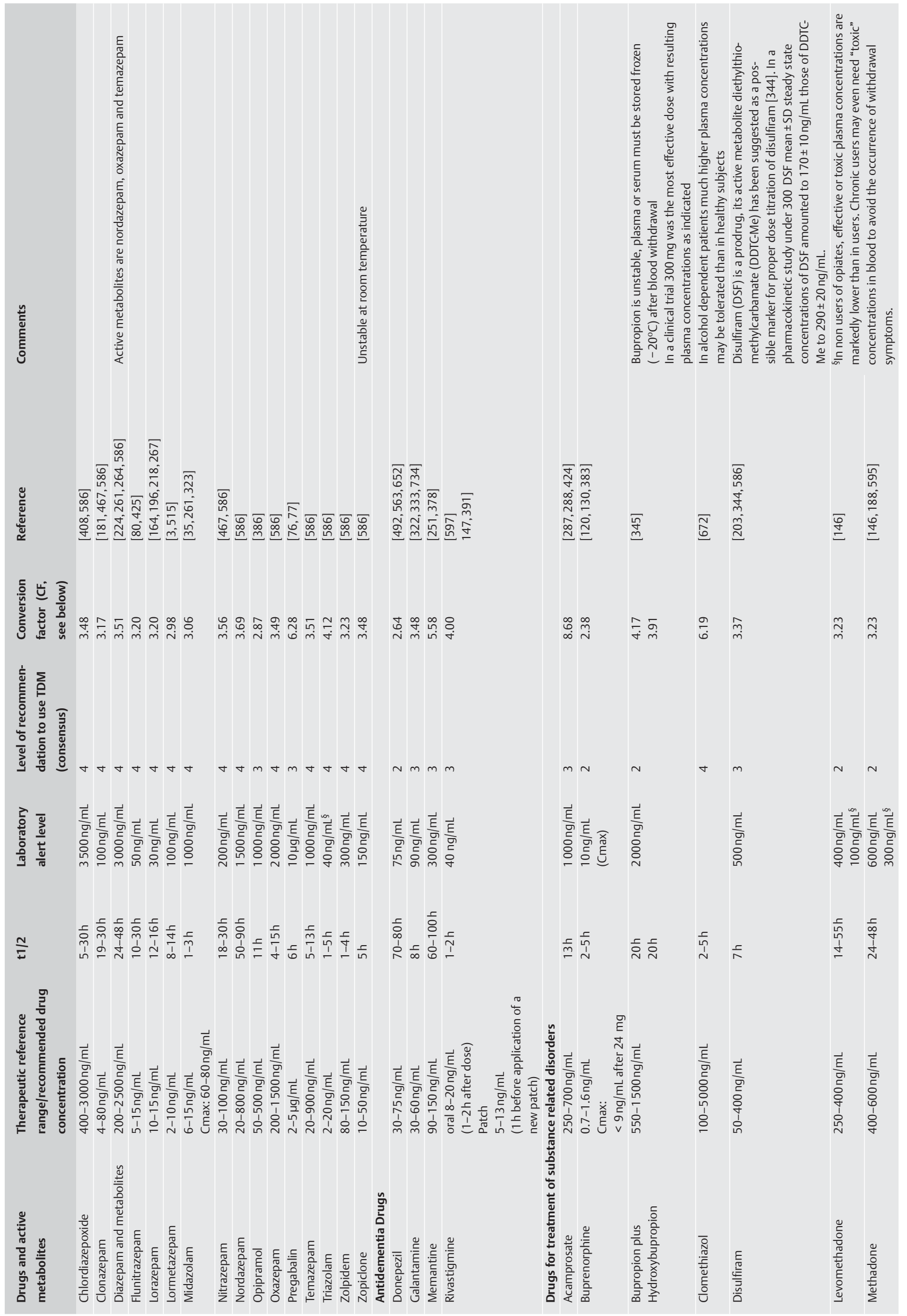




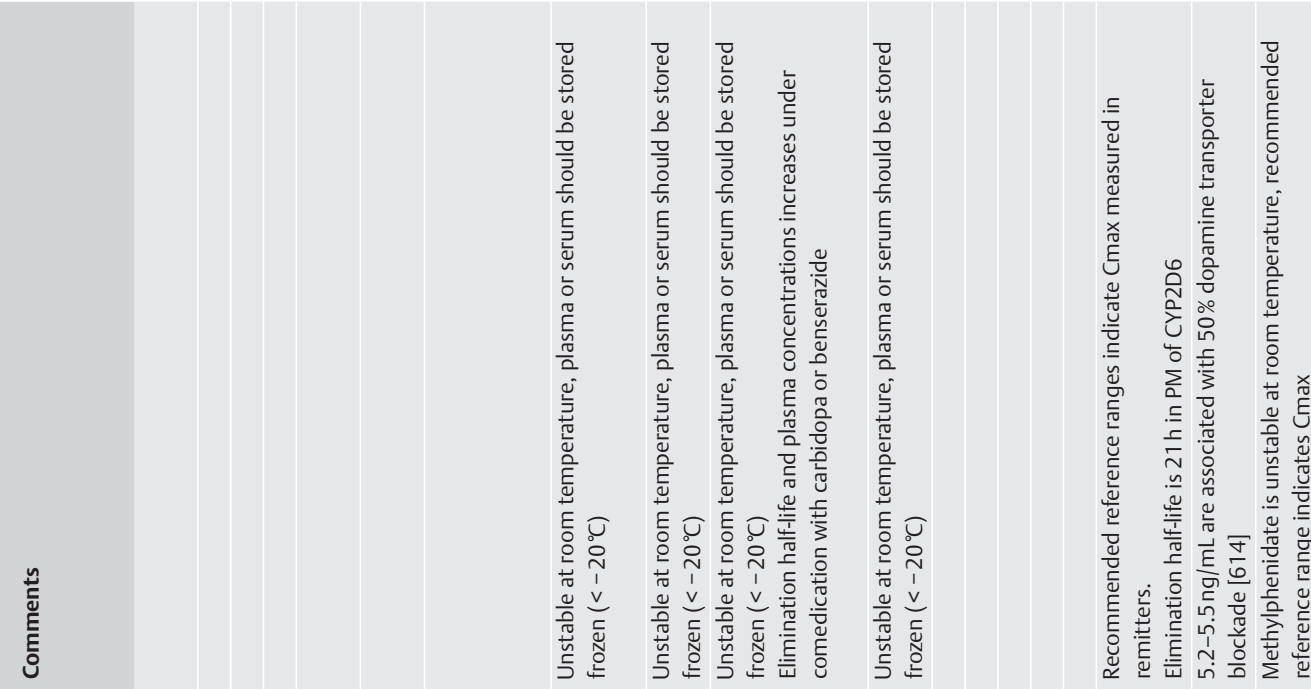

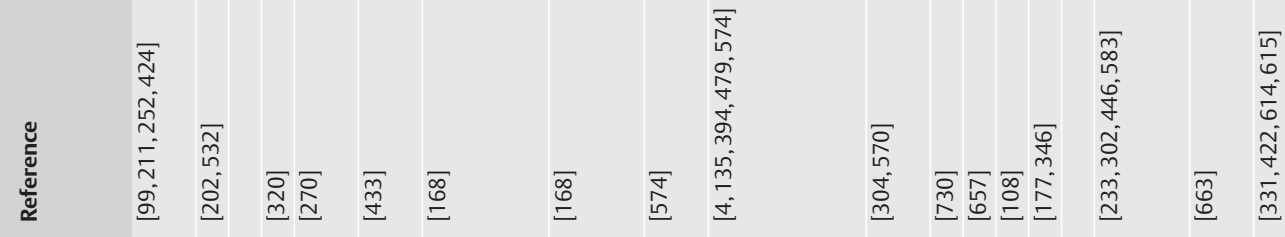

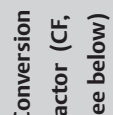

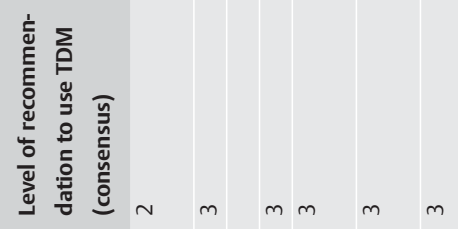

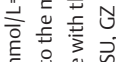

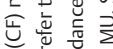

$m$ m

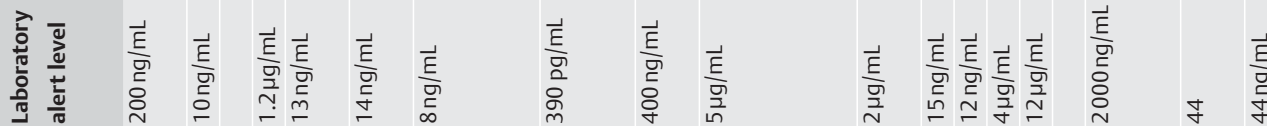

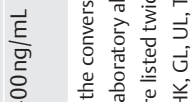

$\frac{10}{\pi}$

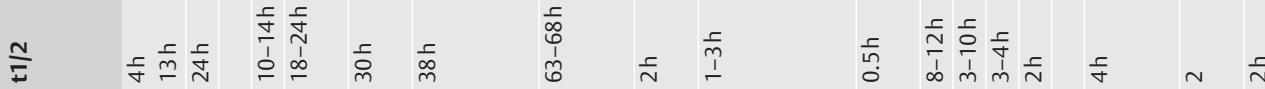


valproic acid, which are therefore listed twice in 0 Table 5. Moreover, it should be mentioned that studies are on the way to evaluate therapeutic reference ranges for children or adolescent patients and for elderly patients.

\section{Estimation of the lower limit of the therapeutic reference range}

Estimation of a therapeutic reference range (TRR) requires estimation of a lower and an upper limit of drug concentration in plasma. A generally accepted method for calculation of these limits does not exist. Whenever possible the lower limit of a drug's therapeutic range should be based on studies on the relationship between a drug's plasma concentration and clinical effectiveness. Below this limit, therapeutic effects are not significantly different from placebo. The optimum study design for evaluation of the lower limit of the therapeutic range is a prospective double-blind study where patients are treated with drug doses which lead to a defined plasma concentration range of the drug. Such a design was applied by Van der Zwaag and coworkers for patients treated with clozapine [678]. Patients were titrated to 3 different plasma concentrations of the antipsychotic drug. Significant superiority was found in patients with middle and high plasma concentration compared with low concentrations of clozapine. A similar design was applied for a blood-level study comparing imipramine and mirtazapine [98]. To conduct such studies, however, is a considerable logistic challenge. Fixed dose studies are therefore preferred for evaluation of the lower limit of the therapeutic reference range $[672,674]$.

For the estimation of threshold values of the therapeutic reference range, receiver operating characteristic (ROC) analysis has proven helpful [289]. A ROC plot allows the identification of a cut-off value that separates responders from non-responders and estimates the sensitivity and specificity of the parameter "medication plasma concentration". The usefulness of the ROC analysis has been demonstrated for a number antipsychotic and antidepressant drugs $[461,505,510,703]$.

\section{Estimation of the upper limit of the therapeutic reference range}

In the first study on TDM in psychiatry [31] an U-shaped relationship between plasma concentration and clinical effect was reported for nortriptyline. The lack of effect at high concentrations was attributed to the mechanism of action of the tricyclic antidepressant drug on monoaminergic neurons. According to actual knowledge, however, it seems more likely that reduced amelioration at high concentrations is due to side effects. The upper limit of the therapeutic range is therefore defined by the occurrence of side effects, also in this guideline. For most side effects (type A adverse reactions), it is also assumed that they are a function of dose and drug concentration in the body [335]. This assumption has been confirmed for motor side effects of antipsychotic drugs [536] and for unwanted side effects of tricyclic antidepressant drugs $[153,282]$. For paroxetine, a positive correlation was found between drug concentration in plasma and serotonin syndrome symptoms [303]. When such data are available, it is possible to apply ROC analysis for the calculation of the upper limit of the therapeutic range [461]. For many psychotropic drugs listed in 0 Table 5, however, valid data on both plasma concentration and the incidence of side effects are lacking. Case reports on tolerability problems or intoxications do often not include drug concentration measurements in plasma. Sporadic reports on fatal cases and intoxications are of limited value. Most blood concentrations reported to have caused death are far above drug concentrations that are associated with maximum therapeutic effects $[544,622]$. Post mortem redistribution of medications from or into the blood can lead to dramatic changes in blood levels [382,518], and the direction of the change does not follow a general rule [359]. Estimation of an upper threshold level above which tolerability decreases or the risk of intoxication increases is therefore more difficult than estimation of the lower threshold level, especially for drugs with a broad therapeutic index like SSRIs.

\section{Estimation and definition of a laboratory alert level}

As explained above, plasma concentrations with an increased risk of toxicity are normally much higher than the upper threshold levels of the therapeutic reference ranges for most psychotropic drugs shown in 0 Table 5. For the present guidelines, we therefore defined an upper plasma concentration limit above which it seems unlikely that therapeutic effects may be enhanced and added a "laboratory alert level" which was defined as follows:

\section{Definition}

The "laboratory alert levels" reported in this guideline ( $\bullet$ Table 5) indicate drug concentrations above the recommended reference range that causes the laboratory to feedback immediately to the prescribing physician. The alert levels are based on reports on intolerance or intoxications and plasma concentration measurements. In most cases, however, it was arbitrarily defined as a plasma concentration that is 2-fold higher than the upper limit of the therapeutic reference range. The laboratory alert should lead to dose reduction when the patient exhibits signs of intolerance or toxicity. When the high drug concentration is well tolerated by the patient and if dose reduction bears the risk of symptom exacerbation, the dose should remain unchanged. The clinical decision, especially in case of unchanged dose needs to be documented in the medical file.

From population-based to subject-based reference values

All therapeutic reference ranges listed in 0 Table 5 are orienting, population-based ranges. The population-derived ranges constitute descriptive statistical values which may not necessarily be applicable to all patients. Individual patients may show the optimum therapeutic response under a drug concentration that differs from the therapeutic reference range. Psychopharmacotherapy should therefore try to identify a patient's "individual therapeutic concentration" to guide the treatment [61,523]. For lithium it has been shown that the recommended plasma concentration range depends on whether the patient is in an acute manic episode or needs maintenance therapy [593]. For clozapine, Gaertner and colleagues [232] determined optimal plasma concentrations required for stable remission of individual patients under maintenance therapy in a relapse prevention study.

\section{Recommendations for measuring plasma concentrations of psychoactive drugs}

The usefulness of TDM varies with the clinical situation and the particular drug involved. In case of suspected non-adherence to medication or intoxications, quantifying plasma concentrations is a generally accepted tool for all drugs and groups of patients. However, it is still a matter of debate if TDM should be imple- 
mented in clinical routine. Based on empirical evidence, 5 levels of recommendation to use TDM were defined in the guidelines 2004 for 65 psychotropic drugs. These definitions were revised and grading reduced to 4 levels of recommendation, now ranging from "strongly recommended" to "potentially useful" as follows:

\section{Definitions}

Level 1: Strongly recommended

Evidence: Reported drug concentrations are established and evaluated therapeutic reference ranges. Controlled clinical trials have shown beneficial effects of TDM, reports on decreased tolerability or intoxications.

Recommendation: TDM is strongly recommended for dose titration and for special indications. For lithium, TDM is a standard of care.

Clinical consequences: At therapeutic plasma concentrations highest probability of response or remission; at "subtherapeutic" plasma concentrations: response rate similar to placebo under acute treatment and risk of relapse under chronic treatment; at "supratherapeutic" plasma concentrations: risk of intolerance or intoxication.

\section{Level 2: Recommended}

Evidence: Reported drug concentrations were obtained from plasma concentrations at therapeutically effective doses and related to clinical effects; reports on decreased tolerability or intoxications at "supratherapeutic" plasma concentrations.

Recommendation: TDM is recommended for dose titration and for special indications or problem solving.

Clinical consequences: TDM will increase the probability of response in non-responders. At "subtherapeutic" plasma concentrations: risk of poor response; at "supratherapeutic" plasma concentrations: risk of intolerance or intoxication.

Level 3: Useful

Evidence: Reported drug concentrations were calculated from plasma concentrations at effective doses obtained from pharmacokinetic studies. Plasma concentrations related to pharmacodynamic effects are either not yet available or based on retrospective analysis of TDM data, single case reports or non-systematic clinical experience.

Recommendation: TDM is useful for special indications or problem solving.

Clinical consequences: TDM can be used to control whether plasma concentrations are plausible for a given dose, or clinical improvement may be attained by dose increase in nonresponders who display too low plasma concentrations.

Level 4: Potentially useful

Evidence: Plasma concentrations do not correlate with clinical effects due to unique pharmacology of the drug, e.g., irreversible blockade of an enzyme, or dosing can be easily guided by clinical symptoms, e.g., sleep induction by a hypnotic drug.

Recommendation: TDM is not recommended for dose titration but may be potentially useful for special indications or problem solving.

Clinical consequences: TDM should be restricted to special indications.

According to our literature-based evaluations, TDM was graded as "strongly recommended" for 15 of the 128 surveyed neuropsychiatric compounds, "recommended" for 52 medications, "useful" for 44 drugs and "potentially useful" for 19 drugs (॰ Table 5).
TDM is highly recommended for most tricyclic antidepressants. It reduces the risk of intoxications $[103,381,459,510,525,527$, $528,530,718]$, and for many tricyclic antidepressants, a plasma concentration - clinical effectiveness relationship has been shown. For SSRIs, TDM is of little clinical importance in clinical practice $[6,537,644]$. Toxicity of this type of antidepressants is low in comparison to most of the pre-SSRI antidepressants $[48,166,314,646,715]$. Data from Sweden revealed that TDM of SSRIs is cost-effective in elderly patients where it helped to use minimum effective doses [410]. For citalopram a recent observational study revealed that plasma concentrations on day 7 of treatment are predictive for later non-response [491]. Patients exhibiting citalopram plasma concentrations below $50 \mathrm{ng} / \mathrm{mL}$ had a significantly reduced improvement on the Hamilton rating scale for depression. Evidence for a statistically significant relationship between drug concentration and therapeutic outcome is lacking for the tetracyclic antidepressants maprotiline, mianserin and mirtazapine and also for trazodone and reboxetine, the monoamine oxidase inhibitors moclobemide and tranylcypromine.

TDM is strongly recommended for the typical antipsychotic drugs haloperidol, perphenazine and fluphenazine, and for the atypical antipsychotics amisulpride, clozapine, olanzapine, and risperidone ( $\bullet$ Table 5). Overdosing may lead to extrapyramidal side effects. In the case of clozapine, there is a strong correlation between clozapine plasma levels and incidence of seizures. Avoiding overdosing of typical antipsychotic drugs by TDM is for the majority of patients a matter of quality of life rather than safety [136]. TDM of antipsychotics is also useful when medication is switched from the oral to the depot form, or vice versa. With regard to the mood stabilizing and/or antimanic drugs lithium, valproic acid and carbamazepine, therapeutic reference ranges and toxic levels are well defined. Therefore TDM is strongly recommended for these drugs ( $\bullet$ Table 5). For lithium TDM is even the standard of care $[133,170,185,280,395,593$, $706,721]$. For its long-term use, plasma concentrations of $0.5-$ $0.8 \mathrm{nmol} / \mathrm{L}$ are advised. For an acute treatment with lithium, it may be justified to increase its concentrations up to $1.2 \mathrm{mmol} / \mathrm{L}$. Compounds that have been shown to be effective as antidementia drugs are donepezil, rivastigmine, galantamine and memantine. TDM is rarely used for the treatment of dementia, though there is evidence that it can be useful. For donepezil, it has been shown that the patients' improvement was significantly better if their plasma concentrations were above $50 \mathrm{ng} / \mathrm{mL}$ as compared to patients that showed lower drug concentrations [563].

Most anxiolytic and hypnotic drugs belong to the class of benzodiazepines. Anxiolytic and hypnotic effects are rapid. Treatment can therefore be guided by immediate clinical impression rather than by TDM. In case of lack of therapeutic effects under usual doses, however, TDM may clarify if non-response was due to drug abuse that has led to tolerance or due to pharmacokinetic abnormalities. For alprazolam, TDM may be useful to suppress panic attacks [722].

The opiate agonists methadone, R-methadone (levomethadone), buprenorphine, l- $\alpha$-acetylmethadol (LAAM) and slowrelease formulations of morphine are used for the treatment of opioid addiction. TDM is indicated for patients treated with methadone or R-methadone. The usefulness of TDM for monitoring treatment with "anti-craving" medications such as acamprosate or naltrexone, employed for the treatment of alcohol use disorders, has recently been reviewed elsewhere [99]. TDM was recommended to enhance the moderate efficacy of these drugs. 
For anticonvulsant drugs, TDM is well established, especially for old drugs which are more toxic than the new ones [499].

For antiparkinson drugs, TDM has not been established so far. For the dopamine agonists, data on reference ranges are scarce. For L-dopa, there is an imperfect correlation between plasma concentrations and short-term clinical response [479]. Nevertheless, we considered the pharmacologic properties of these neurological drugs ( $\bullet$ Table 1,5 ), since psychiatric patients may receive antiparkinson drugs that possibly interfere with the action of psychotropic medication. For most of these drugs Cmax values are given.

\section{Indications for measuring plasma concentrations of psychoactive drugs}

- Table 6 presents a list of indications for TDM in psychiatry. The validity of these indications has to be examined on an individual basis and evaluated for each case individually. Similar to any diagnostic test, TDM should only be requested when there is evidence that the result will provide an answer to a well defined question.

For drugs with well defined therapeutic reference ranges or with a narrow therapeutic index it makes sense to measure plasma levels for dose titration after initial prescription or after dose change. Even without a specific problem, there is sufficient evidence that TDM has beneficial effects for patients treated with these drugs. This holds true for lithium, tricyclic antidepressants, several antipsychotics or anticonvulsants ( $\bullet$ Table 5). For lithium, TDM is even mandatory for safety reasons.

In case of suspected non-adherence or lack of clinical improvement under recommended doses: TDM is a valid tool for treatment with all drugs considered in these guidelines. Loss of adherence is a major problem of long-term medication $[10,55,401]$. In patients with schizophrenia [55,351] and in patients with unipolar or bipolar disorders non-adherence ranges from 10 to $69 \%$ [401,439]. Methods used to measure adherence include pill counting, examining case-note recordings, interviewing patients or noting the attending physicians' clinical judgement about adherence $[11,355,685,708]$. Studies have shown that clinicians cannot reliably predict their patients' adherence [104,579]. TDM is advantageous, since it is an objective method and tells the prescribing physician if the drug is in the body at a concentration that is potentially sufficient for the expected clinical response. Deviations from the expected doserelated reference range ( $\bullet$ Table 4 ) indicate if the patient has taken his/her medication, and concomitant determination of metabolites is another approach to clarify if the drug was taken continuously as recommended. For interpretation, however, possible interactions with co-medications exhibiting enzyme inhibiting or inducing properties must be considered ( $\bullet$ Table 3 ). Reis and coworkers [546,547] analysed the compliance of patients who were treated with sertraline by repeated determination of serum drug concentrations of the parent compound and of the metabolite. Variations of the ratios of concentrations of norsertraline to sertraline were highly indicative for hidden and partial non-adherence. To be able to use this approach, these guidelines were supplemented with data on ratios of concentrations for 32 psychoactive drugs ( $\bullet$ Table 2). By taking several blood samples per day and by calculation the observed and expected time dependent plasma concentrations it can be differentiated if a low plasma concentration is due to reduced bioavailability, enhanced degradation or poor adherence. Pharmacokinetic modelling of the expected time dependent plasma concentration thereby considers a drug's basic pharmacokinetic properties $[4,78,340,626,654]$.

When clinical improvement under recommended doses is insufficient and the drug is well tolerated, TDM will clarify if the drug concentration is too low and if it makes sense to increase the dose.

When adverse effects are associated with clinical improvement under recommended doses, measurement of the plasma concentration may clarify if side effects are related to excessively high drug levels in the blood and if the dose should be decreased. When combining medications that are inhibitors or inducers of drug metabolizing enzymes ( $\bullet$ Table 1 ), pharmacokinetic drug interactions will occur if the comedication is a substrate of the inhibited or induced enzyme ( Table 3 ). Dose adaptation should be guided by TDM in combination with an inducer or inhibitor and avoid loss of action, poor tolerability or intoxication due to a pharmacokinetic drug-drug interaction $[215,244,594]$. With regard to environmental factors smoking is of high clinical relevance for drugs that are substrates of CYP1A2 ( $\bullet$ Table 1). The isoenzyme is dose dependently induced by constituents of cigarette smoke (polycyclic aromatic hydrocarbons, not nicotine). Its activity increases by 1.2 -fold, 1.5 -fold for 1.7 fold for 1-5, 6-10 and > 10 cigarettes smoked per day [201]. On the other hand, CYP1A2 activity decreases until the fourth day immediately on cessation of heavy smoking [200]. Smoking effects should therfore be considered when patients are under therapy with a CYP1A2 substrate ( $\bullet$ Table 1 ) such as clozapine $[81,676]$, duloxetine [222] or olanzapine [749]. It should also be mentioned that many pharmacokinetic drug-drug interactions have been found by TDM either by chance or by retrospective analysis of TDM data bases [112,537].

In pharmacovigilance programs, the safety of drug use is supervised under naturalistic conditions [271,285]. In case of observed adverse events, measurement of plasma concentrations is most helpful for clarification [335].

Relapse prevention is a major goal of maintenance treatment. Reduction of relapse rates by TDM is highly cost-effective, as relapses can lead to hospitalization [377]. In schizophrenic patients, it has been shown that fluctuations of clozapine plasma concentrations are predictive for relapses $[232,670]$ and rehospitalizations [627]. In these patients, TDM may help reduce the risk of relapse or recurrence by increasing adherence to the medication. One day in the hospital is 4-16 times more expensive than a single drug concentration measurement in the laboratory.

\section{Recommendation}

Though clinical evidence is still scarce, we recommend regular monitoring of plasma concentrations under maintenance therapy, at least every 3-6 months, to prevent relapses and rehospitalizations. The frequency of TDM requests may be increased if patients are known to be non-adherent to the medication or in case of changes of co-medications or of smoking that affect the pharmacokinetics of the drug.

In patients exhibiting genetic peculiarities of drug metabolizing enzymes, doses must be adapted. Kirchheiner and coworkers [362,365] calculated doses for PM or UM of CYP2D6 based on pharmacokinetic and pharmacodynamic findings. However, even in the case of a confirmed abnormal CYP genotype, TDM is recommended, because genotyping can only roughly predict to 
which extent the plasma concentration may be changed in the individual patient [496,497,625].

For special groups of patients, such as pregnant or breastfeeding patients, children or adolescent patients $[22,373,194]$, individuals with intellectual disabilities $[158,300]$, or elderly patients, especially patients aged above 75 years [374], TDM is highly recommended.

Any psychopharmacologic therapy of pregnant or breastfeeding women should assure that the plasma concentration of the drug is in the therapeutic reference range to minimize the risk of relapse on the mother's side and, at the same time, to minimize risks associated with drug exposure of the fetus or the child $[169,174]$. Renal clearance and the activity of the CYP isoenzymes 3A4, 2D6 and 2C9, and uridine 5'-diphosphate glucuronosyltransferase are increased during pregnancy, whereas activities of CYP1A2 and 2C19 decrease [21]. TDM in pregnant women and/or mothers should be carried out at least once per trimester and within $24 \mathrm{~h}$ after delivery [65].

Many psychoactive drugs are not approved for use in children or adolescents [248]. Pharmacokinetics and pharmacodynamics change during development $[194,438,514,516]$. In adolescents suffering from psychotic disorders, comorbid drug abuse is very common, and compliance with an antipsychotic treatment is generally marginal [318]. Therefore, TDM is recommended in these patients. To raise data on the effectiveness and tolerability of psychoactive drugs under every day conditions, a TDM network was established for child and adolescent patients [see http://www.tdm-kjp.de/eng/contact.html].

In elderly patients, who frequently are hypersensitive to medication, TDM is helpful to distinguish between pharmacokinetic and pharmacodynamic factors when adverse effects occur [666]. Ageing involves progressive impairments of the functional reserve of multiple organs [407], especially renal excretion, and body composition changes significantly $[361,374]$. Hepatic clearance can be reduced by up to $30 \%$. Phase I reactions are more likely to be impaired than phase II reactions. On the other hand, there are no age-dependent changes in CYP isoenzyme activity [374]. Age-related changes in physiologic and pharmacokinetic functions as well as the comorbidity and polypharmacy complicate pharmacotherapy in the elderly [125]. Therefore, TDM should be used for these patients to improve safety and tolerability of psychopharmacotherapy.

In individuals with intellectual disabilities, new generation antipsychotic drugs are frequently used. Recently published guidelines recommend TDM for these patients, at least when treated with risperidone or olanzapine [158]. For ethical and legal reasons, patients with intellectual disabilities are excluded from clinical trials. On the other hand, many of these patients need medication. In these individuals, it may be difficult to differentiate between morbogenic and pharmacogenic reasons for symptom aggravation. Though evidence is poor, TDM is recommended to guide the pharmacotherapy of these patients [158].

In forensic psychiatry the primary aim of pharmacotherapy, consisting mostly antipsychotic drugs, is reduction of dangerous behaviour $[458,462]$. To consistently reduce the risk of violence and aggression, adherence to the prescribed medication is essential [658]. Therefore, TDM is recommended for this group of psychiatric patients. It is, however, not clear if effective plasma concentrations are identical in forensic and general psychiatry patients. Castberg and Spigset [113] analyzed data obtained by survey in a high security forensic unit and found higher doses in forensic patients than in a control group. The dose related
Table 6 Typical indications for measuring plasma concentrations of medications in psychiatry.

- Dose optimization after initial prescription or after dose change

- Drugs, for which TDM is mandatory for safety reasons (e. g., lithium)

- Suspected complete or partial non-adherence (non-compliance) to medication

- Lack of clinical improvement under recommended doses

- Adverse effects and clinical improvement under recommended doses

- Combination treatment with a drug known for its interaction potential or suspected drug interaction

- TDM in pharmacovigilance programs

- Relapse prevention under maintenance treatment

- Recurrence under adequate doses

- Presence of a genetic particularity concerning drug metabolism (genetic deficiency, gene multiplication)

- Pregnant or breast feeding patient

- Children and adolescent patient

- Elderly patient ( $>65 \mathrm{y}$ )

- Individuals with intellectual disabilities

- Patients with pharmacokinetically relevant comorbidities (hepatic or renal insufficiency, cardiovascular disease)

- Forensic patient

- Problems occurring after switching from an original preparation to a generic form (and vice versa)

plasma concentrations were significantly lower for olanzapine but higher for quetiapine in the forensic patients than in the control group.

The indication "problem occurring after switching from an original preparation to a generic form (and vice versa)" is still under-investigated and data are scarce $[124,139]$.

Another potential indication for TDM not listed in 0 Table 6 is the increasing availability of counterfeit drugs on the internet [599]. WHO launched a program in 2006 to combat this illegal industry. There are no data published on this type of market concerning psychotropic drugs, but patients may be co-medicated (mostly auto-medication) with other drugs obtained from this source. The counterfeit medications may not comply with purity and dosage standards and therefore increase the risk for interactions.

\section{Practical Aspects for TDM in Psychiatry}

Essential for an effective TDM service is the availability of appropriate analytical methods that produce results within a reasonable time, i.e., $48 \mathrm{~h}$, and advice from someone who understands pharmacokinetics and therapeutics [184]. As shown in $\bullet$ Fig. 1, the TDM process starts with the request and ends with the final decision about how to adjust a given patient's therapeutic regimen by the health care professional.

\section{Request for plasma concentration quantification}

As mentioned above, TDM should only be requested when there is evidence that the result will provide an answer to a specific question. If it is not clear what the question is, the answer is of little value. Typical indications are listed in $\odot$ Table 6. A single measurement is often insufficient for problem solving. For example, a series of measurements may be required at appropriate intervals to clarify if a low plasma concentration is either due to poor compliance, reduced bioavailability or abnormally rapid elimination. 


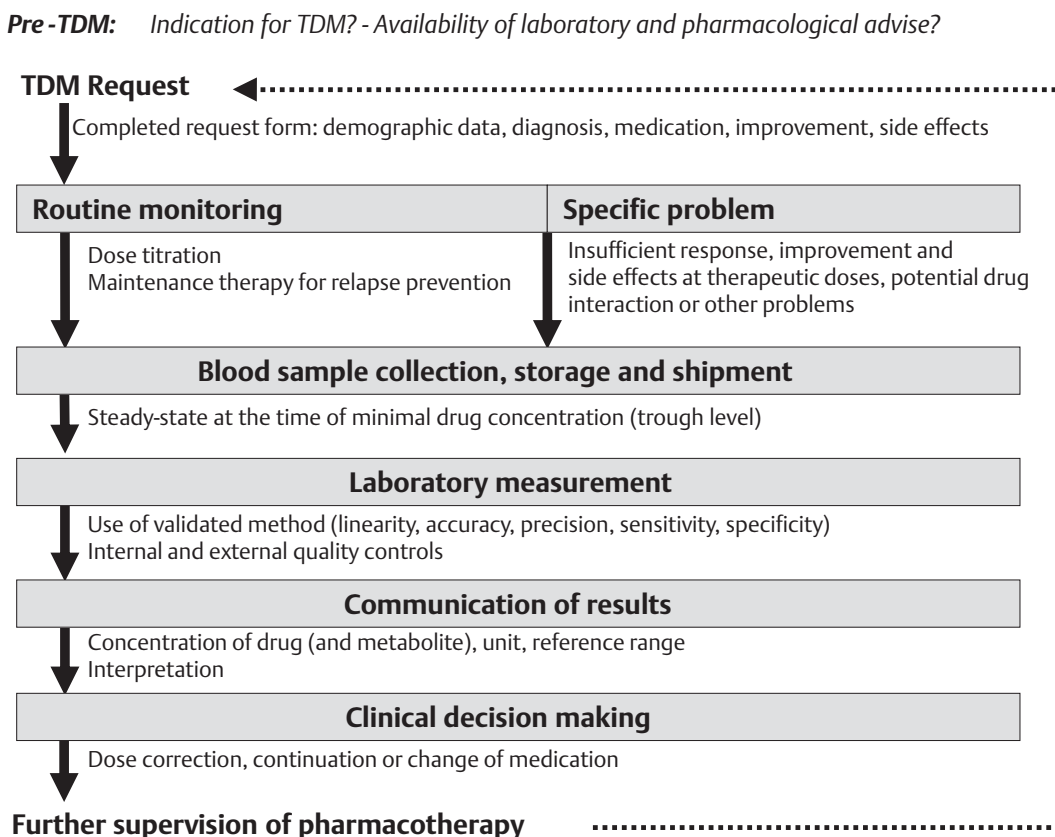

Fig. 1 Schematic overview of the TDM process as a guide for psychopharmacotherapy. Routine TDM is primarily applied to drugs with a narrow therapeutic index and a well-defined therapeutic reference range. However, TDM is useful for any psychotropic drug when addressing special therapeutic problems such as "therapy refractoriness" or side effects under recommended dosage.

\section{LABORATORY \\ Address \\ Phone \\ Fax}

\begin{tabular}{|l|l|l|}
\hline PATIENT DETAILS & Name or Code & \\
\hline Date of birth & Sex & \\
\hline$\square$ HIV-patient & Weight $(\mathrm{kg})$ & Sm \\
& & \\
\hline
\end{tabular}

REASON FOR REQUEST

(tick more than one if applicable) $\square$ Control of adherence

$\square$ Dose adaptation
$\square$ Insufficient improvement
$\square$ Adverse effects (specify below)

$\square$ Adverse effects (specify below)

\section{REQUESTING HOSPITAL / DOCTOR \\ Address \\ Phone in case of alert \\ Fax}

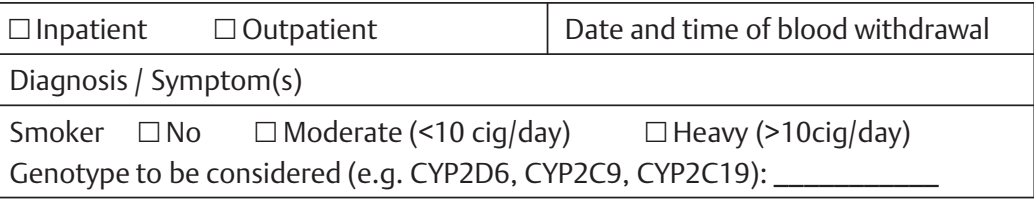

\section{SEVERITY OF ILLNESS}

(CGI-S)

How mentally ill is the patient

at this time?

\section{IMPROVEMENT}

(CGI-I)

Change compared to

condition at admission?

$\square$ Very much improved (1)

$\square$ Much improved (2)

$\square$ Minimally improved (3)

$\square$ Borderline mentally ill (2)

$\square$ Mildly ill (3)

$\square$ No change (4)

$\square$ Minimally worse (5)

$\square$ Much worse (6)

$\square$ Very much worse (7)

\section{$\square$ Drug-drug interaction \\ $\square$ Control under maintenance therapy \\ $\square$ Other reason (to be specified)}

$\square$ Moderately ill (4)

$\square$ Severely ill (6)

$\square$ Extremely ill (7)

\begin{tabular}{|c|c|c|c|}
\hline \multicolumn{4}{|c|}{ SIDE EFFECTS (UKU) } \\
\hline \multirow{2}{*}{\multicolumn{2}{|c|}{$\begin{array}{l}\square \text { Concentration difficulties } \\
\square \text { Tension/inner unrest }\end{array}$}} & $\square$ Asthenia & Sedation \\
\hline & & $\square$ Sleep disturbances & $\square$ Emotional indifference \\
\hline \multirow{2}{*}{$\begin{array}{l}\square \text { Dystonia } \\
\square \text { Akathisia }\end{array}$} & $\square$ Rigidity & $\square$ Hypokinesia/Akinesia & $\square$ Hyperkinesia \\
\hline & $\square$ Epilepticse & izures $\square$ Paresthesias & $\square$ Headache \\
\hline \multicolumn{4}{|c|}{$\square$ Accomodation disturbance } \\
\hline \multirow{4}{*}{\multicolumn{2}{|c|}{$\begin{array}{l}\square \text { Nausea/Vomiting } \\
\square \text { Polyuria/Polydypsia } \\
\square \text { Sexual dysfunction }\end{array}$}} & \multirow{3}{*}{\multicolumn{2}{|c|}{$\begin{array}{l}\square \text { Diarrhoea } \square \text { Constipation } \square \text { Micturation disturbance } \\
\square \text { Increased sweating } \square \text { Galactorrhoea } \quad \square \text { Weight gain } \\
\square \text { Other (to be specified) }\end{array}$}} \\
\hline & & & \\
\hline & & & \\
\hline & & ationship: & ble $\square$ possible $\square$ probat \\
\hline
\end{tabular}

\begin{tabular}{|l|l|l|l|l|}
\hline Drug(s) to be assayed & Formulation & Daily dose & Date started & Time of last dose \\
\hline & & & & \\
\hline & & & & \\
\hline
\end{tabular}

\section{Other medications (include herbals, over-the-counter drugs etc)}

TDM request : Blood should be withdrawn under steady-state conditions, Date of sample receipt: preferably in the morning BEFORE taking the morning dose. Return the completed form, together with a minimum of $2 \mathrm{ml}$ serum or plasma.

Signature:

Fig. 2 Request form for therapeutic drug monitoring in psychiatry. 
TDM requests must include a completed request form ( 0 Fig. 2 ) which is essential for effective drug concentration measurements and an adequate interpretation of the results $[501,635]$. The form should contain the patient name or code, demographic data, diagnosis, medication, reason for the request, the commercial and the generic name of the drug and its dose, the galenic formulation, the time of the last change of the dose, time of blood withdrawal. A brief comment on the clinical situation should be given for interpretation of the results. We recommend to use objective symptom rating, e.g., application of the clinical global impression (CGI) scale [283], to measure severity of illness and therapeutic improvement. The summary form of the UKU scale is useful to evaluate the occurrence and severity of side effects [402]. However, documented feedback to questionnaires indicates that clinicians often do NOT want to put that much information on the form. Moreover, the filled-in information is often not accurate. As an alternative, feedback by phone may be offered for interested physicians.

When interpretation of the results is requested from the laboratory, it is absolutely necessary to fill out the request forms adequately and completely. Thereby computerized ordering of TDM has advantages. It is inexpensive and it guides the ordering physician to give the relevant information required for interpretation in a comfortable way. Computerized ordering, however, is still not widely used. But effective packages are on the way to become available (e.g., www.konbest.de).

\section{Blood sample collection}

Generally, TDM is carried out in plasma or serum samples. The analysis of whole blood, which is long established for immunosuppressant drugs by using immunoassays [693], has been abandoned for TDM in psychiatry. There is no consensus whether plasma or serum should be preferred. Definite experimental data are still lacking which clearly demonstrate differences in the drug concentrations using either plasma or serum. The few available comparisons indicate that values obtained from serum or plasma can be used interchangeably [308]. Most psychoactive drugs are intensively bound to blood cells of plasma proteins. Concentrations of neuropsychiatric drugs reported in this guideline refer to the total drug fraction in accordance with the literature. For imipramine, it has been shown that the drug is rapidly and almost totally cleared by the brain through a single passage in the microvasculature [555]. The extraction was not significantly affected in the presence of albumin, lipoproteins or erythrocytes. For nortriptyline, statistical relationships between free levels of drug and clinical response were found to be insignificant [506]. Therefore it seems likely that the clinical response depends on the total drug fraction. Analysis of psychotropic medications in other materials such as urine, spinal fluid, tears, hairs or maternal milk have not been introduced for TDM purposes, and no validated data are available which deal with therapeutic concentrations. Saliva offers the advantage of non-invasive collection $[20,25,356]$. However, the drug concentration in saliva corresponds to the free (i.e., nonprotein-bound) fraction of the drug in blood - which is for most psychopharmacologic medications only $10 \%$ or less of the total concentration. Thus detection problems may occur when using saliva instead of blood plasma or serum. In any case, more data will have to be obtained for saliva as a matrix for measurement of drug concentrations.

With few exceptions, TDM relies on trough steady-state plasma concentrations. Blood should therefore be collected after at least
4 drug elimination half-lives after the start of or a change in dosage and during the terminal ß-elimination phase. For most psychotropic drugs, elimination half-lives vary between 12 and $36 \mathrm{~h}$ ( $\odot$ Table 5). Notable exceptions are quetiapine, trazodone, or venlafaxine, which display elimination half-lives around $6 \mathrm{~h}$. Fluoxetine and aripiprazole have longer elimination half-lives. In clinical practice, the appropriate sampling time for most psychoactive drugs is one week after stable daily dosing and immediately before ingestion of the morning dose, which usually is $12-16 \mathrm{~h}$ (or $24 \mathrm{~h}$ if the drug is given once daily in the morning) after the last medication. If, for logistics reasons, blood can only be collected late in the morning, the patient should not be medicated before blood withdrawal. In an outpatient setting it is important to indicate exactly the time of administration of the last dose for interpretation. Trough levels can then be extrapolated by pharmacokinetic modelling.

In patients treated with a depot preparation of an antipsychotic drug, blood should be sampled immediately before the next injection. Formulations of antipsychotic drugs such as haloperidol decanoate or risperidone microspheres are characterised by a slow absorption after intramuscular administration. Maximum plasma concentration of first generation depot antipsychotics are reached after 1-14 days after injection, and the apparent elimination half-life is $2-3$ weeks [647]. Similar properties exhibits the newly introduced paliperidone palmitate [131]. For risperidone microspheres the mean time to peak concentrations is 4 weeks and its plasma half life $4-6$ days [647]. For other drugs delivered in extended or retarded release formulations like paliperidone [70] or quetiapine [212], special attention has to be given to the time of drug intake for correct interpretation (see $\odot$ Table 5). In these formulations, the time of maximum plasma concentration is delayed but the elimination half-life remains essentially unchanged. The long acting olanzapine pamoate is a new depot formulation [399]. The salt slowly releases olanzapine from the injection site into the muscle tissue. However, it dissolves rapidly when it is in contact with blood or plasma. The latter results in high plasma concentrations and may lead to marked sedation and delirium, the so called post-injection syndrome [399,647]. Considering this special problem it could be useful to control plasma concentrations of olanzapine shortly (i.e., about $2 \mathrm{~h}$ ) after the i.m. injection to monitor if plasma concentrations increase. This approach, however, relies on the rapid quantification of olanzapine.

TDM may of course be carried at any time after drug ingestion if unexpected side effects are observed. It is not necessary to measure trough levels, but the dosing schedule should be reported for interpretation.

\section{Storage and shipment of blood samples}

When samples must be stored and sent frozen, it is required to prepare serum or plasma before freezing, since it is not possible to prepare serum or plasma from frozen blood. With few exceptions, serum or plasma samples can be stored in the dark (at $4^{\circ} \mathrm{C}$ ) for at least $24 \mathrm{~h}$, and most drug samples can be sent without freezing [305]. Exceptions are light and/or oxygen sensitive substances. For the determination of bupriopion or methylphenidate, however, serum samples must be frozen or extracted and stabilized immediately after blood withdrawal and centrifugation (see $\odot$ Table 5). Olanzapine must be stored

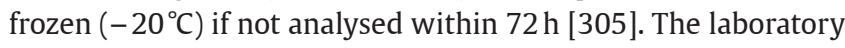
should give instructions on its web site or the request form how 
to collect (plasma volume, labelling of the samples), store and mail the sample.

\section{Laboratory measurements}

Selective and sensitive analytical methods for the quantitative evaluation of drugs and their metabolites (analytes) are essential for the successful conduct of TDM. Methods must be validated which includes all of the procedures that demonstrate that a particular method used for quantitative measurement of analytes in a given biological matrix is reliable and reproducible for the intended use. The fundamental parameters for this validation include (1) accuracy, (2) precision, (3) selectivity, (4) sensitivity, (5) reproducibility and (6) stability. Validation involves documenting, through the use of specific laboratory investigations, that the performance characteristics of the method are suitable and reliable for the intended analytical applications. The acceptability of analytical data corresponds directly to the criteria used to validate the method [114,219].

For psychoactive drugs, chromatographic techniques (gas chromatography (GC), and high-performance liquid chromatography (HPLC), in combination with suitable detection methods, are preferred [186]. They are sufficiently precise, accurate and robust and can be adapted to the analysis of a huge number of drugs. A disadvantage is the need for sample preparation before chromatographic separation and hence a limited sample throughput. Throughput can be enhanced by automated sample preparation prior to GC or HPLC. Some laboratories have introduced HPLC with column switching which allows direct injection of plasma or serum into the HPLC system. Such procedures are available for a number of antidepressant [269,292-294,297, $298,702,710]$ and antipsychotic drugs $[368,369,571-573,709-$ 712]. Another high-throughput chromatographic method is liquid chromatography coupled with mass spectroscopy (LC-MS) especially tandem MS (LC-MS/MS). LC/MSMS methods can be applied to almost any psychotropic drug including metabolites [577]. They are most sensitive and selective and can be used without time-consuming sample preparation. Many compounds can be analysed simultaneously. An excellent example is the LC-MS/MS method described by Kirchherr and Kühn-Felten [366]. This method was validated for over 50 psychoactive drugs. Disadvantageous for LC-MS/MS methods are high costs. Moreover, quantification can be problematic due to ion suppression and the availability of suitable calibration standards, preferentially deuterated analogues [584].

In case of suspected intoxications, TDM methods should enable drug analysis within $1-2 \mathrm{~h}$ [215]. For this purpose automated methods are advantageous.

The laboratory should not only analyse the drug but also its active metabolites, e.g., bupropion plus hydroxybupropion, clomipramine plus desmethylclomipramine, fluoxetine plus norfluoxetine, naltrexone plus naltrexol, risperidone plus 9-hydroxyrisperidone or venlafaxine plus O-desmethylvenlafaxine ( $\bullet$ Table 5 ). For some drugs, the determination of metabolites that do not contribute to the overall clinical effect (e.g., norsertraline, normirtazapine, norcitalopram) is also useful to monitor drug adherence of the patient [546], to get information on his/her capacity to metabolise drugs, or to interprete drugdrug interactions when drugs are involved exhibiting enzyme inhibiting or inducing properties ( $\odot$ Table 2). "Normal" ratios of concentrations of metabolites to parent drugs that are expected in $68.3 \%$ of the patients are listed in 0 Table 3 . Any ratio outside the reported "normal" range should be considered as a signal pointing to individual abnormalities due to a drug-drug-interaction, gene polymorphism, altered liver function, non-adherence or drug intake few hours before blood withdrawal.

The assay of enantiomers of chiral compounds requires either stereoselective derivatisation of the drugs prior to their quantification, or their separation by chiral chromatographic GC or HPLC columns. LC-MS/MS may be the method of choice. As an example, the TDM of the enantiomers of methadone using a classical detection method such as fluorescence or ultraviolet light absorption is often jeopardized by comedication or by coconsumption drugs of abuse. These problems may be circumvented by use of a mass detector, preferably a tandem mass spectrometer

Within the therapeutic reference range, intraday- and interday precision should not exceed 15\% (coefficient of variation) and accuracy should not deviate more than $15 \%$ from the nominal value $[114,219]$.

To ensure quality and reliability of plasma concentrations assays, internal and external quality control procedures are mandatory. Samples must contain suitable internal standards, and each series of samples must include internal control samples. If standards are not available commercially, they should be prepared by personnel other than those performing the assays and by separate weighing of reference material. Reporting of results requires that the results of the quality controls are within the expected range. If quality controls are outside the expected range, the reason underlying the outlier needs to be clarified and documented.

The laboratory has to participate in an external quality assessment scheme, although this is not a legal requirement in all countries. For neuropsychiatric drugs, the first external quality program was introduced by Cardiff Bioanalytical Services Ltd in 1972 [720]. It has currently 450 participants from 36 countries (www.heathcontrol.com). Instand e.V. (www.instanddev.de/ ringversuche/) is another recommended provider of external control, the external quality control scheme was recently expanded to multiple psychoactive drugs samples. Moreover, reference materials are also available from forensic chemistry (http://www.pts-gtfch.de/).

\section{Communication of results}

The concentration of the psychoactive drug as well as that of active metabolites contributing to the therapeutic action should be reported with reference ranges ( $\bullet$ Table 5 ) either in mass or molar units. We recommend the use of mass units to relate concentration to dose. Laboratories vary in the presentation of their results. The clinician should take note of the units (i.e., ng $/ \mathrm{mL}$, $\mu \mathrm{g} / \mathrm{L}, \mu \mathrm{mol} / \mathrm{L}$, or $\mathrm{nmol} / \mathrm{L}$ ) in which the results of the analysis are expressed. This is especially recommended for comparisons of TDM values obtained from different laboratories or with those in the literature. To transform molar units into mass units and vice versa conversion factors are given in $\bullet$ Table 5 .

When drug concentrations are below the limit of quantification (LOQ), which refers to the lowest concentration of the standard curve that can be measured with at least $20 \%$ accuracy and precision, this limit should be indicated.

The results should be available for decision making within a clinically meaningful time. Although $24 \mathrm{~h}$ TDM service would be desirable, $48 \mathrm{~h}$ turnaround time is sufficient in most cases. In case of suspected intoxications, a few hours service is necessary [215]. To assist rapid intervention in patients at risk for toxicity or loss of tolerability, prompt information (phone call) of the 
treating physician is required when the laboratory measures drug concentrations above the "laboratory alert level" which was newly defined (see above) in the present consensus guidelines ( $\bullet$ Table 5).

\section{Interpretation of results}

We recommend that interpretation and pharmacologic advice are provided with every report. Expert interpretation of a drug concentration measurement and the adequate use of the information are essential to ensure the full clinical benefit of TDM. Reporting of results with inclusion of dose recommendations and other comments must be guided by the best available evidence. Expert knowledge may be necessary to calculate dose corrections or to analyse drug-drug interactions. It is therefore advantageous for the clinician to choose a laboratory that offers this service. Otherwise, the treating physician, a clinical pharmacologist or a trained expert of the clinic has to interpret the results. Access to specialist advice is also necessary if TDM results suggest that genotyping may be advisable [335].

Diagnosis and drug dose are important information for interpretation, since they permit a judgement on whether a result is plausible or not. Moreover, it must be controlled if blood samples were collected under recommended conditions, especially when the plasma concentration is unexpectedly high in an outpatient. When the drug was taken a few hours before blood sampling the drug concentration can be several-fold higher than the trough level.

For the interpretation of the results, it should not only be considered whether the plasma concentration of the drug is within the "therapeutic reference range" ( $\bullet$ Table 5). It must also be considered if the drug plasma concentration is consistent with the dose ( Table 4). A plasma concentration may be outside the therapeutic reference range, just because a low or high dose was taken. In addition, it is wise to take into account the level of evidence underlying the "therapeutic reference range" of the particular drug ( $\bullet$ Table 5). It should also be considered if the daily drug dose was given as a single or a multiple dose.

Often it is necessary to deal with pharmacokinetic properties such as metabolic pathways, enzymes involved and substrate and inhibitor properties of all drugs taken by the patient for interpretation of the results. Supportive information is therefore given in the present updated guidelines showing literature based substrate ( $\bullet$ Table 1 ) and inhibitor or inducer properties of drugs ( 0 Table 3 ) to deal with possible drug-drug interactions.

Any drug concentration outside its dose-related reference range ( $\triangle$ Table 5) should alert the TDM laboratory to actively look for non-average pharmacokinetic drug disposition of the patient, drug-drug-interactions, gene polymorphisms that give rise to poor or ultra rapid metabolism, altered function of the excretion organs liver and kidneys, age and/or disease-related changes in the patient's pharmacokinetics, compliance (adherence) problems, a non-steady state and even signal interference from other medications that the patient may not have declared to the prescribing physician (e.g., St. John's wort) in the laboratory analysis. It may also be informative to calculate the dose related reference range ( $\bullet$ Table 4 ) if the drug concentration lies outside the recommended therapeutic reference range ( $\bullet$ Table 5) [285].

Plasma concentrations must be interpreted with the clinical presentation in mind. Recommendations on dosage changes constitute the most frequent advice. Other information which could be of help for the physician are those related to genetic polymorphisms, risks of pharmacokinetic interactions in the case of polypragmasy, pharmacokinetic properties of the drug in patients belonging to a "special population", e.g., elderly patients, or patients with hepatic or renal insufficiency. For the treatment of pain, relatively low plasma concentrations of tricyclic antidepressants may be sufficient. They may be within the "dose related reference range" ( $\bullet$ Table 4 ) but outside the "therapeutic reference range" of $\bullet$ Table 5 which was established for the indication of depression.

A laboratory may recommend that an additional sample should be taken after a certain period, because in cases with unusually low or high plasma concentrations, repeated measurements may help to decide whether the patient's adherence is inconstant (irregular intake of the drug) or whether the patient is an abnormal metabolizer.

Since the interpretation of TDM results relies on complex quantitative relationships, training in clinical psychopharmacology and pharmacokinetics and the application of TDM is essential. Regular conferences with discussion of the interpretation of real cases are most helpful for learning. It is also recommended that junior psychiatrists interpret the results under supervision of an expert.

\section{Clinical decision making}

A TDM result is a guide to proper dosing of the individual patient. The physician has to be aware that, under optimal conditions, reporting of results with inclusion of dose recommendations and other comments by the laboratory is guided by the best available evidence [310]. The laboratory, however, has only a restricted knowledge of the clinical situation. On the other hand, most treating physicians have limited pharmacokinetic knowledge. Therefore it is essential to be aware that optimal TDM is an interdisciplinary task that requires close communication between laboratory and clinical experts.

If the plasma concentration of the drug is within the therapeutic reference range, an adaptation of the dose is, of course only recommended when clinical reasons, such as adverse effects or non-response clearly justify such a decision. Evidently, the treating physician has to decide whether the treatment strategy is to be changed or not. On the other hand, when the advice given on the TDM report is not followed, the reason for this course of action must be substantiated to allow evaluation of the treating physician's decision should the patient come to harm. Recommendations for such an evaluation in a court of law have been recently published by the TDM-AGNP group [741].

In patients with abnormally rapid elimination it may be useful to prescribe a dose above the maximal recommended dose, since such patients can exhibit drug concentrations below the reference range under standard doses. However, the medication should be changed if the patient exhibited sufficiently high drug concentrations for a sufficiently long treatment period, i.e., for at least 2 weeks, and did not improve by at least $20 \%$.

When adverse effects are associated with clinical improvement under recommended doses, measurement of the plasma concentration may clarify if side effects are related to exceedingly high drug levels in the blood. In this situation, the dose can be decreased, normally without risk of loss of action.

For the treatment with antidepressant or antipsychotic drugs, there is good evidence that clinical non-improvement at week 2 is highly predictive for later response and remission $[119,138$, $392,620,621,638]$. Especially the absence of early improvement 


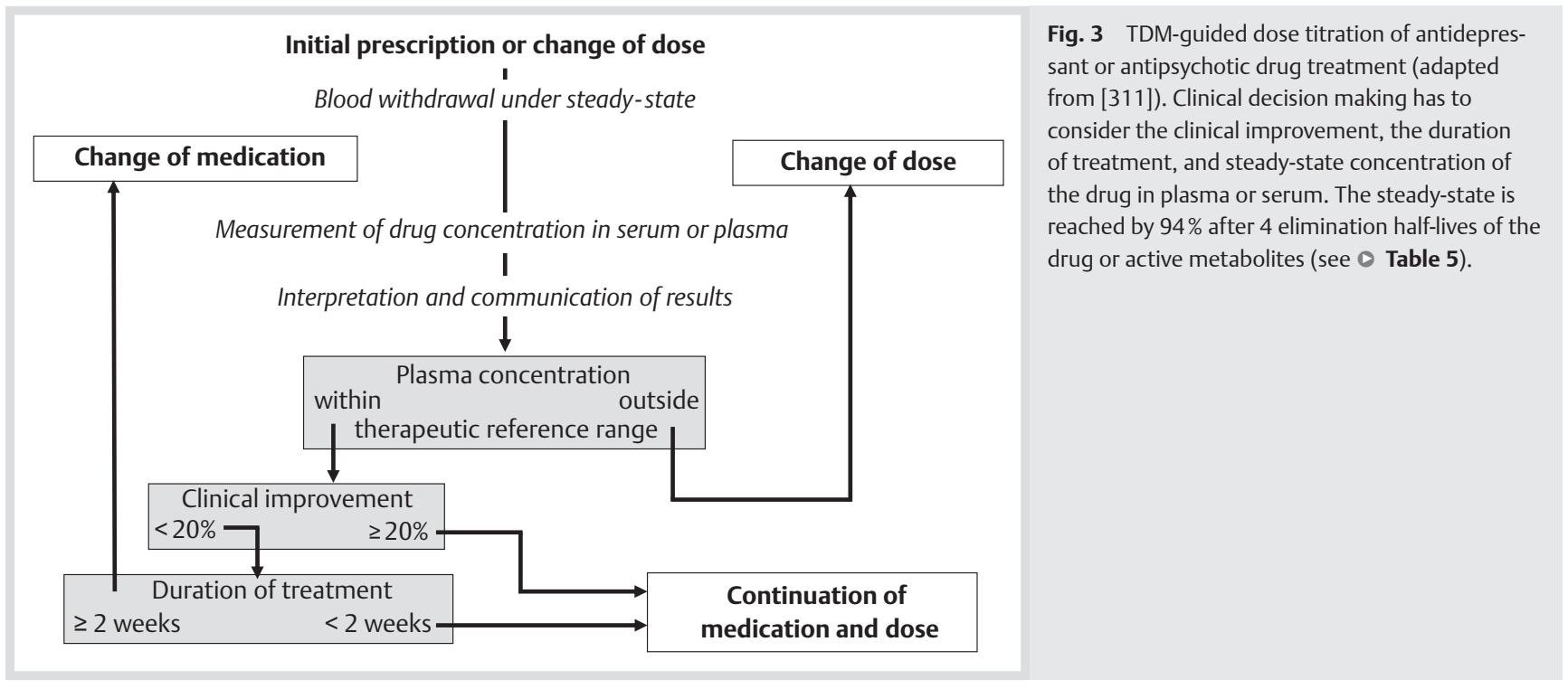

appears to be a highly reliable predictor of later non-response [358]. For dose titration with antidepressant and antipsychotic drugs we therefore recommend to include symptom rating by the treating physician [138] at baseline and at week 2 in addition to drug concentration measurements. Fig. 3 summarizes the above recommendations in a flow chart.

When further plasma concentration measurements are recommended after a modification of the dose or after prescription of a comedication that is known to inhibit or enhance the metabolism of the drug to be measured, the next TDM should be delayed until steady-state conditions are reached again. For this, the terminal elimination half-life of the drug has to be considered (๑ Table 5).

\section{Pharmacogenetic tests in addition to TDM}

Concentrations outside the reference range may be due to gene polymorphisms that give rise to slow/rapid metabolizers. As a consequence, the laboratory may also suggest that a pharmacogenetic test should be carried out $[14,144,158,193,335,362$, $365,377,623,624,675]$. Genotyping, however, is not available in all TDM laboratories, and we recommend consultation of specialized laboratories for interpretation of the results.

Situations and cases where pharmacogenetic tests could advantageously be combined with TDM are explained in more detail by Jaquenoud Sirot and coworkers [335]. Some of the most important indications for the combination of genotyping with TDM are the following:

- the patient is treated with a substrate the metabolism of which shows a wide interindividual variability;

- a drug is characterized by a small therapeutic index: risk of toxicity in the case of a genetically impaired metabolism, or on the other hand, risk of non-response due to an ultrarapid metabolism and the inability to reach therapeutic drug levels;

- the patient presents unusual plasma concentrations of the drug or its metabolite(s) and genetic factors are suspected to be responsible;

- the patient suffers from a chronic illness, which requires lifelong treatment.

In a patient who is genotyped as a PM or UM, the medication should not automatically be replaced by another as suggested by some authors, but the dose can often be adapted, using clinical judgement and TDM.

\section{Conclusions and Perspectives}

The choice of pharmacologic treatment should always take into account the clinical presentation of the patient and consider psychopathology and drug history. TDM is, if used appropriately, a valid tool for optimising pharmacotherapy. During the past decades, knowledge on the metabolic fate and actions of psychotropic drugs in the human body has markedly advanced. Pharmacogenetic and environmental factors have been identified and summarized in the first part of this review. The present updated AGNP guidelines describe the best practice of TDM in psychiatry in order to promote the appropriate use of TDM.

Although a considerable body of data for plasma concentrations of psychotropic drugs has been accumulated and although our knowledge about the quantitative relationship between plasma concentration and therapeutic response has improved, there is still a need to conduct further controlled and randomised concentration-response studies to improve the quality of data on therapeutic reference ranges. We also recommend inclusion of pharmacokinetic measurements during phase III and IV studies. Product information should be supplemented with TDM related data to enhance the therapeutic effectiveness of psychoactive drugs. Analyses of German [671] and French [568] summaries of product characteristics (SPC) revealed that many SPC do not contain TDM related information in spite of available valid clinical-scientific evidence. Another need for research is to study cost-effectiveness of TDM when the method is used in an appropriate way. Polypharmacy is very common in psychiatry while essentially all TDM recommendations are based on single-medication trials. Thus, the efficacy of drug combinations constitutes a severely under-investigated area of TDM. Finally, one should never forget that TDM is an interdisciplinary task that sometimes requires the respectful discussion of apparently discrepant data so that, ultimately, the patient can profit from such a joint effort. 


\section{Conflicts of Interest}

\section{$\nabla$}

Christoph Hiemke has received speaker's or consultancy fees from the following pharmaceutical companies: Bristol-Meyers Squibb, Pfizer, Lilly and Servier. He is managing director of the psiac GmbH which provides an internet based drug-drug interaction program for psychopharmacotherapy. He reports no conflict of interest with this publication. Pierre Baumann has received speaker's or consultancy fees from almost all pharmaceutical companies selling psychotropic drug in Switzerland. He reports no conflict of interest with this publication. Niels Bergemann, Mirjam Fric, Christine Greiner, Hartmut Kirchherr, Ulrich C Lutz, Bernhard Rambeck, Bernd Schoppek, Julia C Stingl, Manfred Uhr and Roland Waschgler have no conflict of interest to declare. Andreas Conca has served as a consultant for Lilly, BMS, Pfizer. He has served on the speakers' bureau of Lilly, BMS, Astra Zeneca, Lundbeck, Italfarma, Janssen. He reports no conflict of interest with this publication. Otto Dietmaier has received speaker's or consultancy fees from Bristol-Myers Squibb, Janssen, Eli Lilly and Lundbeck. He reports no conflict of interest with this publication. Ursula Havemann-Reinecke has received speaker's or consultancy fees or unrestricted educational grants from AstraZeneca, Bristol-Myers Squibb, Cephalon, Essex, Janssen Cilag, Lundbeck, Pfizer, Schering-Plough, Wyeth. She reports no conflict of interest with this publication. Ekkehard Haen has served as a consultant and received speaker's fees from JanssenCilag, Lilly, Pfizer, GlaxoSmithKline, AstraZeneca, Bristol-Myers Squibb, Otsuka, Bayer Vital, Servier and Südmedica GmbH. He reports no conflict of interest with this publication. Karin Egberts has received speaker's fees or travel grants from Wyeth and Medice. She participated in performing clinical trials for AstraZeneca, Janssen-Cilag, Lilly and Shire. She reports no conflict of interest with this publication. Gerhard Gründer has served as a consultant for Astra Zeneca, Bristol-Myers Squibb, Eli Lilly, Johnson \& Johnson, and Otsuka. He has served on the speakers' bureau of Astra Zeneca, Bristol-Myers Squibb, Eli Lilly, Janssen Cilag, Otsuka, Pfizer, Servier, and Wyeth. He has received grant support from Alkermes, Bristol-Myers Squibb, Eli Lilly, and Johnson \& Johnson. He is co-founder of Pharma-Image - Molecular Imaging Technologies $\mathrm{GmbH}$. He reports no conflict of interest with this publication. Eveline Jaquenoud Sirot is managing director of mediQ which sells an internet based drug-drug interaction program for psychiatry. She reports no conflict of interest with this publication. Gerd Laux has received speaker's or consultancy fees or unrestricted educational grants from AstraZeneca, Bayer, Eli Lilly, Lundbeck, Merz, Pfizer, Servier and Wyeth. He reports no conflict of interest. Bruno Pfuhlmann has received speaker's or consultancy fees from AstraZeneca, Janssen and Pfizer. He reports no conflict of interest with this publication. Manfred Gerlach has received speaker's or consultancy honoraria or restricted research grants from Boehringer Ingelheim Pharma GmbH \& Co. KG, Desitin Arzneimittel GmbH, Janssen Cilag GmbH, Lundbeck GmbH and Merz Pharmaceuticals $\mathrm{GmbH}$. He reports no conflict of interest with this paper. Thomas Messer has received speaker's or consultancy fees or unrestricted educational grants from Eli Lilly, Bristol-Myers Squibb, Janssen, Servier, Pfizer, Lundbeck and Bayer Vital Health Care. He reports no conflict of interest with this publication. Matthias J. Müller has received speaker's or consultancy fees from Janssen, Servier, Pfizer, and Astra-Zeneca. He reports no conflict of interest with this publication. Sven Ulrich is an employe of Ariston Pharma GmbH, Berlin, Germany. He reports no conflict of interest with this publication. Gerald Zernig has received speaker's or consultancy fees or unrestricted educational grants from AlcaSynn, AstraZeneca, Bio-Rad, BristolMyers Squibb, Eli Lilly, Lundbeck, Mundipharma, Novartis, Pfizer, and Wyeth. He reports no conflict of interest with this publication.

\section{Acknowledgements \\ $\nabla$}

The authors thank Sonja Brünen, Elnaz Ostad Haji, Christiane Knoth and Viktoria Stieffenhofer for helping us to calculate ratios of plasma concentrations of metabolite and parent compound reported in the literature and shown in 0 Table 2. We thank Ralf Köber for his help in evaluating the therapeutic reference ranges of antidementia drugs. We thank Michaela Jahnke, Christiane Kobelt and Nina Wenzel for most helpful editorial assistance, especially for organization of the long list of references.

\section{Affiliations}

${ }^{1}$ Department of Psychiatry and Psychotherapy, University Medical Center of Mainz, Germany

2 Department of Psychiatry, University of Lausanne, Prilly-Lausanne, Switzerland

${ }^{3}$ Psychiatric Hospital, Bad Arolsen, Germany

${ }^{4}$ Psychiatric Hospital, Bolzano, Italy

5 Psychiatrc Hospital, Weinsberg, Germany

${ }^{6}$ Department Child and Adolescent Psychiatry, University Hospital of Würzburg, Germany

Kliniken des Bezirks Oberbayern (kbo) Salzach-Inn-Klinikum, Wasserburg a. Inn, Germany

${ }^{8}$ Federal Institute for Drugs and Medical Devices (BfArM), Bonn, Germany ${ }^{9}$ Department of Psychiatry and Psychotherapy, University of Aachen, Germany

${ }^{10}$ Clinical Pharmacology, Department of Psychiatry and Psychosomatics, University of Regensburg, Germany

${ }^{11}$ Department of Psychiatry and Psychosomatics, University of Göttingen, Germany

${ }^{12}$ Psychiatric Hospital, Königsfelden, Brugg, Aargau, Switzerland

${ }^{13}$ Medical Laboratory Bremen, Germany

${ }^{14}$ Department of Psychiatry and Psychotherapy, University of Tübingen, Germany

${ }^{15}$ Psychiatric Hospital, Pfaffenhofen, Germany

${ }^{16}$ Psychiatric Hospital, Marburg and Gießen, Germany

${ }^{17}$ Department of Psychiatry, Psychotherapy and Psychosomatics, University

Hospital of Würzburg, Germany

${ }^{18}$ Center of Epilepsy, Bielefeld, Germany

${ }^{19}$ Psychiatric Hospital, Haar, Germany

${ }^{20}$ Department of Pharmacology of Natural Products and Clinical Pharmacology, University of Ulm, Germany

${ }^{21}$ Max Planck Institute of Psychiatry, Munich, Germany

${ }^{22}$ Aristo Pharma GmbH, Berlin, Germany

${ }^{23}$ Psychiatric Hospital, Feldkirch, Austria

${ }^{24}$ Experimental Psychiatry Unit, Department of Psychiatry and Psychotherapy, Medical University of Innsbruck, Austria

\section{References}

1 Abbott NJ, Patabendige AA, Dolman DE et al. Structure and function of the blood-brain barrier. Neurobiol Dis 2010; 37: 13-25

2 Abernethy DR, Greenblatt DJ, Shader RI. Imipramine and desipramine disposition in the elderly. J Pharmacol Exp Ther 1985; 232: 183-188

3 Adam K, Oswald I. Effects of lormetazepam and of flurazepam on sleep. Br J Clin Pharmacol 1984; 17: 531-538

4 Adamiak U, Kaldonska M, Klodowska-Duda G et al. Pharmacokineticpharmacodynamic modeling of levodopa in patients with advanced Parkinson disease. Clin Neuropharmacol 2010; 33: 135-141

5 Addington $D$. Best practices: improving quality of care for patients with first-episode psychosis. Psychiatr Serv 2009; 60: 1164-1166

6 Adli M, Baethge C, Heinz A et al. Is dose escalation of antidepressants a rational strategy after a medium-dose treatment has failed? Eur Arch Psychiatry Clin Neurosci 2005; 55: 387-400 
7 Aichhorn W, Marksteiner J, Walch T et al. Influence of age, gender, body weight and valproate comedication on quetiapine plasma concentrations. Int Clin Psychopharmacol 2006; 21: 81-85

8 Aichhorn W, Weiss $U$, Marksteiner J et al. Influence of age and gender on risperidone plasma concentrations. J Psychopharmacol 2005; 19 : 395-401

9 Aichhorn $W$, Whitworth $A B$, Weiss ME et al. Second-generation antipsychotics: Is there evidence for sex differences in pharmacokinetic and adverse effect profiles? Drug Saf 2006; 29: 587-598

10 Åkerblad AC, Bengtsson F, Ekselius $L$ et al. Effects of an educational compliance enhancement programme and therapeutic drug monitoring on treatment adherence in depressed patients managed by general practitioners. Int Clin Psychopharmacol 2003; 18: 347-354

11 Åkerblad AC, Bengtsson F, Holgersson $M$ et al. Identification of primary care patients at risk of nonadherence to antidepressant treatment. Patient Prefer Adherence 2008; 2: 379-386

12 Aklillu E, Kalow W, Endrenyi L et al. CYP2D6 and DRD2 genes differentially impact pharmacodynamic sensitivity and time course of prolactin response to perphenazine. Pharmacogenet Genomics 2007; 17: 989-993

13 Akutsu T, Kobayashi K, Sakurada $\mathrm{K}$ et al. Identification of human cytochrome $\mathrm{p} 450$ isozymes involved in diphenhydramine $\mathrm{N}$-demethylation. Drug Metab Dispos 2007; 35: 72-78

14 Albers LJ, Ozdemir V, Marder SR et al. Low-dose fluvoxamine as an adjunct to reduce olanzapine therapeutic dose requirements: a prospective dose-adjusted drug interaction strategy. J Clin Psychopharmacol 2005; 25: 170-174

15 Alderman J, Wolkow R, Fogel IM. Drug concentration monitoring with tolerability and efficacy assessments during open-label, long-term sertraline treatment of children and adolescents. J Child Adolesc Psychopharmacol 2006; 16: 117-129

16 Allen MH, Hirschfeld RM, Wozniak PJ et al. Linear relationship of valproate serum concentration to response and optimal serum levels for acute mania. Am J Psychiatry 2006; 163: 272-275

17 Allqvist A, Miura J, Bertilsson L et al. Inhibition of CYP3A4 and CYP3A5 catalyzed metabolism of alprazolam and quinine by ketoconazole as racemate and four different enantiomers. Eur J Clin Pharmacol 2007; 63: $173-179$

18 Altamura AC, Moro AR, Percudani M. Clinical pharmacokinetics of fluoxetine. Clin Pharmacokinet 1994; 26: 201-214

19 Althaus M, Retzow A, Castell JV et al. In vitro identification of the cytochrome $\mathrm{P} 450$ isoform responsible for the metabolism of alphadihydroergocryptine. Xenobiotica 2000; 30: 1033-1045

20 Aman MG, Vinks AA, Remmerie B et al. Plasma pharmacokinetic characteristics of risperidone and their relationship to saliva concentrations in children with psychiatric or neurodevelopment disorders. Clin Therap 2007; 29: 1476-1486

21 Anderson D, Reed S, Lintemoot J et al. A first look at duloxetine (Cymbalta ${ }^{\circledR}$ ) in a post-mortem laboratory. J Analyt Toxicology 2006; 30: 576-579

22 Anderson GD. Pregnancy-induced changes in pharmacokinetics: a mechanistic-based approach. Clin Pharmacokinet 2005; 44: 989-1008

23 Anderson IM, Ferrier IN, Baldwin RC et al. Evidence-based guidelines for treating depressive disorders with antidepressants: a revision of the 2000 British Association for Psychopharmacology guidelines. J Psychopharmacol 2008; 22: 343-396

24 Aoki FY, Sitar DS. Clinical pharmacokinetics of amantadine hydrochloride. Clin Pharmacokinet 1988; 14: 35-51

25 Aps JK, Martens LC. Review: The physiology of saliva and transfer of drugs into saliva. Forensic Sci Int 2005; 150: 119-131

26 Arakawa $\mathrm{R}$, Ito $\mathrm{H}$, Takano $A$ et al. Dose-finding study of paliperidone ER based on striatal and extrastriatal dopamine D2 receptor occupancy in patients with schizophrenia. Psychopharmacology (Berl) 2008; 197: 229-235

27 Aravagiri M, Marder SR, Yuwiler A et al. Distribution of fluphenazine and its metabolites in brain regions and other tissues of the rat. Neuropsychopharmacology 1995; 13: 235-247

28 Aravagiri M, Teper Y, Marder SR. Pharmacokinetics and tissue distribution of olanzapine in rats. Biopharm Drug Dispos 1999; 20: 369-377

29 Aravagiri M, Yuwiler A, Marder SR. Distribution after repeated oral administration of different dose levels of risperidone and 9-hydroxyrisperidone in the brain and other tissues of rat. Psychopharmacology 1998; 139: 356-363

30 Åsberg M, Cronholm B, Sjöqvist F et al. Correlation of subjective side effects with plasma concentrations of nortriptyline. Br Med J 1970; 5726: $18-21$
31 Åsberg M, Crönholm B, Sjöqvist F et al. Relationship between plasma level and therapeutic effect of nortriptyline. Br Med J 1971; 3: 331-334

32 Bachmann CJ, Haberhausen M, Heinzel-Gutenbrunner $M$ et al. Large intraindividual variability of olanzapine serum concentrations in adolescent patients. Ther Drug Monit 2008; 30: 108-112

33 Bachmann CJ, Rieger-Gies A, Heinzel-Gutenbrunner $M$ et al. Large variability of aripiprazole and dehydroaripiprazole serum concentrations in adolescent patients with schizophrenia. Ther Drug Monit 2008; 30: 462-466

34 Bachus R, Bickel U, Thomsen T et al. The O-demethylation of the antidementia drug galanthamine is catalysed by cytochrome P450 2D6. Pharmacogenetics 1999; 9: 661-668

35 Backman JT, Olkkola KT, Ojala M et al. Concentrations and effects of oral midazolam are greatly reduced in patients treated with carbamazepine or phenytoin. Epilepsia 1996; 37: 253-257

36 Bagli M, Höflich G, Rao ML et al. Bioequivalence and absolute bioavailability of oblong and coated levomepromazine tablets in CYP2D6 phenotyped subjects. Int J Clin Pharmacol Ther 1995; 33: 646-652

37 Baker GB, Urichuk LJ, McKenna KF et al. Metabolism of monoamine oxidase inhibitors. Cell Mol Neurobiol 1999; 19: 411-426

38 Bakken GV, Rudberg I, Christensen $\mathrm{H}$ et al. Metabolism of quetiapine by CYP3A4 and CYP3A5 in presence or absence of cytochrome B5. Drug Metab Dispos 2009; 37: 254-258

39 Balant LP, Balant-Gorgia AE, Eisele R et al. Clinical and pharmacokinetic evaluation of zuclopenthixol acetate in Viscoleo. Pharmacopsychiatry 1989; 22: 250-254

40 Balant-Gorgia AE, Eisele R, Aeschlimann JM et al. Plasma flupentixol concentrations and clinical response in acute schizophrenia. Ther Drug Monit 1985; 7: 411-414

41 Barbhaiya RH, Shukla UA, Pfeffer M et al. Disposition kinetics of buspirone in patients with renal or hepatic impairment after administration of single and multiple doses. Eur J Clin Pharmacol 1994; 46: 41-47

42 Bareggi SR, Bianchi L, Cavallaro $R$ et al. Citalopram concentrations and response in obsessive-compulsive disorder - Preliminary results. CNS Drugs 2004; 18: 329-335

43 Barski OA, Tipparaju SM, Bhatnagar A. The aldo-keto reductase superfamily and its role in drug metabolism and detoxification. Drug Metab Rev 2008; 40: 553-624

44 Baruzzi A, Bordo B, Bossi L et al. Plasma levels of di-no-propylacetate and clonazepam in epileptic patients. Int J Clin Pharmacol Biopharm 1977; 15: 403-408

45 Bates DW, Gawande AA. Improving safety with information technology. N Engl J Med 2003; 348: 2526-2534

46 Bauer M, Whybrow PC, Angst J et al. World Federation of Societies Biological Psychiatry Task Force on Treatment Guidelines for Unipolar Depressive Disorders. World Federation of Societies of Biological Psychiatry (WFSBP) Guidelines for Biological Treatment of Unipolar Depressive Disorders, Part 1: Acute and continuation treatment of major depressive disorder. World J Biol Psychiatry 2002; 3: 5-43

47 Bauer S, David Rudd G, Mylius V et al. Lacosamide intoxication in attempted suicide. Epilepsy Behav 2010; 17: 549-551

48 Baumann P. Pharmacokinetic-pharmacodynamic relationship of the selective serotonin reuptake inhibitors. Clin Pharmacokinet 1996; 31: 444-469

49 Baumann P, Barbe R, Vabre-Bogdalova A et al. Epileptiform seizure after sertraline treatment in an adolescent experiencing obsessivecompulsive disorder and presenting a rare pharmacogenetic status. J Clin Psychopharmacol 2006; 26: 679-681

50 Baumann $P$, Hiemke $C$, Ulrich $S$ et al. Le dosage plasmatique des médicaments psychotropes à des fins thérapeutiques: recommandations du groupe d'experts AGNP-TDM. Rev Med Suisse 2006; 2: $1413-1418$

51 Baumann P, Hiemke C, Ulrich $S$ et al. The AGNP-TDM expert group consensus guidelines: therapeutic drug monitoring in psychiatry. Pharmacopsychiatry 2004; 37: 243-265

52 Baumann P, Ulrich S, Eckermann G et al. The AGNP-TDM Expert Group Consensus Guidelines: focus on therapeutic monitoring of antidepressants. Dialogues Clin Neurosci 2005; 7: 231-247

53 Baumann P, Zullino DF, Eap CB. Enantiomers' potential in psychopharmacology - a critical analysis with special emphasis on the antidepressant escitalopram. Eur Neuropsychopharmacol 2002; 12: 433-444

54 Bazire S. Psychotropic Drug Directory 2010. Aberdeen: Healthcomm UK Ltd, 2011 
55 Beasley CM Jr, Stauffer VL, Liu-Seifert $H$ et al. All-cause treatment discontinuation in schizophrenia during treatment with olanzapine relative to other antipsychotics: an integrated analysis. J Clin Psychopharmacol 2007; 27: 252-258

56 Bech P, Gex-Fabry M, Aubry JM et al. Olanzapine plasma level in relation to antimanic effect in the acute therapy of manic states. Nord J Psychiatry 2006; 60: 181-182

57 Becquemont L, Mouajjah S, Escaffre 0 et al. Cytochrome P-450 3A4 and 2C8 are involved in zopiclone metabolism. Drug Metab Dispos 1999; 27: 1068-1073

58 Beedham C, Miceli JJ, Obach RS. Ziprasidone metabolism, aldehyde oxidase, and clinical implications. J Clin Psychopharmacol 2003; 23 : 229-232

59 Benedetti MS, Whomsley R, Poggesi I et al. Drug metabolism and pharmacokinetics. Drug Metab Rev 2009; 41: 344-390

60 Benetton SA, Fang C, Yang YO et al. P450 phenotyping of the metabolism of selegiline to desmethylselegiline and methamphetamine. Drug Metab Pharmacokinet 2007; 22: 78-87

61 Bengtsson $F$. Therapeutic drug monitoring of psychotropic drugs. TDM "nouveau". Ther Drug Monit 2004; 26: 145-151

62 Bennett JP Jr, Piercey MF. Pramipexole: a new dopamine agonist for the treatment of Parkinson's disease. J Neurol Sci 1999; 163: 25-31

63 Bergemann N, Frick A, Parzer P et al. Olanzapine plasma concentration, average daily dose, and interaction with co-medication in schizophrenic patients. Pharmacopsychiatry 2004; 37: 63-68

64 Bergemann N, Kopitz J, Kress KR et al. Plasma amisulpride levels in schizophrenia or schizoaffective disorder. Eur Neuropsychopharmacology 2004; 14: 245-250

65 Bergemann N, Rommel F, Conca A. Therapeutisches Drug-Monitoring von Psychopharmaka in der Schwangerschaft. J Neurol Neurochir Psychiatr 2009; 10: 38-40

66 Bergmann TK, Bathum L, Brøsen K. Duplication of CYP2D6 predicts high clearance of desipramine but high clearance does not predict duplication of CYP2D6. Eur J Clin Pharmacol 2001; 57: 123-127

67 Bergstrom RF, Cerimele BJ. Olanzapine in subjects with and without renal failure (data on file). Lilly Laboratory for Clinical Research. Eli Lilly and Co. 1996

68 Berry D, Millington C. Analysis of pregabalin at therapeutic concentrations in human plasma/serum by reversed-phase HPLC. Ther Drug Monit 2005; 27: 451-456

69 Bertelsen KM, Venkatakrishnan K, von Moltke LL et al. Apparent mechanism-based inhibition of human CYP2D6 in vitro by paroxetine: comparison with fluoxetine and quinidine. Drug Metab Dispos 2003; 31: 289-293

70 Berwaerts J, Cleton A, Rossenu S et al. A comparison of serum prolactin concentrations after administration of paliperidone extendedrelease and risperidone tablets in patients with schizophrenia. J Psychopharmacol 2010; 24: 1011-1018

71 Bigliani V, Mulligan RS, Acton PD et al. Striatal and temporal cortical D2/D3 receptor occupancy by olanzapine and sertindole in vivo: a [123I] epidepride single photon emission tomography (SPET) study. Psychopharmacology (Berl) 2000; 150: 132-140

72 Birkenhäger TK, van den Broek WW, Moleman P et al. Imipramine dose in relation to therapeutic plasma level: are clinical trials using imipramine as a positive control flawed? Psychopharmacology (Berl) 2005; 181: 595-599

73 Bjerkenstedt L, Flyckt L, Overø KF et al. Relationship between clinical effects, serum drug concentration and serotonin uptake inhibition in depressed patients treated with citalopram. A double-blind comparison of three dose levels. Eur J Clin Pharmacol 1985; 28: 553-557

74 Bjørndal N, Bjerre M, Gerlach J et al. High dosage haloperidol therapy in chronic schizophrenic patients: a double-blind study of clinical response, side effects, serum haloperidol, and serum prolactin. Psychopharmacology (Berl) 1980; 67: 17-23

75 Bockbrader HN. Clinical pharmacokinetics of gabapentin. Drugs Today 1995; 31: 613-619

76 Bockbrader HN, Burger P, Knapp L et al. Population pharmacokinetics of pregabalin in healthy subjects and patients with chronic pain or partial seizures. Epilepsia 2011; 52: 248-257

77 Bockbrader HN, Wesche D, Miller $R$ et al. A comparison of the pharmacokinetics and pharmacodynamics of pregabalin and gabapentin. Clin Pharmacokinet 2010; 49: 661-669

78 Bogaards JJ, Hissink EM, Briggs $M$ et al. Prediction of interindividual variation in drug plasma levels in vivo from individual enzyme kinetic data and physiologically based pharmacokinetic modeling. Eur J Pharm Sci 2000; 12: 117-124
79 Bomsien S, Aderjan R, Mattern R et al. Effect of psychotropic medication on the in vitro metabolism of buprenorphine in human cDNAexpressed cytochrome P450 enzymes. Eur J Clin Pharmacol 2006; 62: 639-643

80 Bond A, Seijas D, Dawling $S$ et al. Systemic absorption and abuse liability of snorted flunitrazepam. Addiction 1994; 89: 821-830

81 Bondolfi G, Morel F. Crettol et al. Increased clozapine plasma concentrations and side effects induced by smoking cessation in 2 CYP1A2 genotyped patients. Ther Drug Monit 2005; 27: 539-543

82 Bont $L$, Bosker HA, Brus $F$ et al. Torsade de pointes after pipamperone intoxication. Pharm World Sci 1998; 20: 137

83 Borgstrom L, Larsson H, Molander L. Pharmacokinetics of parenteral and oral melperone in man. Eur J Clin Pharmacol 1982; 23: 173-176

84 Borys DJ, Setzer SC, Ling LJ et al. Acute fluoxetine overdose: a report of 234 cases. Am J Emerg Med 1992; 10: 115-120

85 Bosse GM, Spiller HA, Collins AM. A fatal case of venlafaxine overdose. J Med Toxicol 2008; 4: 18-20

86 Brachtendorf L, Jetter A, Beckurts KT et al. Cytochrome P450 enzymes contributing to demethylation of maprotiline in man. Pharmacol Toxicol 2002; 90: 144-149

87 Brahmi N, Kouraichi $N$, Abderrazek $H$ et al. Clinical experience with carbamazepine overdose: relationship between serum concentration and neurological severity. J Clin Psychopharmacol 2008; 28: 241-243

88 Brandt C, Baumann P, Eckermann G et al. Therapeutic drug monitoring in Epileptologie und Psychiatrie (Therapeutic drug monitoring in epileptology and psychiatry). Nervenarzt 2008; 79: 167-174

89 Bressan RA, Erlandsson K, Jones HM et al. Is regionally selective D2 D3 dopamine occupancy sufficient for atypical antipsychotic effect? An in vivo quantitative [123I] epidepride SPET study of amisulpridetreated patients. Am J Psychiatry 2003; 160: 1413-1420

90 Breyer-Pfaff $U$. The metabolic fate of amitriptyline, nortriptyline and amitriptyline oxide in man. Drug Metab Rev 2004; 36: 723-746

91 Breyer-Pfaff $U$, Brinkschulte M, Rein W et al. Prediction and evaluation criteria in perazine therapy of acute schizophrenics pharmacokinetic data. Pharmacopsychiatry 1983; 16: 160-165

92 Breyer-Pfaff $U$, Nill K. Carbonyl reduction of naltrexone and dolasetron by oxidoreductases isolated from human liver cytosol. J Pharm Pharmacol 2004; 56: 1601-1606

93 Brockmöller J, Kirchheiner J, Schmider J et al. The impact of the CYP2D6 polymorphism on haloperidol pharmacokinetics and on the outcome of haloperidol treatment. Clin Pharmacol Ther 2002; 72: 438-452

94 Brøsen $K$. Drug-metabolizing enzymes and therapeutic drug monitoring in psychiatry. Ther Drug Monit 1996; 18: 393-396

95 Brøsen K, Gram LF, Klysner $R$ et al. Steady-state levels of imipramine and its metabolites: significance of dose-dependent kinetics. Eur J Clin Pharmacol 1986; 30: 43-49

96 Brøsen K, Klysner R, Gram LF et al. Steady-state concentrations of imipramine and its metabolites in relation to the sparteine/debrisoquine polymorphism. Eur J Clin Pharmacol 1986; 30: 679-684

97 Brøsen K, Naranjo CA. Review of pharmacokinetic and pharmacodynamic interaction studies with citalopram. Eur Neuropsychopharmacol 2001; 11: 275-283

98 Bruijn JA, Moleman P, Mulder PG et al. A double-blind, fixed bloodlevel study comparing mirtazapine with imipramine in depressed in-patients. Psychopharmacology (Berl) 1996; 127: 231-237

99 Brünen S, Vincent DP, Baumann P et al. Therapeutic Drug Monitoring (TDM) for drugs used in the treatment of substance related disorders. Literature review using a TDM appropriateness rating scale. Ther Drug Monit 2011 in press

100 Brunton LL, Lazo JS, Parker KL. Goodman and Gilman's The Pharmacological Basis of Therapeutics. $11^{\text {th }}$ edn. McGraw-Hill, New York 2006

101 Buchanan RW, Kreyenbuhl J, Kelly DL et al. Schizophrenia Patient Outcomes Research Team (PORT). The 2009 schizophrenia PORT psychopharmacological treatment recommendations and summary statements. Schizophr Bull 2010; 36: 71-93

102 Buckley NA, Dawson AH, Whyte IM et al. Greater toxicity in overdose of dothiepin than of other tricyclic antidepressants. Lancet 1994; 343: 159-162

103 Burke MJ, Preskorn SH. Therapeutic drug monitoring of antidepressants - cost implications and relevance to clinical practice. Clin Pharmacokinet 1999; 37: 147-165

104 Byerly MJ, Thompson A, Carmody $T$ et al. Validity of electronically monitored medication adherence and conventional adherence measures in schizophrenia. Psychiatr Serv 2007; 58: 844-847 
105 Caccia S, Garattini S. Pharmacokinetic and pharmacodynamic significance of antidepressant drug metabolites. Pharmacol Res 1992; 26: 317-329

106 Caccia S, Pasia L, Nobili L. New atypical antipsychotics for schizophrenia: iloperidone. Drug Des Devel Ther 2010; 4: 33-48

107 Callaghan JT, Bergstrom RF, Ptak LR et al. Olanzapine. Pharmacokinetic and pharmacodynamic profile. Clin Pharmacokinet 1999; 37 : 177-193

108 Canal M, Desanti CR, Santoni JP. A new oral formulation of tiapride (drops): pharmacokinetic profile and therapeutic applications. Clin Drug Investig 1998; 15: 455-460

109 Canal-Raffin M, Déridet E, Titier K et al. Simplified ultraviolet liquid chromatographic method for determination of sertindole, dehydrosertindone and norsertindole, in human plasma. J Chromatography B 2005; 814: 61-67

110 Canal-Raffin M, Titier K, Déridet E et al. Myocardium distribution of sertindole and its metabolite dehydrosertindole in guinea-pigs. Biopharm Drug Dispos 2006; 27: 171-179

111 Carlsson B, Olsson G, Reis $M$ et al. Enantioselective analysis of citalopram and metabolites in adolescents. Ther Drug Monit 2001; 23: 658-664

112 Castberg I, Skogvoll E, Spigset O. Quetiapine and drug interactions: evidence from a routine therapeutic drug monitoring service. J Clin Psychiatry 2007; 68: 1540-1545

113 Castberg I, Spigset 0 . Prescribing pattern and use of therapeutic drug monitoring of psychotropic medication in a psychiatric high-security unit. Ther Drug Monit 2008; 30: 597-603

114 Causon $R$. Validation of chromatographic methods in biomedical analysis. Viewpoint and discussion. J Chromatogr B Biomed Sci Appl 1997; 689: 175-180

115 Cawello W, Braun M, Boekens $H$. Absorption, disposition, metabolic fate, and elimination of the dopamine agonist rotigotine in man: administration by intravenous infusion or transdermal delivery. Drug Metab Dispos 2009; 37: 2055-2060

116 Centerholt $C$, Ekblom M, Odergren $T$ et al. Pharmacokinetics and sedative effects in healthy subjects and subjects with impaired liver function after continuous infusion of clomethiazole. Eur J Clin Pharmacol 2003; 59: 117-122

117 Chakraborty BS, Midha KK, McKay G et al. Single dose kinetics of thioridazine and its two psychoactive metabolites in healthy humans: a dose proportionality study. J Pharm Sci 1989; 78 : 796-801

118 Chan $V$, Morris RG, Ilett KF et al. Population pharmacokinetics of lamotrigine. Ther Drug Monit 2001; 23: 630-635

119 Chang YC, Lane HY, Yang KH et al. Optimizing early prediction for antipsychotic response in schizophrenia. J Clin Psychopharmacol 2006; 26: 554-559

120 Chawarski MC, Schottenfeld RS, O'Connor PG et al. Plasma concentrations of buprenorphine 24 to 72 hours after dosing. Drug Alcohol Depend 1999; 55: 157-163

121 Chen H, Grover S, Yu L et al. Bioactivation of lamotrigine in vivo in rat and in vitro in human liver microsomes, hepatocytes, and epidermal keratinocytes: characterization of thioether conjugates by liquid chromatography/mass spectrometry and high field nuclear magnetic resonance spectroscopy. Chem Res Toxicol 2010; 23: 159-170

122 Chen P, Tanasijevic MJ, Schoenenberger RA et al. A computer-based intervention for improving the appropriateness of antiepileptic drug level monitoring. Am J Clin Pathol 2003; 119: 432-438

123 Cheng YF, Paalzow LK, Bondesson $U$ et al. Pharmacokinetics of haloperidol in psychotic patients. Psychopharmacology (Berl) 1987; 91: 410-414

124 Chenu F, Batten LA, Zernig $G$ et al. Comparison of pharmacokinetic profiles of brand-name and generic formulations of citalopram and venlafaxine: a crossover study. J Clin Psychiatry 2009; 70: 958-966

125 Chermá MD, Löfgren UB, Almkvist G et al. Assessment of the prescription of antidepressant drugs in elderly nursing home patients. J Clin Psychopharmacol 2008; 28: 424-431

126 Chermá MD, Reis $M$, Hägg $S$ et al. Therapeutic drug monitoring of ziprasidone in a clinical treatment setting. Ther Drug Monit 2008; 30: 682-688

127 Chetty M, Gouws E, Miller R et al. The use of a side effect as a qualitative indicator of plasma chlorpromazine levels. Eur Neuropsychopharmacol 1999; 9: 77-82

128 Choc MG, Hsuan F, Honigfeld G et al. Single- vs. multiple-dose pharmacokinetics of clozapine in psychiatric patients. Pharm Res 1990; 7: 347-351
129 Choong E, Dobrinas M, Carrupt PA et al. The permeability P-glycoprotein: a focus on enantioselectivity and brain distribution. Expert Opin Drug Metab Toxicol 2010; 6: 953-965

130 Ciraulo DA, Hitzemann RJ, Somoza E et al. Pharmacokinetics and pharmacodynamics of multiple sublingual buprenorphine tablets in dose-escalation trials. J Clin Pharmacol 2006; 46: 179-192

131 Citrome L. Paliperidone palmitate - review of the efficacy, safety and cost of a new second-generation depot antipsychotic medication. Int J Clin Pract 2010; 64: 216-239

132 Citrome L, Stauffer VL, Chen L et al. Olanzapine plasma concentrations after treatment with 10,20 , and $40 \mathrm{mg} / \mathrm{d}$ in patients with schizophrenia. J Clin Psychopharmacol 2009; 29: 278-283

133 Collins N, Barnes TR, Shingleton-Smith A et al. Standards of lithium monitoring in mental health trusts in the UK. BMC Psychiatry 2010; 10: 80

134 Conca A, Schmidt E, Pastore $M$ et al. Therapeutic drug monitoring in Italian psychiatry. Pharmacopsychiatry 2011; 44: 259-262

135 Contin M, Riva R, Martinelli $P$ et al. Effect of meal timing on the kinetic-dynamic profile of levodopa/carbidopa controlled is release in parkinsonian patients. Eur J Clin Pharmacol 1998; 54: 303-308

136 Cooper TB. Plasma level monitoring of antipsychotic drugs. Clin Pharmacokinet 1978; 3: 14-38

137 Coppen A, Kopera $H$. Workshop on the clinical pharmacology and efficacy of mianserin. Br J Clin Pharmacol 1978; 5: 91S-99S

138 Correll CU, Malhotra AK, Kaushik S et al. Early prediction of antipsychotic response in schizophrenia. Am J Psychiatry 2003; 160: 2063-2065

139 Couchman L, Morgan PE, Spencer EP et al. Plasma clozapine and norclozapine in patients prescribed different brands of clozapine (Clozaril, Denzapine, and Zaponex). Ther Drug Monit 2010; 32: 624-627

140 Couchman L, Morgan PE, Spencer EP et al. Plasma clozapine, norclozapine, and the clozapine: norclozapine ratio in relation to prescribed dose and other factors: data from a therapeutic drug monitoring service, 1993-2007. Ther Drug Monit 2010; 32: 438-447

141 Coulomb F, Ducret F, Laneury JP et al. Pharmacokinetics of single-dose reboxetine in volunteers with renal insufficiency. J Clin Pharmacol 2000; 40: 482-487

142 Cournoyer G, De Montigny C, Ouellette J et al. A comparative doubleblind controlled study of trimipramine and amitriptyline in major depression: lack of correlation with 5-hydroxytryptamine reuptake blockade. J Clin Psychopharmacol 1987; 7: 385-393

143 Court $M H$. Interindividual variability in hepatic drug glucuronidation: studies into the role of age, sex, enzyme inducers, and genetic polymorphism using the human liver bank as a model system. Drug Metab Rev 2010; 42: 202-217

144 Crettol S, Besson J, Croquette-Krokar M et al. Association of dopamine and opioid receptor genetic polymorphisms with response to methadone maintenance treatment. Prog Neuropsychopharmacol Biol Psychiatry 2008; 32: 1722-1727

145 Crettol S, Déglon JJ, Besson J et al. ABCB1 and cytochrome P450 genotypes and phenotypes: influence on methadone plasma levels and response to treatment. Clin Pharmacol Ther 2006; 80: 668-681

146 Crettol S, Déglon JJ, Besson J et al. Methadone enantiomer plasma levels, CYP2B6, CYP2C19, and CYP2C9 genotypes, and response to treatment. Clin Pharmacol Ther 2005; 78: 593-604

147 Cummings J, Lefèvre G, Small G et al. Pharmacokinetic rationale for the rivastigmine patch. Neurology 2007; 69 (Suppl 1): S10-S13

$148 \mathrm{Dahl} \mathrm{SG}$. Active metabolites of neuroleptic drugs: possible contribution to therapeutic and toxic effects. Ther Drug Monit 1982; 4: 33-40

149 Dahl SG, Strandjord RE, Sigfusson S. Pharmacokinetics and relative bioavailability of levomepromazine after repeated administration of tablets and syrup. Eur J Clin Pharmacol 1977; 11: 305-310

150 Darby JK, Pasta DJ, Wilson MG et al. Long-term therapeutic drug monitoring of risperidone and olanzapine identifies altered steadystate pharmacokinetics: a clinical, two-group, naturalistic study. Clin Drug Investig 2008; 28: 553-564

151 Daviss WB, Perel JM, Birmaher B et al. Steady-state clinical pharmacokinetics of bupropion extended-release in youths. J Am Acad Child Adolesc Psychiatry 2006; 45: 1503-1509

152 Daviss WB, Perel JM, Brent DA et al. Acute antidepressant response and plasma levels of bupropion and metabolites in a pediatric-aged sample: an exploratory study. Ther Drug Monit 2006; 28: 190-198

153 Dawling $S$. Monitoring of tricyclic antidepressant therapy. Clin Biochem 1982; 15: 56-61

154 de Lange EC. Potential role of $\mathrm{ABC}$ transporters as a detoxification system at the blood-CSF barrier. Adv Drug Deliv Rev 2004; 56: 1793-1809 
155 de Leon J. Glucuronidation enzymes, genes and psychiatry. Int J Neuropsychopharmacol 2003; 6: 57-72

156 de Leon J. Incorporating pharmacogenetics into clinical practice: reality of a new tool in psychiatry. Current issues in clinical implementation. CNS Spectr 2006; 11 (Suppl 3): 8-12

157 de Leon J. The crucial role of the therapeutic window in understanding the clinical relevance of the poor versus the ultrarapid metabolizer phenotypes in subjects talking drugs metabolized by CYP2D6 or CYP2C19. J Clin Psychopharmacol 2007; 27: 241-245

158 de Leon J, Greenlee B, Barber J et al. Practical guidelines for the use of new generation antipsychotic drugs (except clozapine) in adult individuals with intellectual disabilities. Res Dev Disabil 2009; 30: 613-669

159 de Leon J, Susce MT, Pan RM et al. A study of genetic (CYP2D6 and $A B C B 1$ ) and environmental (drug inhibitors and inducers) variables that may influence plasma risperidone levels. Pharmacopsychiatry 2007; 40: 93-102

160 de Leon J, Susce MT, Pan RM et al. The CYP2D6 poor metabolizer phenotype may be associated with risperidone adverse drug reactions and discontinuation. J Clin Psychiatry 2005; 66: 15-27

161 de Leon J, Wynn G, Sandson NB. The pharmacokinetics of paliperidone versus risperidone. Psychosomatics 2010; 51: 80-88

162 de Mey C, Althaus M, Ezan E et al. Erythromycin increases plasma concentrations of alpha-dihydroergocryptine in humans. Clin Pharmacol Ther 2001; 70: 142-148

163 de Vries MH, Raghoebar M, Mathlener IS et al. Single and multiple oral dose fluvoxamine kinetics in young and elderly subjects. Ther Drug Monit 1992; 14: 493-498

164 de Wit M, Best AM, Epstein SK et al. Lorazepam concentrations, pharmacokinetics and pharmacodynamics in a cohort of mechanically ventilated ICU patients. Int J Clin Pharmacol Ther 2006; 44: 466-473

165 Degen J, Wölke E, Seiberling $M$ et al. Comparative study of the pharmacokinetics of amitriptyline oxide and trimipramine after single administration in healthy male probands and patients with renal failure. Med Klin (Munich) 1993; 88: 129-133

166 Degner D, Grohmann R, Kropp S et al. Severe adverse drug reactions of antidepressants: results of the German multicenter drug surveillance program AMSP. Pharmacopsychiatry 2004; 37 (Suppl 1): S39-S45

167 Del Dotto P, Bonuccelli U. Clinical pharmacokinetics of cabergoline. Clin Pharmacokinet 2003; 42: 633-645

168 Deleu D, Northway MG, Hanssens Y. Clinical pharmacokinetic and pharmacodynamic properties of drugs used in the treatment of Parkinson's disease. Clin Pharmacokinet 2002; 41: 261-309

169 Deligiannidis KM. Therapeutic drug monitoring in pregnant and postpartum women: recommendations for SSRIs, lamotrigine, and lithium. J Clin Psychiatry 2010; 71: 649-650

170 Delva NJ, Hawken ER. Preventing lithium intoxication. Guide for physicians. Can Fam Physician 2001; 47: 1595-1600

171 Desta Z, Kerbusch T, Soukhova N et al. Identification and characterization of human cytochrome $\mathrm{P} 450$ isoforms interacting with pimozide. J Pharmacol Exp Ther 1998; 285: 428-437

172 Deuschle M, Härtter S, Hiemke C et al. Doxepin and its metabolites in plasma and cerebrospinal fluid in depressed patients. Psychopharmacology (Berl) 1997; 131: 19-22

173 DeVane CL, Boulton DW, Miller LF et al. Pharmacokinetics of trazodone and its major metabolite $\mathrm{m}$-chlorophenylpiperazine in plasma and brain of rats. Int J Neuropsychopharmacol 1999; 2: 17-23

174 DeVane CL, Stowe ZN, Donovan JL et al. Therapeutic drug monitoring of psychoactive drugs during pregnancy in the genomic era: challenges and opportunities. J Psychopharmacol 2006; 20 (Suppl): 54-59

175 Diaz FJ, de Leon J, Josiassen RC et al. Plasma clozapine concentration coefficients of variation in a long-term study. Schizophr Res 2005; 72: 131-135

176 Diaz FJ, Santoro V, Spina E et al. Estimating the size of the effects of co-medications on plasma clozapine concentrations using a model that controls for clozapine doses and confounding variables. Pharmacopsychiatry 2008; 41: 81-91

177 Dingemanse J, Jorga K, Zürcher $G$ et al. Multiple-dose clinical pharmacology of the catechol-0-methyl-transferase inhibitor tolcapone in elderly subjects. Eur J Clin Pharmacol 1996; 50: 47-55

178 Dockens RC, Salazar DE, Fulmor IE et al. Pharmacokinetics of a newly identified active metabolite of buspirone after administration of buspirone over its therapeutic dose range. J Clin Pharmacol 2006; 46: $1308-1312$
179 Doose DR, Walker SA, Gisclon LG et al. Single-dose pharmacokinetics and effect of food on the bioavailability of topiramate, a novel antiepileptic drug. J Clin Pharmacol 1996; 36: 884-891

180 Doran A, Obach RS, Smith BJ et al. The impact of P-glycoprotein on the disposition of drugs targeted for indications of the central nervous system: evaluation using the MDR1A/1B knockout mouse model. Drug Metab Dispos 2005; 33: 165-174

181 dos Santos FM, Gonçalves JC, Caminha R et al. Pharmacokinetic/pharmacodynamic modeling of psychomotor impairment induced by oral clonazepam in healthy volunteers. Ther Drug Monit 2009; 31: 566-574

182 Dunbar JL, Turncliff RZ, Hayes SC et al. Population pharmacokinetics of extended-release injectable naltrexone (XR-NTX) in patients with alcohol dependence. J Stud Alcohol Drugs 2007; 68: 862-870

183 Dutheil F, Jacob A, Dauchy S et al. ABC transporters and cytochromes P450 in the human central nervous system: influence on brain pharmacokinetics and contribution to neurodegenerative disorders. Expert Opin Drug Metab Toxicol 2010; 6: 1161-1174

184 Dvorchik BH, Vesell ES. Pharmacokinetic interpretation of data gathered during therapeutic drug monitoring. Clin Chem 1976; 22: 868-878

185 Eagles JM, McCann I, MacLeod TN et al. Lithium monitoring before and after the distribution of clinical practice guidelines. Acta Psychiatr Scand 2000; 101: 349-353

186 Eap CB, Baumann P. Analytical methods for the quantitative determination of selective serotonin reuptake inhibitors for therapeutic drug monitoring purposes in patients. J Chromatogr B Biomed Appl 1996; 686: 51-63

187 Eap CB, Bender S, Gastpar $M$ et al. Steady state plasma levels of the enantiomers of trimipramine and of its metabolites in CYP2D6-, CYP2C19- and CYP3A4/5-phenotyped patients. Ther Drug Monit 2000; 22: 209-214

188 Eap CB, Bertschy G, Baumann P et al. High interindividual variability of methadone enantiomer blood levels to dose ratios. Arch Gen Psychiatry 1998; 55: 89-90

189 Eap CB, Buclin T, Baumann P. Interindividual variability of the clinical pharmacokinetics of methadone: implications for the treatment of opioid dependence. Clin Pharmacokinet 2002; 41: 1153-1193

190 Eap CB, Finkbeiner T, Gastpar M et al. Replacement of R-methadone by a double dose of $(R, S)$-methadone in addicts: interindividual variability of the $\mathrm{R} / \mathrm{S}$ ratios and evidence of adaptive changes in methadone pharmacokinetics. Eur J Clin Pharmacol 1996; 50: 385-389

191 Eap CB, Koeb L, Baumann P. Determination of trimipramine and its demethylated and hydroxylated metabolites in plasma by gas chromatography-mass spectrometry. J Chromatogr 1994; 652: 97-103

192 Eap CB, Lima CA, Macciardi F et al. Steady state concentrations of the enantiomers of mianserin and desmethylmianserin in poor and in homozygous and heterozygous extensive metabolizers of debrisoquine. Ther Drug Monit 1998; 20: 7-13

193 Eichelbaum M, Ingelman-Sundberg M, Evans WE. Pharmacogenomics and individualized drug therapy. Annu Rev Med 2006; 57: 119-137

194 Egberts K, Mehler-Wex C, Gerlach M. 2011; Therapeutic drug monitoring in child and adolescent psychiatry. Pharmacopsychiatry 2011; 44: 249-253

195 Eggert Hansen C, Rosted Christensen T, Elley J et al. Clinical pharmacokinetic studies of perphenazine. Br J Clin Pharmacol 1976; 3 : 915-923

196 Ellinwood EHJR, Heatherly DG, Nikaido AM et al. Comparative pharmacokinetics and pharmacodynamics of lorazepam, alprazolam and diazepam. Psychopharmacology 1985; 86: 392-399

197 Ereshefsky L, Jann MW, Saklad SR et al. Effects of smoking on fluphenazine clearance in psychiatric inpatients. Biol Psychiatry 1985; 20: $329-332$

198 Evans LE, Bett JH, Cox JR et al. The bioavailability of oral and parenteral chlorimipramine (Anafranil). Prog Neuropsychopharmacol 1980; 4: 293-302

199 Evans WE, Relling MV. Pharmacogenomics: translating functional genomics into rational therapeutics. Science 1999; 286: 487-491

200 Faber MS, Fuhr U. Time response of cytochrome P450 1A2 activity on cessation of heavy smoking. Clin Pharmacol Ther 2004; 76: $178-184$

201 Faber MS, Jetter A, Fuhr U. Assessment of CYP1A2 activity in clinical practice: why, how, and when? Basic Clin Pharmacol Toxicol 2005; 97: $125-134$

202 Faessel HM, Gibbs MA, Clarc DJ et al. Multiple-does pharmacokinetics of the selective nicotinic receptor partial agonist, varenicline, in healthy smokers. J Clin Pharmacol 2006; 46: 1439-1448 
203 Faiman MD, Jensen JC, Lacoursiere RB. Elimination kinetics of disulfiram in alcoholics after single and repeated doses. Clin Pharmacol Ther 1984; 36: 520-526

204 Falkai P, Wobrock T, Lieberman J et al. World Federation of Societies of Biological Psychiatry (WFSBP) guidelines for biological treatment of schizophrenia, Part 1: acute treatment of schizophrenia. World J Biol Psychiatry 2005; 6: 132-191

205 Falkai P, Wobrock T, Lieberman J et al. World Federation of Societies of Biological Psychiatry (WFSBP) guidelines for biological treatment of schizophrenia, part 2: long-term treatment of schizophrenia. World J Biol Psychiatry 2006; 7: 5-40

206 Fanton L, Bévalot F, Grait H et al. Fatal intoxication with milnacipran. J Forensic Leg Med 2008; 15: 388-390

207 Farde L, Nordström AL, Wiesel FA et al. Positron emission tomographic analysis of central D1 and D2 dopamine receptor occupancy in patients treated with classical neuroleptics and clozapine. Arch Gen Psychiatry 1992; 49: 538-544

208 Feng Y, Pollock BG, Coley K et al. Population pharmacokinetic analysis for risperidone using highly sparse sampling measurements from the CATIE study. J Clin Pharmacol 2008; 66: 629-639

209 Feng Y, Pollock BG, Ferrell RE et al. Paroxetine: population pharmacokinetic analysis in late-life depression using sparse concentration sampling. Br J Clin Pharmacol 2006; 61: 558-569

210 Fenner KS, Troutman MD, Kempshall S et al. Drug-drug interactions mediated through P-glycoprotein: clinical relevance and in vitro-in vivo correlation using digoxin as a probe drug. Clin Pharmacol Ther 2009; 85: 173-181

211 Ferrari A, Bertolotti $M$, Dell Utri A et al. Serum time course of naltrexone and 6ß-naltrexol levels during long term treatment in drug addicts. Drug Alcohol Depend 1998; 52: 211-220

212 Figueroa C, Brecher M, Hamer-Maansson JE et al. Pharmacokinetic profiles of extended release quetiapine fumarate compared with quetiapine immediate release. Prog Neuropsychopharmacol Biol Psychiatry 2009; 33: 199-204

213 Findling $R L$, Reed $M D$, Myers $C$ et al. Paroxetine pharmacokinetics in depressed children and adolescents. J Am Acad Child Adolesc Psychiatry 1999; 38: 952-959

214 Fitzgerald PB, Kapur S, Remington G et al. Predicting haloperidol occupancy of central dopamine D2 receptors from plasma levels. Psychopharmacology (Berl) 2000; 149: 1-5

215 Flanagan RJ. Developing an analytical toxicology service: principles and guidance. Toxicol Rev 2004; 23: 251-263

216 Fleming J, Chetty $M$. Therapeutic monitoring of valproate in psychiatry: how far have we progressed? Clin Neuropharmacol 2006; 29: $350-360$

217 Fogelman SM, Schmider J, Venkatakrishnan K et al. O- and N-demethylation of venlafaxine in vitro by human liver microsomes and by microsomes from cDNA-transfected cells: effect of metabolic inhibitors and SSRI antidepressants. Neuropsychopharmacology 1999; 20: $480-490$

218 Fontaine $R$, Mercier $P$, Beaudry $P$ et al. Bromazepam and lorazepam in generalized anxiety: a placebo-controlled study with measurement of drug plasma concentrations. Acta Psychiatr Scand 1986; 74: 451-458

219 Food and Drug Administration. Guidance for industry: bioanalytical method validation. 2001; http://www.fda.gov/cvm

220 Foti RS, Rock DA, Wienkers LC et al. Selection of alternative CYP3A4 probe substrates for clinical drug interaction studies using in vitro data and in vivo simulation. Drug Metab Dispos 2010; 38: 981-987

221 Fountoulakis KN. An update of evidence-based treatment of bipolar depression: where do we stand? Curr Opin Psychiatry 2010; 23: 19-24

222 Fric M, Pfuhlmann B, Laux $G$ et al. The influence of smoking on the serum level of duloxetine. Pharmacopsychiatry 2008; 41: 151-155

223 Frieboes RM, Sonntag A, Yassouridis A et al. Clinical outcome after trimipramine in patients with delusional depression - a pilot study. Pharmacopsychiatry 2003; 36: 12-17

224 Friedman H, Greenblatt DJ, Peters GR et al. Pharmacokinetics and pharmacodynamics of oral diazepam: effect of dose, plasma concentration, and time. Clin Pharmacol Ther 1992; 52: 139-150

225 Fritze J, Laux G, Sofic E et al. Plasma moclobemide and metabolites: lack of correlation with clinical response and biogenic amines. Psychopharmacology (Berl) 1989; 99: 252-256

226 Fröscher W, Schier KR, Hoffmann $M$ et al. Topiramate: a prospective study on the relationship between concentration, dosage and adverse events in epileptic patients on combination therapy. Epileptic Disord 2005; 7: 237-248
227 Fudio S, Borobia AM, Piñana E et al. Evaluation of the influence of sex and CYP2C19 and CYP2D6 polymorphisms in the disposition of citalopram. Eur J Pharmacol 2010; 626: 200-204

228 Fukasawa T, Suzuki A, Otani K. Effects of genetic polymorphism of cytochrome P450 enzymes on the pharmacokinetics of benzodiazepines. J Clin Pharm Ther 2007; 32: 333-341

229 Furlanut M, Montanari G, Benetello P et al. Steady-state serum concentrations of imipramine, its main metabolites and clinical response in primary enuresis. Pharmacol Res 1989; 21: 561-566

230 Furukori $H$, Kondo $T$, Yasui $N$ et al. Effects of itraconazole on the steady-state plasma concentrations of bromperidol and reduced bromperidol in schizophrenic patients. Psychopharmacology (Berl) 1999; 145: 189-192

231 Gaertner HJ, Golfinopoulos G, Breyer-Pfaff U. Response to Maprotiline treatment in depressive patients, relationship to urinary MHPG excretion, and plasma drug level. Pharmacopsychiatria 1982; 15: $170-174$

232 Gaertner I, Gaertner HJ, Vonthein $R$ et al. Therapeutic drug monitoring of clozapine in relapse prevention: a five-year prospective study J Clin Psychopharmacol 2001; 21: 305-310

233 Garnock-Jones KP, Keating GM. Atomoxetine: a review of its use in attention-deficit hyperactivity disorder in children and adolescents. Paediatr Drugs 2009; 11: 203-226

234 Gelenberg AJ. A review of the current guidelines for depression treatment. J Clin Psychiatry 2010; 71: e15

235 Genton P, Guerrini R, Perucca E. Tiagabine in clinical practice. Epilepsia 2001; 42 (Suppl 3): 42-45

236 Gerlach $M$, Hünnerkopf $R$, Rothenhöfer S et al. Therapeutic drug monitoring of quetiapine in adolescents with psychotic disorders. Pharmacopsychiatry 2007; 40: 72-76

237 Gerstenberg G, Aoshima T, Fukasawa $T$ et al. Relationship between clinical effects of fluvoxamine and the steady-state plasma concentrations of fluvoxamine and its major metabolite fluvoxamino acid in Japanese depressed patients. Psychopharmacology (Berl) 2003; 167: 443-448

238 Gervasini G, Carrillo JA, Benitez J. Potential role of cerebral cytochrome P450 in clinical pharmacokinetics: modulation by endogenous compounds. Clin Pharmacokinet 2004; 43: 693-706

239 Gex-Fabry M, Balant-Gorgia AE, Balant LP. Clomipramine concentration as a predictor of delayed response: a naturalistic study. Eur J Clin Pharmacol 1999; 54: 895-902

240 Gex-Fabry M, Balant-Gorgia AE, Balant LP. Therapeutic drug monitoring of olanzapine: the combined effect of age, gender, smoking, and comedication. Ther Drug Monit 2003; 25: 46-53

241 Gex-Fabry M, Balant-Gorgia AE, Balant LP et al. Time course of clinical response to venlafaxine: relevance of plasma level and chirality. Eur J Clin Pharmacol 2004; 59: 883-891

242 Gex-Fabry M, Gervasoni N, Eap CB et al. Time course of response to paroxetine: influence of plasma level. Prog Neuropsychopharmacol Biol Psychiatry 2007; 31: 892-900

243 Gilles M, Deuschle M, Kellner S et al. Paroxetine serum concentrations in depressed patients and response to treatment. Pharmacopsychiatry 2005 ; $38: 118-121$

244 Gillman PK. Tricyclic antidepressant pharmacology and therapeutic drug interactions updated. Br J Pharmacol 2007; 151: 737-748

245 Glassman AH, Perel JM, Shostak $M$ et al. Clinical implications of imipramine plasma levels for depressive illness. Arch Gen Psychiatry 1977; 34: 197-204

246 Glassmann AH, Schildkraut IJ, Orsulak PJ et al. Tricyclic antidepressants, blood level measurements and clinical outcome: an APA task force report. Am J Psychiat 1985; 142: 155-162

247 Glauser TA, Pippenger CE. Controversies in blood-level monitoring: reexamining its role in the treatment of epilepsy. Epilepsia 2000; 41 (Suppl 8): S6-S15

248 Gleason MM, Egger HL, Emslie GJ et al. Psychopharmacological treatment for very young children: contexts and guidelines. J Am Acad Child Adolesc Psychiatry 2007; 46: 1532-1572

249 Glotzbach RK, Preskorn SH. Brain concentrations of tricyclic antidepressants: Single-dose kinetics and relationship to plasma concentrations in chronically dosed rats. Psychopharmacology 1982; 78: 25-27

250 Goeringer KE, Raymon L, Christian GD et al. Postmortem forensic toxicology of selective serotonin reuptake inhibitors: a review of pharmacology and report of 168 cases. J Forensic Sci 2000; 45: 633-648

251 Gomolin IH, Smith C, Jeitner TM. Once-daily memantine: pharmacokinetic and clinical considerations. J Am Geriatr Soc 2010; 58: $1812-1813$ 
252 Gonzalez JP, Brogden RN. Naltrexone. A review of its pharmacodynamic and pharmacokinetic properties and therapeutic efficacy in the management of opioid dependence. Drugs 1988; 35: 192-213

253 Goodnick PJ, Dominguez RA, DeVane CL et al. Bupropion slow-release response in depression: diagnosis and biochemistry. Biol Psychiatry 1998; 44: 629-632

254 Goodwin GM. Consensus Group of the British Association for Psychopharmacology. Evidence-based guidelines for treating bipolar disorder: revised second edition-recommendations from the British Association for Psychopharmacology. J Psychopharmacol 2009; 23: 346-388

255 Gram LF, Guentert TW, Grange S et al. Moclobemide, a substrate of CYP2C19 and an inhibitor of CYP2C19, CYP2D6, and CYP1A2: a panel study. Clin Pharmacol Ther 1995; 57: 670-677

256 Grandjean EM, Aubry JM. Lithium: updated human knowledge using an evidence-based approach. Part II: Clinical pharmacology and therapeutic monitoring. CNS Drugs 2009; 23: 331-349

257 Grasmäder K, Verwohlt PL, Kühn KU et al. Relationship between mirtazapine dose, plasma concentration, response, and side effects in clinical practice. Pharmacopsychiatry 2005; 38: 113-117

258 Grasmäder K, Verwohlt PL, Rietschel M et al. Impact of polymorphisms of cytochrome-P450 isoenzymes 2C9, 2C19 and 2D6 on plasma concentrations and clinical effects of antidepressants in a naturalistic clinical setting. Eur J Clin Pharmacol 2004; 60: 329-336

259 Greenblatt DJ, Blaskovich PD, Nuwayser ES et al. Clonazepam pharmacokinetics: comparison of subcutaneous microsphere injection with multiple-dose oral administration. J Clin Pharmacol 2005; 45: 1288-1293

260 Greenblatt DJ, Divoll M, Harmatz JS et al. Oxazepam kinetics: effects of age and sex. J Pharmacol Exp Ther 1980; 215: 86-91

261 Greenblatt DJ, Ehrenberg BL, Gunderman J et al. Pharmacokinetic and electroencephalographic study of intravenous diazepam, midazolam, and placebo. Clin Pharmacol Ther 1989; 45: 356-365

262 Greenblatt DJ, Friedman H, Burstein ES et al. Trazodone kinetics: effect of age, gender, and obesity. Clin Pharmacol Ther 1987; 42: 193-200

263 Greenblatt DJ, Gan L, Harmatz JS et al. Pharmocokinetics and pharmacodynamics of single-dose triazolam: electroencephalography compared with the Digit-Symbol Substitution Test. Br J Clin Pharmacol 2005; 60: 244-248

264 Greenblatt DJ, Harmatz JS, Friedman $H$ et al. A large-sample study of diazepam pharmacokinetics. Ther Drug Monit 1989; 11: 652-657

265 Greenblatt DJ, Harmatz JS, von Moltke LL et al. Comparative kinetics and dynamics of zaleplon, zolpidem, and placebo. Clin Pharmacol Ther 1998; 64: 553-561

266 Greenblatt DJ, Shader RI, Franke K et al. Pharmacokinetics and bioavailability of intravenous, intramuscular, and oral lorazepam in humans. J Pharm Sci 1979; 68: 57-63

267 Greenblatt DJ, von Moltke LL, Ehrenberg BL et al. Kinetics and dynamics of lorazepam during and after continuous intravenous infusion. Crit Care Med 2000; 28: 2750-2757

268 Greenblatt DJ, von Moltke LL, Harmatz JS et al. Short-term exposure to low-dose ritonavir impairs clearance and enhances adverse effects of trazodone. J Clin Pharmacol 2003; 43: 414-422

269 Greiner C, Hiemke C, Bader W et al. Determination of citalopram and escitalopram together with their active main metabolites desmethyl(es-)citalopram in human serum by column-switching high performance liquid chromatography (HPLC) and spectrophotometric detection. J Chromatogr B Analyt Technol Biomed Life Sci 2007; 848: 391-394

270 Grimaldi R, Perucca E, Ruberto G et al. Pharmacokinetic and pharmacodynamic studies following the intravenous and oral administration of the antiparkinsonian drug biperiden to normal subjects. Eur J Clin Pharmacol 1986; 29: 735-737

271 Grohmann R, Engel RR, Rüther E et al. The AMSP drug safety program: methods and global results. Pharmacopsychiatry 2004; 37 (Suppl 1): S4-S11

272 Gründer G, Carlsson A, Wong DF. Mechanism of new antipsychotic medications. Occupancy is not just antagonism. Arch Gen Psychiatry 2003; 60: 974-977

273 Gründer G, Fellows C, Janouschek $H$ et al. Brain and plasma pharmacokinetics of aripiprazole in patients with schizophrenia: an [18F] fallypride PET study. Am J Psychiatry 2008; 165: 988-995

274 Gründer G, Hiemke C, Paulzen M et al. Therpaeutic drug concentrations of antidepressants and antipsychotics: Guidance from PET imaging. Pharmacopsychiatry 2011; 44: 236-248

275 Gründer G, Hippius H, Carlsson A. The 'atypicality' of antipsychotics: a concept re-examined and re-defined. Nat Rev Drug Discov 2009; 8: $197-202$
276 Grunze H, Vieta E, Goodwin GM. The World Federation of Societies of Biological Psychiatry (WFSBP) guidelines for the biological treatment of bipolar disorders: update 2009 on the treatment of acute mania. World J Biol Psychiatry 2009; 10: 85-116

277 Guay DR. Rasagiline (TVP-1012): a new selective monoamine oxidase inhibitor for Parkinson's disease. Am J Geriatr Pharmacother 2006; 4: 330-346

278 Guberman A, Couture M, Blaschuk K et al. Add-on trial of clobazam in intractable adult epilepsy with plasma level correlations. Can J Neurol Sci 1990; 17: 311-316

279 Gunes A, Spina E, Dahl ML et al. ABCB1 polymorphisms influence steady-state plasma levels of 9-hydroxyrisperidone and risperidone active moiety. Ther Drug Monit 2008; 30: 628-633

280 Gupta N. Guidelines for lithium monitoring: are they ideal? Acta Psychiatr Scand 2001; 104: 76-77

281 Gupta RN, Dziurdzy SA. Therapeutic monitoring of sertraline. Clin Chem 1994; 40: 498-499

282 Gupta SK, Shah JC, Hwang SS. Pharmacokinetic and pharmacodynamic characterization of OROS and immediate-release amitriptyline. Br J Clin Pharmacol 1999; 48: 71-78

283 Guy W. editor. ECDEU Assessment Manual for Psychopharmacology. Rockville, MD. U.S Department of Health, Education, and Welfare, 1976

284 Haberstroh J, Hampel H, Pantel J. Optimal management of Alzheimer's disease patients: Clinical guidelines and family advice. Neuropsychiatr Dis Treat 2010; 6: 243-253

285 Haen E, Greiner C, Bader W et al. Wirkstoffkonzentrationsbestimmungen zur Therapieleitung. Ergänzung therapeutischer Referenzbereiche durch dosisbezogene Referenzbereiche. Nervenarzt 2008; 79: 558-566

286 Hallett C, Dean BC. Bromazepam: acute benefit-risk assessment in general practice. Curr Med Res Opin 1984; 8: 683-688

287 Hammarberg A, Beck O, Eksborg S et al. Acamprosate determinations in plasma and cerebrospinal fluid after multiple dosing measured by liquid chromatography-mass spectroscopy: a pharmacokinetic study in healthy volunteers. Ther Drug Monit 2010; 32: 489-496

288 Hammarberg A, Jayaram-Lindström N, Berck $O$ et al. The effects of acomprosate on alcohol-cue reactivity and alcohol priming in dependent patients: a randomized controlled trial. Psychopharmacol 2009; 205: 53-62

289 Hanley JA, McNeil BJ. The meaning and use of the area under a receiver operating characteristic (ROC) curve. Radiology 1982; 143: 29-36

290 Harden $C L$, Trifiletti $R$, Kutt $H$. Felbamate levels in patients with epilepsy. Epilepsia 1996; 37: 280-283

291 Härtter S, Dingemanse J, Baier D et al. The role of cytochrome P450 2D6 in the metabolism of moclobemide. Eur Neuropsychopharmacol 1996; 6: 225-230

292 Härtter S, Hermes B, Hiemke C. Automated determination of trimipramine and $\mathrm{N}$-desmethyl-trimipramine in human plasma or serum by HPLC with on-line solid phase extraction. J Liq Chromatogr 1995; 18: 3495-3505

293 Härtter S, Hermes B, Szegedi A et al. Automated determination of paroxetine and its main metabolite by column switching and on-line high-performance liquid chromatography. Ther Drug Monit 1994; 16: 400-406

294 Härtter S, Hiemke C. Column switching and high-performance liquid chromatography in the analysis of amitriptyline, nortriptyline and hydroxylated metabolites in human plasma or serum. J Chromatogr 1992; 578: 273-282

295 Härtter S, Tybring G, Friedberg $T$ et al. The N-demethylation of the doxepin isomers is mainly catalyzed by the polymorphic CYP2C19. Pharm Res 2002; 19: 1034-1037

296 Härtter S, Wang X, Weigmann $H$ et al. Differential effects of fluvoxamine and other antidepressants on the biotransformation of melatonin. J Clin Psychopharmacol 2001; 21: 167-174

297 Härtter S, Weigmann H, Hiemke C. Automated determination of reboxetine by high-performance liquid chromatography with column-switching and ultraviolet detection. J Chromatogr B Biomed Sci Appl 2000; 740: 135-140

298 Härtter S, Wetzel H, Hiemke C. Automated determination of fluvoxamine in plasma by column-switching high-performance liquid chromatography. Clin Chem 1992; 38: 2082-2086

299 Hasselstrøm J, Linnet K. Quetiapine serum concentrations in psychiatric patients: the influence of comedication. Ther Drug Monit 2004; 26: $486-491$ 
300 Hässler F, Reis $O$. Pharmacotherapy of disruptive behavior in mentally retarded subjects: A review of the current literature. Dev Disabil Res Rev 2010; 16: 265-272

301 Haymond J, Ensom MH. Does valproic acid warrant therapeutic drug monitoring in bipolar affective disorder? Ther Drug Monit 2010; 32: $19-29$

302 Hazell P, Becker K, Nikkanen EA et al. Relationship between atomoxetine plasma concentration, treatment response and tolerability in attention-deficit/hyperactivity disorder and comorbid oppositional defiant disorder. Atten Defic Hyperact Disord 2009; 1: 201-210

303 Hegerl U, Bottlender R, Gallinat J et al. The serotonin syndrome scale: first results on validity. Eur Arch Psychiatry Clin Neuroci 1998; 248: 96-103

304 Heikkinen H, Saraheimo M, Antila S et al. Pharmacokinetics of entacapone, a peripherally acting catechol-O-methyltransferase inhibitor, in man. A study using a stable isotope technique. Eur J Clin Pharmacol 2001; 56: 821-826

305 Heller S, Hiemke C, Stroba G et al. Assessment of storage and transport stability of new antidepressant and antipsychotic drugs for a nationwide TDM service. Ther Drug Monit 2004; 26: 459-461

306 Hendset M, Hermann M, Lunde H et al. Impact of the CYP2D6 genotype on steady-state serum concentrations of aripiprazole and dehydroaripiprazole. Eur J Clin Pharmacol 2007; 63: 1147-1151

307 Herman BD, Fleishaker JC, Brown MT. Ketoconazole inhibits the clearance of the enantiomers of the antidepressant reboxetine in humans. Clin Pharmacol Ther 1999; 66: 374-379

308 Hermida J, Paz E, Tutor JC. Clozapine and norclozapine concentrations in serum and plasma samples from schizophrenic patients. Ther Drug Monit 2008; 30: 41-45

309 Hesse LM, He P, Krishnaswamy S et al. Pharmacogenetic determinants of interindividual variability in bupropion hydroxylation by cytochrome P450 2B6 in human liver microsomes. Pharmacogenetics 2004; 14 : 225-238

310 Hiemke C. Clinical utility of drug measurement and pharmacokinetics - therapeutic drug monitoring in psychiatry. Eur J Clin Pharmacol 2008; 64: 159-166

311 Hiemke C. Therapeutic drug monitoring in neuropharmacology: does it hold its promises? Eur Arch Psychiatry Clin Neurosci 2008; 258 (Suppl 1): 21-27

312 Hiemke C, Baumann P, Laux G et al. Therapeutisches Drug-Monitoring in der Psychiatrie. Konsensus-Leitlinie der AGNP. Psychopharmakotherapie 2005; 12: 166-182

313 Hiemke C, Dragicevic A, Gründer G et al. Therapeutic monitoring of new antipsychotic drugs. Ther Drug Monit 2004; 26: 156-160

314 Hiemke C, Härtter S. Pharmacokinetics of selective serotonin reuptake inhibitors. Pharmacol Ther 2000; 85: 11-28

315 Higuchi H, Yoshida K, Takahashi $H$ et al. Milnacipran plasma levels and antidepressant response in Japanese major depressive patients. Hum Psychopharmacol 2003; 18: 255-259

316 Höjer J, Hulting J, Salmonson H. Fatal cardiotoxicity induced by venlafaxine overdosage. Clin Toxicol (Phila) 2008; 46: 336-337

317 Holbrook JM, Parks-Veal P, Mimbs J. Clinical monitoring guidelines for neuroleptic and antidepressant drugs. Central State Hospital, Milledgeville, Georgia. Hosp Pharm 1991; 26: 783-784, 787-793

318 Holzer L, Preuss U, Baumgartner L et al. Quetiapine in adolescents with non-affective psychotic disorders: An open-label trial. Pharmacopsychiatry 2011; 44: 87-95

319 Hooper WD, Dickinson RG, Dunstan PR et al. Oxcarbazepine: preliminary clinical and pharmacokinetic studies on a new anticonvulsant. Clin Exp Neurol 1987; 24: 105-112

320 Horadam VW, Sharp JG, Smilack JD et al. Pharmacokinetics of amantadine hydrochloride in subjects with normal and impaired renal function. Ann Intern Med 1981; 94: 454-458

321 Hrdina PD, Lapierre YD. Plasma levels of maprotiline and zimelidine and their relationship to clinical response in depressed patients. Ther Drug Monit 1986; 8: 400-406

322 Hsieh YH, Yang YH, Yeh HH et al. Simultaneous determination of galantamine, rivastigmine and NAP 226-90 in plasma by MEKC and its application in Alzheimer's disease. Electrophoresis 2009; 30 : 644-653

323 Hughes J, Gill AM, Mulhearn H et al. Steady-state plasma concentrations of midazolam in critically ill infants and children. Ann Pharmacother 1996; 30: 27-30

324 Hui WK, Mitchell LB, Kavanagh KM et al. Melperone: electrophysiologic and antiarrhythmic activity in humans. J Cardiovasc Pharmacol 1990; 15: 144-149
325 Ilett KF, Blythe TH, Hackett LP et al. Plasma concentrations of dothiepin and its metabolites are not correlated with clinical efficacy in major depressive illness. Ther Drug Monit 1993; 15: 351-357

326 Isacsson $G$, Holmgren P, Druid $H$ et al. The utilization of antidepressants - a key issue in the prevention of suicide: an analysis of 5281 suicides in Sweden during the period 1992-1994. Acta Psychiatr Scand 1997; 96: 94-100

327 Isbister GK, Hackett LP, Dawson AH et al. Moclobemide poisoning: toxicokinetics and occurrence of serotonin toxicity. Br J Clin Pharmacol 2003; 56: 441-450

328 Ishida M, Otani K, Kaneko $S$ et al. Effects of various factors on steady state plasma concentrations of trazodone and its active metabolite m-chlorophenylpiperazine. Int Clin Psychopharmacol 1995; 10: $143-146$

329 Iwersen S, Schmoldt A. One fatal and one nonfatal intoxication with tranylcypromine. Absence of amphetamines as metabolites. J Anal Toxicol 1996; 20: 301-304

330 Jaanson $P$, Marandi $T$, Kiivet RA et al. Maintenance therapy with zuclopenthixol decanoate: associations between plasma concentrations, neurological side effects and CYP2D6 genotype. Psychopharmacology (Berl) 2002; 162: 67-73

331 Janis GC, Markowitz JS. Influence of ethanol and gender on methylphenidate pharmacokinetics and pharmacodynamics. Clin Pharmacol Ther 2007; 81: 346-353

332 Jann MW, Grimsley SR, Gray EC et al. Pharmacokinetics and pharmacodynamics of clozapine. Clin Pharmacokinet 1993; 24: 161-176

333 Jann MW, Shirley KL, Small GW. Clinical pharmacokinetics and pharmacodynamics of cholinesterase inhibitors. Clin Pharmacokinet 2002; 41: 719-739

334 Jaquenoud Sirot E, Knezevic B, Morena GP et al. ABCB1 and cytochrome P450 polymorphisms: clinical pharmacogenetics of clozapine. J Clin Psychopharmacol 2009; 29: 319-326

335 Jaquenoud Sirot E, van der Velden JW, Rentsch $K$ et al. Therapeutic drug monitoring and pharmacogenetic rests as tools in pharmacovigilance. Drug Safety 2006; 29: 735-768

336 Jefferson JW, Pradko JF, Muir KT. Bupropion for major depressive disorder: pharmacokinetic and formulation considerations. Clin Therap 2005; 27: 1685-1695

337 Jerling M, Dahl ML, Aberg-Wistedt A et al. The CYP2D6 genotype predicts the oral clearance of the neuroleptic agents perphenazine and zuclopenthixol. Clin Pharmacol Ther 1996; 59: 423-428

338 Ji P, Damle B, Xie J et al. Pharmacokinetic interaction between efavirenz and carbamazepine after multiple-dose administration in healthy subjects. J Clin Pharmacol 2008; 48: 948-956

339 Jimmink A, Caminada K, Hunfeld NG et al. Clinical toxicology of citalopram after acute intoxication with the sole drug or in combination with other drugs: overview of 26 cases. Ther Drug Monit 2008; 30 : 365-371

340 Jin $Y$, Pollock BG, Frank $E$ et al. The effect of reporting methods for dosing times on the estimation of pharmacokinetic parameters of escitalopram. J Clin Pharmacol 2009; 49: 176-184

341 Jochemsen $R$, Wesselman JG, Hermans J et al. Pharmacokinetics of brotizolam in healthy subjects following intravenous and oral administration. Br J Clin Pharmacol 1983; 16 (Suppl 2): 285S-290S

342 Johannessen SI, Battino D, Berry DJ et al. Therapeutic drug monitoring of the newer antiepileptic drugs. Ther Drug Monitor 2003; 25: 347-363

343 Johannessen SI, Tomson T. Pharmacokinetic variability of newer antiepileptic drugs: when is monitoring needed? Clin Pharmacokinet 2006; 45: 1061-1075

344 Johansson B. A review of the pharmacokinetics and pharmacodynamics of disulfiram and its metabolites. Acta Psychiatr Scand Suppl 1992; 369: 15-26

345 Johnston JA, Fiedler-Kelly J, Glover ED et al. Relationship between drug exposure and the efficacy and safety of bupropion sustained release for smoking cessation. Nicotine Tob Res 2001; 3: 131-140

346 Jorga KM, Fotteler B, Heizmann P et al. Pharmacokinetics and pharmacodynamics after oral and intravenous administration of tolcapone, a novel adjunct to Parkinson's disease therapy. Eur J Clin Pharmacol 1998; 54: 443-447

347 Jorga KM, Larsen JP, Beiske A et al. The effect of tolcapone on the pharmacokinetics of benserazide. Eur J Neurol 1999; 6: 211-219

348 Jørgensen A. Pharmacokinetic studies in volunteers of intravenous and oral cis(Z)-flupentixol and intramuscular cis (Z)-flupentixol decanoate in Viscoleo. Eur J Clin Pharmacol 1980; 18: 355-360

349 Jornil J, Jensen KG, Larsen $F$ et al. Identification of cytochrome P450 isoforms involved in the metabolism of paroxetine and estimation of their importance for human paroxetine metabolism using a population-based simulator. Drug Metab Dispos 2010; 38: 376-385 
350 Kandasamy M, Srinivas $P$, Subramaniam K et al. Differential outcomes from metabolic ratios in the identification of CYP2D6 phenotypes focus on venlafaxine and O-desmethylvenlafaxine. Eur J Clin Pharmacol 2010; 66: 879-887

351 Kane JM, Leucht S, Carpenter D et al. The expert consensus guideline series. Optimizing pharmacologic treatment of psychotic disorders. Introduction: methods, commentary, and summary. J Clin Psychiatry 2003; 12 (Suppl): 5-19

352 Kaplan SA, Jack ML, Weinfeld RE et al. Biopharmaceutical and clinical pharmacokinetic profile of bromazepam. J Pharmacokinet Biopharm 1976; 4: 1-16

353 Kasper S, Dötsch M, Kick H et al. Plasma concentrations of fluvoxamine and maprotiline in major depression: implications on therapeutic efficacy and side effects. Eur Neuropsychopharmacol 1993; 3: 13-21

354 Katoh Y, Uchida S, Kawai $M$ et al. Effects of cigarette smoking and cytochrome P450 2D6 genotype on fluvoxamine concentration in plasma of Japanese patients. Biol Pharm Bull 2010; 33: 285-288

355 Katon W, Cantrell CR, Sokol MS et al. Impact of antidepressant drug adherence on comorbid medication use and resource utilization. Arch Intern Med 2005; 165: 2497-2503

356 Kaufman E, Lamster IB. The diagnostic applications of saliva - a review. Crit Rev Oral Biol Med 2002; 13: 197-212

357 Kaye CM, Nicholls B. Clinical pharmacokinetics of ropinirole. Clin Pharmacokinet 2000; 39: 243-254

358 Kemp DE, Ganocy SJ, Brecher $M$ et al. Clinical value of early partial symptomatic improvement in the prediction of response and remission during short-term treatment trials in 3369 subjects with bipolar I or II depression. J Affect Disord 2011; 130: 171-179

359 Kennedy MC. Post mortem drug concentrations. Intern Med J 2010; 40: 183-187

360 Kerr BM, Thummel KE, Wurden CJ et al. Human liver carbamazepine metabolism. Role of CYP3A4 and CYP2C8 in 10,11-epoxide formation. Biochem Pharmacol 1994; 47: 1969-1979

361 Kinirons MT, O'Mahony MS. Drug metabolism and ageing. Br J Clin Pharmacol 2004; 57: 540-544

362 Kirchheiner J. CYP2D6 phenotype prediction from genotype: which system is the best? Clin Pharmacol Ther 2008; 83: 225-227

363 Kirchheiner J, Meineke I, Müller G et al. Contributions of CYP2D6, CYP2C9 and CYP2C19 to the biotransformation of E- and Z-doxepin in healthy volunteers. Pharmacogenetics 2002; 12: 571-580

364 Kirchheiner J, Müller G, Meineke I et al. Effects of polymorphisms in CYP2D6, CYP2C9, and CYP2C19 on trimipramine pharmacokinetics. J Clin Psychopharmacol 2003; 23: 459-466

365 Kirchheiner J, Nickchen K, Bauer $M$ et al. Pharmacogenetics of antidepressants and antipsychotics: the contribution of allelic variations to the phenotype of drug response. Mol Psychiatry 2004; 9: 442-473

366 Kirchherr H, Kühn-Velten WN. Quantitative determination of fortyeight antidepressants and antipsychotics in human serum by HPLC tandem mass spectrometry: a multi-level, single-sample approach. J Chromatogr B 2006; 843: 100-113

367 Kirkton C, McIntyre IM. Therapeutic and toxic concentrations of mirtazapine. J Anal Toxicol 2006; 30: 687-691

368 Kirschbaum KM, Müller MJ, Malevani J et al. Serum levels of aripiprazole and dehydroaripiprazole, clinical response and side effects. World J Biol Psychiatry 2008; 9: 212-218

369 Kirschbaum KM, Müller MJ, Zernig G et al. Therapeutic monitoring of aripiprazole by HPLC with column-switching and spectrophotometric detection. Clin Chem 2005; 51 : 1718-1721

370 Kirschbaum KM, Uhr M, Holthoewer D et al. Pharmacokinetics of acute and sub-chronic aripiprazole in P-glycoprotein deficient mice. Neuropharmacology 2010; 59: 474-479

371 Kjolbye $M$, Thomsen K, Rogne $T$ et al. Search for a therapeutic range for serum zuclopenthixol concentrations in schizophrenic patients. Ther Drug Monit 1994; 16: 541-547

372 Klamerus KJ, Maloney K, Rudolph RL et al. Introduction of a composite parameter to the pharmacokinetics of venlafaxine and its active O-desmethyl metabolite. J Clin Pharmacol 1992; 32: 716-724

373 Klampfl K, Taurines $R$, Preuss A et al. Serum concentrations, therapeutic response and side effects in children and adolescents with impulsive-aggressive symptoms during risperidone therapy. Pharmacopsychiatry 2010; 43: 58-65

374 Klotz U. Pharmacokinetics and drug metabolism in the elderly. Drug Metab Rev 2009; 41: 67-76

375 Koеpp MJ, Patsalos PN, Sander JW. Sulthiame in adults with refractory epilepsy and learning disability: an open trial. Epilepsy Res 2002; 50: 277-282
376 Kondo T, Otani K, Ishida M et al. Adverse effects of zotepine and their relationship to serum concentrations of the drug and prolactin. Ther Drug Monit 1994; 16: 120-124

377 Koostra-Ros JE, Van Weelden MJ, Hinrichs JW et al. Therapeutic drug monitoring of antidepressants and cytochrome P450 genotyping in general practice. J Clin Pharmacol 2006; 46: 1320-1327

378 Kornhuber J, Quack G, Danysz W et al. Therapeutic brain concentration of the NMDA receptor antagonist amantadine. Neuropharmacology 1995; 34: 713-721

379 Koyama E, Chiba K, Tani M et al. Identification of human cytochrome P450 isoforms involved in the stereoselective metabolism of mianserin enantiomers. J Pharmacol Exp Ther 1996; 278: 21-30

380 Kozer E, Parvez S, Minassian BA et al. How high can we go with phenytoin? Ther Drug Monit 2002; 24: 386-389

381 Krska J, Corner DA. Serum drug level monitoring in affective disorders. J Clin Pharm Ther 1992; 17: 357-363

382 Kugelberg FC, Druid H, Carlsson B et al. Postmortem redistribution of the enantiomers of citalopram and its metabolites: an experimental study in rats. J Analyt Toxicol 2004; 28: 631-637

383 Kuhlman JJJR, Levine B, Johnson RE et al. Relationship of plasma buprenorphine and norbuprenorphine to withdrawal symptoms during dose induction, maintenance and withdrawal from sublingual buprenorphine. Addiction 1998; 93: 549-559

384 Kuss HJ, Feistenauer E. Quantitative high-performance liquid chromatographic assay for the determination of maprotiline and oxaprotiline in human plasma. J Chromatogr 1981; 204: 349-353

385 Kvist EE, Al-Shurbaji A, Dahl ML et al. Quantitative pharmacogenetics of nortriptyline: a novel approach. Clin Pharmacokinet 2001; 40: 869-877

386 Lappenberg-Pelzer $M$. Identification and determination of opipramol metabolites in plasma and urine. J Anal Toxicol 1998; 22: 215-219

387 Lautala P, Ethell BT, Taskinen J et al. The specificity of glucuronidation of entacapone and tolcapone by recombinant human UDP-glucuronosyltransferases. Drug Metab Dispos 2000; 28: 1385-1389

388 Le Bloch Y, Woggon B, Weissenrieder H et al. Routine therapeutic drug monitoring in patients treated with $10-360 \mathrm{mg} /$ day citalopram. Ther Drug Monit 2003; 25: 600-608

389 Lee CA, Cook JA, Reyner EL et al. P-glycoprotein related drug interactions: clinical importance and a consideration of disease states. Expert Opin Drug Metab Toxicol 2010; 6: 603-619

390 Lee SY, Kim YG, Kim HG et al. Pharmacokineitc parameters of bromperidol in Korean subjects. Hum Psychopharmacol 2006; 21 : 409-412

391 Lefèvre $G$, Büche $M$, Sedek $G$ et al. Similar rivastigmine pharmacokinetics and pharmacodynamics in Japanese and white healthy participants following the application of novel rivastigmine patch. J Clin Pharmacol 2009; 49: 430-443

392 Leucht S, Busch R, Kissling W et al. Early prediction of antipsychotic nonresponse among patients with schizophrenia. J Clin Psychiatry 2007; 68: 352-360

393 Leucht S, Steimer W, Kreuz S et al. Doxepin plasma concentrations: is there really a therapeutic range? J Clin Psychopharmacol 2001; 21: 432-439

394 LeWitt PA, Jennings D, Kelly EL et al. Pharmacokinetic-pharmacodynamic crossover comparison of two levodopa extension strategies. Mov Disord 2009; 24: 1319-1324

395 Licht RW, Vestergaard P, Kessing LV et al. Psychopharmacological treatment with lithium and antiepileptic drugs: suggested guidelines from the Danish Psychiatric Association and the Child and Adolescent Psychiatric Association in Denmark. Acta Psychiatr Scand Suppl 2003; 419: 1-22

396 Lieberman JA, Stroup TS, McEvoy JP et al. Effectiveness of Antipsychotic Drugs in Patients with Chronic Schizophrenia. N Engl J Med 2005; 353: 1209-1223

397 Lind $A B$, Reis $M$, Bengtsson $F$ et al. Steady-state concentrations of mirtazapine, N-desmethylmirtazapine, 8-hydroxymirtazapine and their enantiomers in relation to cytochrome P450 2D6 genotype, age and smoking behaviour. Clin Pharmacokinet 2009; 48: 63-70

398 Lindberger M, Luhr O, Johannessen SI et al. Serum concentrations and effects of gabapentin and vigabatrin: observations from a dose titration study. Ther Drug Monit 2003; 25: 457-462

399 Lindenmayer J. Long-acting injectable antipsychotics: focus on Olanzapine pamoate. Neuropsychiatr Dis Treat 2010; 6: 261-267

400 Linder MW, Keck PEJR. Standards of laboratory practice: antidepressant drug monitoring. National Academy of Clinical Biochemistry. Clin Chem 1998; 44: 1073-1084

401 Lingam R, Scott J. Treatment non-adherence in affective disorders. Acta Psychiatr Scand 2002; 105: 164-172 
402 Lingjaerde O, Ahlfors UG, Bech P et al. The UKU side effect rating scale. A new comprehensive rating scale for psychotropic drugs and a cross-sectional study of side effects in neuroleptic-treated patients. Acta Psychiatr Scand Suppl 1987; 334: 1-100

403 Liu Y, Jiao J, Zhang C et al. A simplified method to determine five cytochrome p450 probe drugs by HPLC in a single run. Biol Pharm Bull 2009; 32: 717-720

404 Liu ZQ, Shu Y, Huang SL et al. Effects of CYP2C19 genotype and CYP2C9 on fluoxetine N-demethylation in human liver microsomes. Acta Pharmacol Sin 2001; 22: 85-90

405 Lobo ED, Bergstrom RF, Reddy $S$ et al. In vitro and in vivo evaluations of cytochrome P450 1A2 interactions with duloxetine. Clin Pharmacokinet 2008; 47: 191-202

406 Locatelli I, Kstelic M. Kores-Plesnicar et al. A population pharmacokinetic evalutation of the influence of CYP2D6 genotype on risperidone metabolism in patients with acute episode schizophrenia. Eur J Pharm Sci 2010; 41: 289-298

407 Lotrich FE, Pollock BG. Aging and clinical pharmacology: implications for antidepressants. J Clin Pharmacol 2005; 45: 1106-1122

408 Lucek R, Dixon R. Chlordiazepoxide concentrations in saliva and plasma measured by radioimmunoassay. Res Commun Chem Pathol Pharmacol 1980; 27: 397-400

409 Lundberg J, Christophersen JS, Petereson KB et al. Int J Neuropsychopharmacol 2007; 10: 777-785

410 Lundmark J, Bengtsson F, Nordin C et al. Therapeutic drug monitoring of selective serotonin reuptake inhibitors influences clinical dosing strategies and reduces drug costs in depressed elderly patients. Acta Psychiatr Scand 2000; 101: 354-359

411 Luurila H, Olkkola KT. Pharmacokinetic-pharmacodynamic modelling of zopiclione effects on human central nervous system. Pharmacol Toxicol 1996; 78: 348-353

412 Madan A, Parkinson A, Faiman MD. Identification of the human P-450 enzymes responsible for the sulfoxidation and thionooxidation of diethyldithiocarbamate methyl ester: role of P-450 enzymes in disulfiram bioactivation. Alcohol Clin Exp Res 1998; 22: $1212-1219$

413 Madsen H, Nielsen KK, Brøsen K. Imipramine metabolism in relation to the sparteine and mephenytoin oxidation polymorphisms - a population study. Br J Clin Pharmacol 1995; 39: 433-439

414 Maguire KP, Burrows GD, Norman TR et al. Metabolism and pharmacokinetics of dothiepin. Br J Clin Pharmacol 1981; 12: 405-409

415 Maguire KP, Norman TR, Burrows GD et al. An evaluation of maprotiline intravenous kinetics and comparison of two oral doses. Eur J Clin Pharmacol 1980; 18: 249-254

416 Mahmood I, Sahajwalla C. Clinical pharmacokinetics and pharmacodynamics of buspirone, an anxiolytic drug. Clin Pharmacokinet 1999; 36: 277-287

417 Mallikaarjun S, Salazar DE, Bramer SL. Pharmacokinetics, tolerability, and safety of aripiprazole following multiple oral dosing in normal healthy volunteers. J Clin Pharmacol 2004; 44: 179-187

418 Mamo D, Kapur S, Keshavan M et al. D2 receptor occupancy of olanzapine pamoate depot using positron emission tomography: an open-label study in patients with schizophrenia. Neuropsychopharmacology 2008; 33: 298-304

419 Mamo D, Kapur S, Shammi CM et al. A PET study of dopamine D2 and serotonin 5-HT2 receptor occupancy in patients with schizophrenia treated with therapeutic doses of ziprasidone. Am J Psychiatry 2004; 161: 818-825

420 Mann K, Hiemke C, Lotz J et al. Appropriateness of plasma level determinations for lithium and valproate in routine care of psychiatric inpatients with affective disorders. J Clin Psychopharmacol 2006; 26: 671-673

421 Mann K, Hiemke C, Schmidt LG et al. Appropriateness of therapeutic drug monitoring for antidepressants in routine psychiatric inpatient care. Ther Drug Monit 2006; 28: 83-88

422 Markowitz J, Patrick K. Differential pharmacokinetics and pharmacodynamics of methylphenidate enantiomers: does chirality matter? J Clin Psychopharmacol 2008; 28 (Suppl 2): S54-S61

423 Martines C, Gatti G, Sasso E et al. The disposition of primidone in elderly patients. Br J Clin Pharmacol 1990; 30: 607-611

424 Mason BJ, Goodman AM, Dixon RM et al. A pharmacokinetic and pharmacodynamic drug interaction study of acamprosate and naltrexone. Neuropsychopharmacology 2002; 27: 596-606

425 Mattila MA, Larni HM. Flunitrazepam: a review of its pharmacological properties and therapeutic use. Drugs 1980; 20: 353-374
426 Mauri MC, Laini V, Boscati $L$ et al. Long-term treatment of chronic schizophrenia with risperidone: a study with plasma levels. Eur Psychiatry 2001; 16: 57-63

427 Mauri MC, Volonteri LS, Colasanti A et al. Clinical pharmacokinetics of atypical antipsychotics. A critical review of the relationship between plasma concentrations and clinical response. Clin Pharmacokinet 2007; 46: 359-388

428 May TW, Korn-Merker E, Rambeck B.. Clinical pharmacokinetics of oxcarbazepine. Clin Pharmacokinet 2003; 42: 1023-1042

429 May TW, Korn-Merker E, Rambeck B et al. Pharmacokinetics of sulthiame in epileptic patients. Ther Drug Monit 1994; 16: 251-257

430 May TW, Rambeck B, Jürgens $U$. Serum concentrations of levetiracetam in epileptic patients: the influence of dose and co-medication. Ther Drug Monit 2003; 25: 690-699

431 May TW, Rambeck B, Jürgens $U$. Serum concentrations of topiramate in patients with epilepsy: influence of dose, age, and comedication. Ther Drug Monit 2002; 24: 366-374

432 May TW, Rambeck B, Neb R et al. Serum concentrations of pregabalin in patients with epilepsy: the influence of dose, age, and comedication. Ther Drug Monit 2007; 29: 789-794

433 Mayo BC, Biggs SR, Chasseaud LF et al. The metabolic fate of Sormodren (bornaprine hydrochloride) in animals and humans. Xenobiotica 1980 ; 10: 873-888

434 McAlpine DE, Biernacka JM, Mrazek DA et al. Effect of cytochrome P450 enzyme polymorphisms on pharmacokinetics of venlafaxine. Ther Drug Monit 2011; 33: 14-20

435 McConville BJ, Arvanitis LA, Thyrum PT et al. Pharmacokinetics, tolerability, and clinical effectiveness of quetiapine fumarate: an openlabel trial in adolescents with psychotic disorders. J Clin Psychiatry 2000; 61: 252-260

436 McKenzie ME, Roswell-Harris D. A controlled trial of prothipendyl (tolnate) in mentally subnormal patients. Br J Psychiatry 1966; 112: 95-100

437 Medori R, Mannaert E, Gründer G. Plasma antipsychotic concentration and receptor occupancy, with special focus on risperidone longacting injectable. Eur Neuropsychopharmacol 2006; 16: 233-240

438 Mehler-Wex C, Kölch M, Kirchheiner J et al. Drug monitoring in child and adolescent psychiatry for improved efficacy and safety of psychopharmacotherapy. Child Adolesc Psychiatry Ment Health 2009; 3: 14

439 Meijer WE, Bouvy ML, Heerdink ER et al. Spontaneous lapses in dosing during chronic treatment with selective serotonin reuptake inhibitors. Br J Psychiatry 2001; 179: 519-522

440 Meineke I, Kress I, Poser W et al. Therapeutic drug monitoring and its metabolite desmethylmirtazapine by HPLC with fluorescence detection. Ther Drug Monit 2004; 26: 277-283

441 Meisenzahl EM, Schmitt G, Gründer G et al. Striatal D2/D3 receptor occupancy, clinical response and side effects with amisulpride: an iodine-123-iodobenzamide SPET study. Pharmacopsychiatry 2008; 41: $169-175$

442 Meyer JH. Imaging the serotonin transporter during major depressive disorder and antidepressant treatment. J Psychiatry Neurosci 2007; 32: 86-102

443 Meyer JH, Wilson AA, Sagrati S et al. Serotonin transporter occupancy of five selective serotonin reuptake inhibitors at different doses: an $\left[{ }^{11} \mathrm{C}\right] \mathrm{DASB}$ positron emission tomography study. Am J Psychiatry 2004; 161: 826-835

444 Meyer RP, Gehlhaus $M$, Knoth $R$ et al. Expression and function of cytochrome p450 in brain drug metabolism. Curr Drug Metab 2007; 8: 297-306

445 Meyer-Barner M, Meineke I, Schreeb KH et al. Pharmacokinetics of doxepin and desmethyldoxepin: an evaluation with the population approach. Eur J Clin Pharmacol 2002; 58: 253-257

446 Michelson D, Read HA, Ruff DD et al. CYP2D6 and clinical response to atomoxetine in children and adolescents with ADHD. J Am Acad Child Adolesc Psychiatry 2007; 46: 242-251

447 Mihara K, Yasui-Furukori N, Kondo $T$ et al. Relationship between plasma concentrations of trazodone and its active metabolite $\mathrm{m}$-chlorophenylpiperazine, and its clinical effect in depressed patients. Ther Drug Monit 2002; 24: 563-566

448 Mimaki T. Clinical pharmacology and therapeutic drug monitoring of zonisamide. Ther Drug Monit 1998; 20: 593-597

449 Miura H. Zonisamide monotherapy with once-daily dosing in children with cryptogenic localization-related epilepsies: clinical effects and pharmacokinetic studies. Seizure 2004; 13 (Suppl 1): S17-S23

450 Miura M, Ohkubo T. Identification of human cytochrome P450 enzymes involved in the major metabolic pathway of fluvoxamine. Xenobiotica 2007; 37: 169-179 
451 Moffat AC. editor. Clarke's analysis of drugs and poisons. London: Pharmaceutical Press, 2003; 1468-1469

452 Molden E, Lunde $H$, Lunder $N$ et al. Pharmacokinetic variability of aripiprazole and the active metabolite dehydroaripiprazone in psychiatric patients. Ther Drug Monit 2006; 28: 744-749

453 Montgomery SA, McAuley R, Montgomery DB. Relationsship between mianserin plasma levels and antidepressant effect in a double-blind trial comparing a single night-time and divided daily dose regimens. Br J Clin Pharmacol 1978; 5: 71S-76S

454 Moody DE, Chang $Y$, Huang $W$ et al. The in vivo response of novel buprenorphine metabolites, M1 and M3, to antiretroviral inducers and inhibitors of buprenorphine metabolism. Basic Clin Pharmacol Toxicol 2009; 105: 211-215

455 Morris $R G$, Black $A B$, Harris $A L$ et al. Lamotrigine and therapeutic drug monitoring: retrospective survey following the introduction of a routine service. Br J Clin Pharmacol 1998; 46: 547-551

456 Morris RG, Lee MY, Cleanthous $X$ et al. Long-term follow-up using a higher target range for lamotrigine monitoring. Ther Drug Monit 2004; 26: 626-632

457 Mrazek DA. Psychiatric pharmacogenomic testing in clinical practice. Dialogues Clin Neurosci 2010; 12: 69-76

458 Müller $H$, Eusterschulte B, Havemann-Reinecke $U$ et al. Forensische Aspekte des therapeutischen Drug-Monitorings (TDM) in der Psychiatrie. Psychopharmakotherapie 2009; 16: 52-56

459 Müller MJ, Dragicevic A, Fric $M$ et al. Therapeutic drug monitoring of tricyclic antidepressants: how does it work under clinical conditions? Pharmacopsychiatry 2003; 36: 98-104

460 Müller MJ, Härtter S, Köhler D et al. Serum levels of sulpiride enantiomers after oral treatment with racemic sulpiride in psychiatric patients: a pilot study. Pharmacopsychiatry 2001; 34: 27-32

461 Müller MJ, Regenbogen B, Härtter S et al. Therapeutic drug monitoring for optimizing amisulpride therapy in patients with schizophrenia. J Psychiat Res 2007; 41: 673-679

462 Müller-Isberner R, Freese R, Jöckel $D$ et al. Forensic psychiatric assessment and treatment in Germany. Legal framework, recent developments, and current practice. Int J Law Psychiatry 2000; 23: 467-480

463 Nagy CF, Kumar D, Cullen EI et al. Steady-state pharmacokinetics and safety of donepezil $\mathrm{HCl}$ in subjects with moderately impaired renal function. Br J Clin Pharmacol 2004; 58 (Suppl 1): 18-24

464 Naito $H$, Wachi $M$, Nishida $M$. Clinical effects and plasma concentrations of long-term clonazepam monotherapy in previously untreated epileptics. Acta Neurol Scand 1987; 76: 58-63

465 Nakamura $K$, Yokoi T, Inoue $K$ et al. CYP2D6 is the principal cytochrome P450 responsible for metabolism of the histamine H1 antagonist promethazine in human liver microsomes. Pharmacogenetics 1996; 6: 449-457

466 Nazirizadeh $Y$, Vogel $F$, Bader $W$ et al. Serum concentrations of paliperidone versus risperidone and clinical effects. Eur J Clin Pharmacol 2010; 66: 797-803

467 Neels HM, Sierens AC, Naelaerts K et al. Therapeutic drug monitoring of old and newer anti-epileptic drugs. Clin chem Lab Med 2004; 42: $1228-1255$

468 Nemoda Z, Angyal N, Tarnok $Z$ et al. Carboxylesterase 1 gene polymorphism and methylphenidate response in ADHD. Neuropharmacology 2009; 57: 731-733

469 Nesvag $R$, Hendset $M$, Refsum $H$ et al. Serum concentrations of risperidone and 9-OH risperidone following intramuscular injection of long-acting risperidone compared with oral risperidone medication. Acta Psychiatr Scand 2006; 114: 21-26

470 Nikisch G, Baumann P, Oneda B et al. Cytochrome P450 and ABCB1 genetics: association with quetiapine and norquetiapine plasma and cerebrospinal fluid concentrations and with clinical response in patients suffering from schizophrenia. A pilot study. J Psychopharmacol 2010; Dec 8 [Epub ahead of print]

471 Nikisch G, Mathé AA, Czernik A et al. Stereoselective metabolism of citalopram in plasma and cerebrospinal fluid of depressive patients: relationship with 5-HIAA in CSF and clinical response. J Clin Psychopharmacol 2004; 24: 283-290

472 Nikolaus S, Larisch $R$, Beu $M$ et al. In vivo measurement of D2 receptor density and affinity for $18 \mathrm{~F}-(3-\mathrm{N}$-methyl)benperidol in the rat striatum with a PET system for small laboratory animals. J Nucl Med 2003; 44: 618-624

473 Nilsen OG, Dale O. Single dose pharmacokinetics of trazodone in healthy subjects. Pharmacol Toxicol 1992; 71: 150-153

474 Nilsson MI, Meresaar U, Ånggard E. Clinical pharmacokinetics of methadone. Acta Anaesthesiol Scand Suppl 1982; 74: 66-69
475 Nishikage H, Nakanishi T, Takamitsu $Y$ et al. Sequential changes in the plasma concentration of risperidone following intentional overdose. Clin Neuropharmacol 2002; 25: 307-309

476 Nnadi CU, Malhotra AK. Clinical and pharmacogenetic studies of iloperidone. Per Med 2008; 5: 367-375

477 Norman T, Chiu E, James RH et al. Single oral dose pharmacokinetics of tiapride in patients with Huntington's disease. Eur J Clin Pharmacol 1987; 32: 583-586

478 Nozawa M, Ohnuma T, Matsubara $Y$ et al. The relationship between the response of clinical symptoms and plasma olanzapine concentration, based on pharmacogenetics. Ther Drug Monit 2008; 30: 35-40

479 Nutt JG, Fellman JH. Pharmacokinetics of levodopa. Clin Neuropharmacol 1984; 7: 35-49

480 Nyberg $S$, Nordström AL, Halldin C et al. Positron emission tomography studies on D2 dopamine receptor occupancy and plasma antipsychotic drug levels in man. Int Clin Psychopharmacol 1995; 10 (Suppl 3): 81-85

481 Nyholm D. Pharmacokinetic optimisation in the treatment of Parkinson's disease: an update. Clin Pharmacokinet 2006; 45: 109-136

482 Obach RS, Cox LM, Tremaine LM. Sertraline is metabolized by multiple cytochrome P450 enzymes, monoamine oxidases, and glucuronyl transferases in human: an in vitro study. Drug Metab Dispos 2005; 33: 262-270

483 Öhman D, Cherma MD, Norlander B et al. Determination of serum reboxetine enantiomers in patients on chronic medication with racemic reboxetine. Ther Drug Monit 2003; 25: 174-182

484 Öhman D, Norlander B, Peterson C et al. Bioanalysis of racemic reboxetine and its desethylated metabolite in a therapeutic drug monitoring setting using solid phase extraction and HPLC. Ther Drug Monit $2001 ; 23: 27-34$

485 Olesen OV, Linnet $\mathrm{K}$. Hydroxylation and demethylation of the tricyclic antidepressant nortriptyline by cDNA-expressed human cytochrome P-450 isozymes. Drug Metab Dispos 1997; 25: 740-744

486 Olesen OV, Linnet $K$. Identification of the human cytochrome P450 isoforms mediating in vitro $\mathrm{N}$-dealkylation of perphenazine. $\mathrm{Br} \mathrm{J}$ Clin Pharmacol 2000; 50: 563-571

487 Olesen OV, Linnet $K$. Contributions of five human cytochrome P450 isoforms to the $\mathrm{N}$-demethylation of clozapine in vitro at low and high concentrations. J Clin Pharmacol 2001; 41: 823-832

488 Orsulak PJ. Therapeutic monitoring of antidepressant drugs: current methodology and applications. J Clin Psychiatry 1986; 47 (Suppl): 39-52

489 Orsulak PJ. Therapeutic monitoring of antidepressant drugs: guidelines updated. Ther Drug Monit 1989; 11: 497-507

490 Orsulak PJ, Schildkraut JJ. Guidelines for therapeutic monitoring of tricyclic antidepressant plasma levels. Ther Drug Monit 1979; 1: 199-208

491 Ostad Haji E, Tadić A, Wagner S et al. Association between citalopram serum levels and clinical improvement of patients with major depression. J Clin Psychopharmacol 2011; 31: 281-286

492 Ota T, Shinotoh H, Fukushi $K$ et al. Estimation of plasma IC50 of donepezil for cerebral acetylcholinesterase inhibition in patients with Alzheimer's disease using positron emission tomography. Clin Neuropharmacol 2010; 33: 74-78

493 Palego L, Biondi L, Giannaccini G et al. Clozapine, norclozapine plasma levels, their sum and ratio in 50 psychotic patients: influence of patient-related variables. Prog Neuropsychopharmacol Biol Psychiatry 2002; 26: 473-480

494 Panagiotidis G, Arthur HW, Lindh JD et al. Depot haloperidol treatment in outpatients with schizophrenia on monotherapy: impact of CYP2D6 polymorphism on pharmacokinetics and treatment outcome. Ther Drug Monit 2007; 29: 417-422

495 Paris BL, Ogilvie BW, Scheinkoenig JA et al. In vitro inhibition and induction of human liver cytochrome p450 enzymes by milnacipran. Drug Metab Dispos 2009; 37: 2045-2054

496 Park JY, Kim KA, Park PW et al. Effect of CYP3A5*3 genotype on the pharmacokinetics and pharmacodynamics of alprazolam in healthy subjects. Clin Pharmacol Ther 2006; 79: 590-599

497 Park PW, Seo YH, Ahn JY et al. Effect of CYP3A5*3 genotype on serum carbamazepine concentrations at steady-state in Korean epileptic patients. J Clin Pharm Ther 2009; 34: 569-574

498 Parker DR, McIntyre IM. Case studies of post-mortem quetiapine: therapeutic or toxic concentrations? J Analyt Toxicol 2005; 29: 407-412

499 Patsalos PN, Berry DJ, Bourgeois BF et al. Antiepileptic drugs - best practice guidelines for therapeutic drug monitoring: a position paper by the subcommission on therapeutic drug monitoring, ILAE Commission on Therapeutic Strategies. Epilepsia 2008; 49: 1239-1276 
500 Paz E, Bouzas L, Hermida J et al. Evaluation of three dosing models for the prediction of steady-state trough clozapine concentrations. Clin Biochem 2008; 41: 603-606

501 Pearce GA, Day RO. Compliance with criteria necessary for effective drug concentration monitoring. Ther Drug Monit 1990; 12: 250-257

502 Pedersen OL, Gram LF, Kristensen CB et al. Overdosage of Antidepressants: Clinical and Pharmacokinetic Aspects. Eur J Clin Pharmacol 1982; 23: 513-521

503 Perez J, Chiron C, Musial C et al. Stiripentol: efficacy and tolerability in children with epilepsy. Epilepsia 1999; 40: 1618-1626

504 Perry PJ. The relationship between antidepressant response and tricyclic antidepressant plasma concentrations: a retrospective analysis of the literature using logistic regression analysis. Clin Pharmacokinet 1987; 13: 381-392

505 Perry PJ. Therapeutic drug monitoring of antipsychotics. Psychopharmacol Bull 2001; 35: 19-29

506 Perry PJ, Browne JL, Alexander B et al. Relationship of free nortriptyline levels to therapeutic response. Acta Psychiatr Scand 1985; 72 : 120-125

507 Perry PJ, Miller DD, Arndt SV et al. Clozapine and norclozapine plasma concentrations and clinical response of treatment-refractory schizophrenic patients. Am J Psychiatry 1991; 148: 231-235

508 Perry PJ, Miller DD, Arndt SV et al. Haloperidol dosing requirements: the contribution of smoking and nonlinear pharmacokinetics. J Clin Psychopharmacol 1993; 13: 46-51

509 Perry PJ, Sanger T, Beasley C. Olanzapine plasma concentrations and clinical response in acutely III schizophrenic patients. J Clin Psychopharmacol 1997; 17: 472-477

510 Perry PJ, Zeilmann C, Arndt S. Tricyclic antidepressant concentrations in plasma: an estimate of their sensitivity and specificity as a predictor of response. J Clin Psychopharmacol 1994; 14: 230-240

511 Perucca E, Cloyd J, Critchley D et al. Rufinamide: clinical pharmacokinetics and concentration-response relationships in patients with epilepsy. Epilepsia 2008; 49: 1123-1141

512 Petit P, Lonjon R, Cociglio $M$ et al. Carbamazepine and its 10,11-epoxide metabolite in acute mania: clinical and pharmacokinetic correlates. Eur J Clin Pharmacol 1991; 41: 541-546

513 Peyronneau MA, Delaforge $M$, Riviere R et al. High affinity of ergopeptides for cytochromes P450 3A. Importance of their peptide moiety for P450 recognition and hydroxylation of bromocriptine. Eur J Biochem 1994; 223: 947-956

514 Pichini S, Papaseit E, Joya X et al. Pharmacokinetics and therapeutic drug monitoring of psychotropic drugs in pediatrics. Ther Drug Monit 2009; 31: 283-318

515 Pierce DM, Franklin RA, Harry TV et al. Pharmacodynamic correlates of modified absorption: studies with lormetazepam. Br J Clin Pharmacol 1984; 18: 31-35

516 Poggesi I, Benedetti MS, Whomsley R et al. Pharmacokinetics in special populations. Drug Metab Rev 2009; 41: 422-454

517 Potgieter GE, Groenewoud G, Jordaan PJ et al. Pharmacokinetics of pipamperone from three different tablet formulations. Arzneimittelforschung 2002; 52: 430-444

518 Pounder DJ, Jones GR. Post-mortem drug redistribution - a toxicological nightmare. Forensic Sci Int 1990; 45: 253-263

519 Prakash C, Kamel A, Cui D et al. Identification of the major human liver cytochrome P450 isoform(s) responsible for the formation of the primary metabolites of ziprasidone and prediction of possible drug interactions. Br J Clin Pharmacol 2000; 49 (Suppl 1): 35S-42S

520 Preskorn S, Patroneva A, Silman $H$ et al. Comparison of the pharmacokinetics of venlafaxine extended release and desvenafaxine in extensive and poor cytochrome P450 metabolizers. J Clin Psychopharmacol 2009; 29: 39-43

521 Preskorn SH. CNS drug development: part I: the early period of CNS drugs. J Psychiatr Pract 2010; 16: 334-339

522 Preskorn SH. CNS drug development: Part II: Advances from the 1960s to the 1990s. J Psychiatr Pract 2010; 16: 413-415

523 Preskorn SH. Patients who do not respond to the "usual" dose: why Terry fell off the dose-response curve. J Psychiatr Pract 2009; 15: 460-466

524 Preskorn SH. Practical application of therapeutic drug monitoring: a tale of two patients. J Psychiatr Pract 2008; 14: 301-306

525 Preskorn SH. Tricyclic antidepressant plasma level monitoring: an improvement over the dose-response approach. J Clin Psychiatry 1986; 47 (Suppl 1): 24-30

526 Preskorn SH, Burke MJ, Fast GA. Therapeutic drug monitoring: Principles and practice. Ther Drug Monit 1993; 16: 611-641

527 Preskorn SH, Fast GA. Therapeutic drug monitoring for antidepressants: efficacy, safety, and cost effectiveness. J Clin Psychiat 1991; 52 (Suppl): 23-33
528 Preskorn SH, Fast GA. Tricyclic antidepressant-induced seizures and plasma drug concentration. J Clin Psychiatry 1992; 53: 160-162

529 Preskorn SH, Fleck RJ, Schroeder DH. Therapeutic drug monitoring of bupropion. Am J Psychiatry 1990; 147: 1690-1691

530 Preskorn SH, Jerkovich GS. Central nervous system toxicity of tricyclic antidepressants: phenomenology, course, risk factors, and role of therapeutic drug monitoring. J Clin Psychopharmacol 1990; 10: 88-95

531 Puech A, Fleurot O, Rein W. Amisulpride, an atypical antipsychotic, in the treatment of acute episodes of schizophrenia: a dose-ranging study vs. haloperidol. Acta Psychiatr Scand 1998; 98: 65-72

532 Pumariega AJ, Nelson R, Rotenberg L. Varenicline-induced mixed mood and psychotic episode in a patient with a past history of depression. CNS Spectr 2008; 13: 511-514

533 Puozzo C, Albin H, Vinçon G et al. Pharmacokinetics of milnacipran in liver impairment. Eur J Drug Metab Pharmacokinet 1998; 23: 273-279

534 Raaflaub J. On the pharmacokinetics of chlorprothixene in man. Experientia 1975; 31: 557-558

535 Radtke RA. Pharmacokinetics of levetiracetam. Epilepsia 2001; 42 (Suppl 4): 24-27

536 Rao VA, Bishop M, Coppen A. Clinical state, plasma levels of haloperidol and prolactin: a correlation study in chronic schizophrenia. $\mathrm{Br}$ J Psychiatry 1980; 137: 518-521

537 Rasmussen BB, Brøsen $K$. Is therapeutic drug monitoring a case for optimizing clinical outcome and avoiding interactions of the selective serotonin reuptake inhibitors? Ther Drug Monit 2000; 22: 143-154

538 Rasmussen PV, Jensen TS, Sindrup SH et al. TDM-based imipramine treatment in neuropathic pain. Ther Drug Monit 2004; 26: 352-360

539 Rauschenbach R, Gieschen H, Husemann $M$ et al. Stable expression of human cytochrome P450 3A4 in V79 cells and its application for metabolic profiling of ergot derivatives. Eur J Pharmacol 1995; 293: 183-190

540 Ravva P, Gastonguay MR, Tensfeldt TG et al. Population pharmacokinetic analysis of varenicline in adult smokers. Br J Clin Pharmacol 2009; 68: 669-681

541 Rees JA. Clinical interpretation of pharmacokinetic data on dothiepine hydrochloride (Dosulepin, Prothiaden). J Int Med Res 1981; 9: 98-102

542 Regenthal R, Krueger M, Koeppel C et al. Drug levels: therapeutic and toxic serum/plasma concentrations of common drugs. J Clin Monit Comput 1999; 15: 529-544

543 Reimold $M$, Solbach C, Noda S et al. Occupancy of dopamine D(1), D (2) and serotonin (2A) receptors in schizophrenic patients treated with flupentixol in comparison with risperidone and haloperidol. Psychopharmacology (Berl) 2007; 190: 241-249

544 Reis M, Aamo T, Ahlner J et al. Reference concentrations of antidepressants. A compilation of post-mortem and therapeutic levels. J Analyt Toxicol 2007; 31: 254-264

545 Reis M, Aamo T, Spigset $O$ et al. Serum concentrations of antidepressant drugs in a naturalistic setting: compilation based on a large therapeutic drug monitoring database. Ther Drug Monit 2009; 31: 42-56

546 Reis $M$, Åberg-Wistedt A, Ågren $H$ et al. Compliance with SSRI medication during 6 months of treatment for major depression: an evaluation by determination of repeated serum drug concentrations. J Affect Disorders 2004; 82: 443-446

547 Reis M, Akerblad AC, Ekselius L et al. Partial compliance as determined from plasma levels of sertraline and its metabolite in depressed patients in primary care. J Clin Psychopharmacol 2010; 30: 746-748

548 Reis M, Chermá MD, Carlsson B et al. On behalf of the task force for TDM of escitalopram in Sweden. Therapeutic drug monitoring of escitalopram in an outpatient setting. Ther Drug Monit 2007; 29: 758-766

549 Reis M, Lundmark J, Bengtsson F. Therapeutic drug monitoring of racemic citalopram: a 5-year experience in Sweden, 1992-1997. Ther Drug Monit 2003; 25: 183-191

550 Reis M, Lundmark J, Björk $H$ et al. Therapeutic drug monitoring of racemic venlafaxine and its main metabolites in an everyday clinical setting. Ther Drug Monit 2002; 24: 545-553

551 Reis M, Olsson G, Carlsson B et al. Serum levels of citalopram and its main metabolites in adolescent patients treated in a naturalistic clinical setting. J Clin Psychopharmacol 2002; 22: 406-413

552 Reis M, Prochazka J, Sitsen A et al. Inter- and intraindividual pharmacokinetic variations of mirtazapine and its N-demethyl metabolite in patients treated for major depressive disorder: a 6-month therapeutic drug monitoring study. Ther Drug Monit 2005; 27: 469-477 
553 Remington G, Mamo D, Labelle A et al. A PET study evaluating dopamine $D_{2}$ receptor occupancy for long-acting injectable risperidone. Am J Psychiatry 2006; 163: 396-401

554 Renwick AB, Mistry H, Ball SE et al. Metabolism of Zaleplon by human hepatic microsomal cytochrome P450 isoforms. Xenobiotica 1998; 28: $337-348$

555 Riant $P$, Urien S, Albengres $E$ et al. Effects of the binding of imipramine to erythrocytes and plasma proteins on its transport through the rat blood-brain barrier. J Neurochem 1988; 51: 421-425

556 Richens A, Banfield CR, Salfi $M$ et al. Single and multiple dose pharmacokinetics of felbamate in the elderly. Br J Clin Pharmacol 1997; 44: $129-134$

557 Riedel M, Schwarz MJ, Strassnig $M$ et al. Risperidone plasma levels, clinical response and side-effects. Eur Arch Psychiatry Clin Neurosi 2005; 255: 261-268

558 Rivas N, Buelga DS, Elger CE et al. Population pharmacokinetics of lamotrigine with data from therapeutic drug monitoring in German and Spanish patients with epilepsy. Ther Drug Monit 2008; 30: 483-489

559 Rivera-Calimlim L, Castañeda L, Lasagna L. Effects of mode of management on plasma chlorpromazine in psychiatric patients. Clin Pharmacol Ther 1973; 14: 978-986

560 Roberts RL, Joyce PR, Mulder RT et al. A common P-glycoprotein polymorphism is associated with nortriptyline-induced postural hypotension in patients treated for major depression. Pharmacogenomics J 2002; 2: 191-196

561 Robertson PJR, Hellriegel ET. Clinical pharmacokinetic profile of modafinil. Clin Pharmacokinet 2003; 42: 123-137

562 Rochat B, Kosel M, Boss $G$ et al. Stereoselective biotransformation of the selective serotonin reuptake inhibitor, citalopram, and its demethylated metabolites by monoamine oxidases in human liver. Biochem Pharmacol 1998; 56: 15-23

563 Rogers SL, Friedhoff LT. The efficacy and safety of donepezil in patients with Alzheimer's disease: results of a US multicentre, randomized, double-blind, placebo-controlled trial. The Donepezil Study Group. Dementia 1996; 7: 293-303

564 Roman M, Kronstrand R, Lindstedt D et al. Quantitation of seven lowdosage antipsychotic drugs in human postmortem blood using LCMS-MS. J Anal Toxicol 2008; 32: 147-155

565 Ronfeld RA, Tremaine LM, Wilner KD. Pharmacokinetics of sertraline and its N-demethyl metabolite in elderly and young male and female volunteers. Clin Pharmacokinet 1997; 32 (Suppl 1): 22-30

566 Rosenzweig $P$, Canal M, Patat A et al. A review of the pharmacokinetics, tolerability and pharmacodynamics of amisulpride in healthy volunteers. Hum Psychopharmacol 2002; 17: 1-13

567 Rotzinger S, Fang J, Baker GB. Trazodone is metabolized to m-chlorophenylpiperazine by CYP3A4 from human sources. Drug Metab Dispos 1998; 26: 572-575

568 Rougemont $M$, Ulrich $S$, Hiemke $C$ et al. French summaries of product characteristics: content in relation to therapeutic monitoring of psychotropic drugs. Fundam Clin Pharmacol 2010; 24: 377-384

569 Rudorfer $V$, Potter WZ. The role of metabolites of antidepressants in the treatment of depression. CNS Drugs 1997; 7: 273-312

570 Ruottinen HM, Rinne UK. Effect of one month's treatment with peripherally acting catechol-O-methyltransferase inhibitor, entacapone, on pharmacokinetics and motor response to levodopa in advanced parkinsonian patients. Clin Neuropharmacol 1996; 19: 222-233

571 Sachse J, Härtter S, Hiemke C. Automated determination of ziprasidone by HPLC with column switching and spectrophotometric detection. Ther Drug Monit 2005; 27: 158-162

572 Sachse J, Härtter S, Weigmann $H$ et al. Automated determination of amisulpride by liquid chromatography with column switching and spectrophotometric detection. J Chromatogr B Analyt Technol Biomed Life Sci 2003; 784: 405-410

573 Sachse J, Köller J, Härtter $S$ et al. Automated analysis of quetiapine and other antipsychotic drugs in human blood by high performanceliquid chromatography with column-switching and spectrophotometric detection. J Chromatogr B Analyt Technol Biomed Life Sci 2006; 830: 342-348

574 Sagar KA, Smyth MR. Bioavailability studies of oral dosage forms containing levodopa and carbidopa using column-switching chromatography followed by electrochemical detection. Analyst 2000; 125: 439-445

575 Sage JI, Mark MH. Pharmacokinetics of continuous-release carbidopa/levodopa. Clin Neuropharmacol 1994; 17 (Suppl 2): 1-6
576 Sainati SM, Hubbard JW, Chi E et al. Safety, tolerability, and effect of food on the pharmacokinetics of iloperidone (HP 873), a potential atypical antipsychotic. J Clin Pharmacol 1995; 35: 713-720

577 Saint-Marcoux F, Sauvage FL, Marquet P. Current role of LC-MS in therapeutic drug monitoring. Anal Bioanal Chem 2007; 388: 1327-1349

578 Saivin S, Hulot T, Chabac S et al. Clinical pharmacokinetics of acamprosate. Clin Pharmacokinet 1998; 35: 331-345

579 Sajatovic M, Velligan DI, Weiden PJ et al. Measurement of psychiatric treatment adherence. J Psychosom Res 2010; 69: 591-599

580 Salazar DE, Frackiewicz EJ, Dockens $R$ et al. Pharmacokinetics and tolerability of buspirone during oral administration to children and adolescents with anxiety disorder and normal healthy adults. J Clin Pharmacol 2001; 41: 1351-1358

581 Sallee FR, Pollock BG, Stiller RL et al. Pharmacokinetics of pimozide in adults and children with Tourette's syndrome. J Clin Pharmacol 1987; 27: 776-781

582 Sartorius N, Baghai TC, Baldwin DS et al. Antidepressant medications and other treatments of depressive disorders: a CINP Task Force report based on a review of evidence. Int J Neuropsychopharmacol 2007; 10 (Suppl 1): S1-S207

583 Sauer JM, Ring BJ, Witcher JW. Clinical Pharmacokinetics of atomoxetine. Clin Pharmacokinet 2005; 44: 571-590

584 Sauvage FL, Gaulier JM, Lachâtre G et al. Pitfalls and prevention strategies for liquid chromatography-tandem mass spectrometry in the selected reaction-monitoring mode for drug analysis. Clin Chem 2008; 54: 1519-1527

585 Schulberg HC, Katon W, Simon GE et al. Treating major depression in primary care practice: an update of the Agency for Health Care Policy and Research Practice Guidelines. Arch Gen Psychiatry 1998; 55: 1121-1127

586 Schulz M, Schmoldt A. Therapeutic and toxic blood concentrations of more than 800 drugs and other xenobiotics. Pharmazie 2003; 58: 447-474

587 Schwarzenbach F, Netillard C, Demoly P et al. Antidepressant response and fluvoxamine plasma concentrations: a pilot study. Pharm World Sci 2003; 25: 27-29

588 Scordo MG, Spina E, Dahl ML et al. Influence of CYP2C9, 2C19 and 2D6 genetic polymorphisms on the steady-state plasma concentrations of the enantiomers of fluoxetine and norfluoxetine. Basic Clin Pharmacol Toxicol 2005; 97: 296-301

589 Seiler $W$, Wetzel $H$, Hillert A et al. Pharmacokinetics and bioavailability of benperidol in schizophrenic patients after intravenous and two different kinds of oral application. Psychopharmacology (Berl) 1994; 116: 457-463

590 Service JA, Waring WS. QT Prolongation and delayed atrioventricular conduction caused by acute ingestion of trazodone. Clin Toxicol (Phila) 2008; 46: 71-73

591 Shams $M$, Hiemke $C$, Härtter S. Therapeutic drug monitoring of antidepressant mirtazapine and its $\mathrm{N}$-demethylated metabolite in human serum. Ther Drug Monit 2004; 26: 78-84

592 Shams ME, Arneth B, Hiemke C et al. CYP2D6 polymorphism and clinical effect of the antidepressant venlafaxine. J Clin Pharm Ther 2006; 31: 493-502

593 Sharma S, Joshi S, Chadda RK. Therapeutic drug monitoring of lithium in patients with bipolar affective disorder: experiences from a tertiary care hospital in India. Am J Ther 2009; 16: 393-397

594 Shin JG, Soukova N, Flockart DA. Effect of antipsychotic drugs on human liver cytochrome P-450 (CYP) isoforms in vitro: Preferential inhibition of CYP2D6. Drug Metab Dispos 1999; 27: 1078-1084

595 Shinderman $M$, Maxwell S, Brawand-Amey $M$ et al. Cytochrome P4503A4 metabolic activity, methadone blood concentrations, and methadone doses. Drug Alcohol Depend 2003; 69: 205-211

596 Shiraga T, Kaneko $H$, Iwasaki $K$ et al. Identification of cytochrome P450 enzymes involved in the metabolism of zotepine, an antipsychotic drug, in human liver microsomes. Xenobiotica 1999; 29 : 217-229

597 Shua-Haim J, Smith J, Picard F et al. Steady-state pharmacokinetics of rivastigmine in patients with mild to moderate Alzheimer's disease not affected by co-administration of memantine: an open-label, crossover, single-centre study. Clin Drug Investig 2008; 28: 361-374

598 Sidhu J, Priskorn M, Poulsen M et al. Steady-state pharmacokinetics of the enantiomers of citalopram and its metabolites in human. Chirality 1997; 9: 686-692

599 Siva $N$. Tackling the booming trade in counterfeit drugs. Lancet 2010; 376: 1725-1726

600 Skinner MH, Kuan HY, Skerjanec A et al. Effect of age on the pharmacokinetics of duloxetine in women. Br J Clin Pharmacol 2004; 57 : 54-61 
601 Skogh E, Bengtsson F, Nordin C. Could discontinuing smoking be hazardous for patients administered clozapine medication? A case report. Ther Drug Monit 1999; 21: 580-582

602 Skogh E, Reis M, Dahl ML et al. Therapeutic drug monitoring data on olanzapine and its $\mathrm{N}$-demethyl metabolite in the naturalistic clinical setting. Ther Drug Monit 2002; 24: 518-526

603 Small JG, Hirsch SR, Arvanitis LA et al. Quetiapine in patients with schizophrenia - a high- and low-dose double-blind comparison with placebo. Seroquel study group. Arch Gen Psychiatry 1997; 54: 549-557

604 Smith RB, Kroboth PD, Vanderlugt JT et al. Pharmacokinetics and pharmacodynamics of alprazolam after oral and IV administration. Psychopharmacology (Berl) 1984; 84: 452-456

605 Smith SW. Chiral toxicology: it's the same thing...only different. Toxicol Sci 2009; 110: 4-30

606 Snoeck E, Van Peer A, Sack $M$ et al. Influence of age, renal and liver impairment on the pharmacokinetics of risperidone in man. Psychopharmacology (Berl) 1995; 122: 223-229

607 Søgaard B, Mengel H, Rao N et al. The pharmacokinetics of escitalopram after oral and intravenous administration of single and multiple doses to healthy subjects. J Clin Pharmacol 2005; 45: 1400-1406

608 Soldin P, Mattison DR. Sex differences in pharmacokinetics and pharmacodynamics. Clin Pharmacokinet 2009; 48: 143-157

609 Someya T, Muratake T, Hirokane G et al. Interindividual variation in bromperidl metabolism and relationship to therapeutic effects. J Clin Psychopharmacol 2000; 20: 175-180

610 Søndergaard Khinchi M, Nielsen KA, Dahl M et al. Lamotrigine therapeutic thresholds. Seizure 2008; 17: 391-395

611 Soni SD. Fluspirilene in the treatment of non-hospitalized schizophrenic patients. Curr Med Res Opin 1977; 4: 645-649

612 Sparshatt A, Taylor D, Patel MX et al. A systematic review of aripiprazole-dose, plasma concentration, receptor occupancy, and response: implications for therapeutic drug monitoring. J Clin Psychiatry 2010; 71: 1447-1456

613 Sparshatt A, Taylor D, Patel MX et al. Amisulpride - dose, plasma concentration, occupancy and response: implications for therapeutic drug monitoring. Acta Psychiatr Scand 2009; 120: 416-428

614 Spencer TJ, Biederman J, Ciccone PE et al. PET study examining pharmacokinetics, detection and likeability, and dopamine transporter receptor occupancy of short- and long-acting oral methylphenidate. Am J Psychiatry 2006; 163: 387-395

615 Spencer TJ, Bonab AA, Dougherty DD et al. A PET study examining pharmacokinetics and dopamine transporter occupancy of two longacting formulations of methylphenidate in adults. Int J Mol Med 2010; 25: 261-265

616 Spigset 0, Hägg S, Stegmayr B et al. Citalopram pharmacokinetics in patients with chronic renal failure and the effect of haemodialysis. Eur J Clin Pharmacol 2000; 59: 699-703

617 Spina E, Avenoso A, Facciolà $G$ et al. Relationship between plasma risperidone and 9-hydroxyrisperidone concentrations and clinical response in patients with schizophrenia. Psychopharmacology (Berl) 2001; 153: 238-243

618 Spina E, Birgersson C, von Bahr Ö et al. Phenotypic consistency in hydroxylation of desmethylimipramine and debrisoquine in healthy subjects and in human liver microsomes. Clin Pharmacol Ther 1984; 36: 677-682

619 Sproule BA, Hardy BG, Shulman KI. Differential pharmacokinetics of lithium in elderly patients. Drugs Aging 2000; 16: 165-177

620 Stassen $\mathrm{HH}$, Anghelescu IG, Angst J et al. Predicting response to psychopharmacological treatment. Survey of recent results. Pharmacopsychiatry 2011; 44: 263-272

621 Stassen HH, Angst J, Hell D et al. Is there a common resilience mechanism underlying antidepressant drug response? Evidence from 2848 patients. J Clin Psychiatry 2007; 68: 1195-1205

622 Stead AH, Moffat AC. A collection of therapeutic, toxic and fatal blood drug concentrations in man. Hum Exp Toxicol 1983; 3: 437-464

623 Steimer $W$. Pharmacogenetics and Psychoactive Drug Therapy: Ready for the Patient? Ther Drug Monit 2010; 32: 381-386

624 Steimer $W$, Potter JM. Pharmacogenetic screening and therapeutic drugs. Clin Chim Acta 2002; 315: 137-155

625 Steimer W, Zöpf K, von Amelunxen S et al. Amitriptyline or not, that is the question: pharmacogenetic testing of CYP2D6 and CYP2C19 identifies patients with low or high risk for side effects in amitriptyline therapy. Clin Chem 2005; 51: 376-385

626 Stieffenhofer $V$, Hiemke C. Pharmacogenetics, therapeutic drug monitoring and non compliance. Ther Umsch 2010; 67: 309-315
627 Stieffenhofer V, Saglam H, Schmidtmann I et al. Clozapine plasma level monitoring for prediction of rehospitalization schizophrenic outpatients. Pharmacopsychiatry 2011; 44: 55-59

628 Stock B, Spiteller $G$. Metabolism of antiparkinson drugs. An example of competitive hydroxylation. Arzneimittelforschung 1979; 29: 610-615

629 Störmer E, Brockmöller J, Roots I et al. Cytochrome P-450 enzymes and FMO3 contribute to the disposition of the antipsychotic drug in vitro. Psychopharmacology (Berl) 2000; 151: 312-320

630 Störmer E, von Moltke LL, Shader RI et al. Metabolism of the antidepressant mirtazapine in vitro: contribution of cytochromes P-450 1A2, 2D6, and 3A4. Drug Metab Dispos 2000; 28: 1168-1175

631 Suhara T, Takano A, Sudo Y et al. High levels of serotonin transporter occupancy with low-dose clomipramine in comparative occupancy study with fluvoxamine using positron emission tomography. Arch Gen Psychiatry 2003; 60: 386-391

632 Sutfin TA, Perini GI, Molnar G et al. Multiple-dose pharmacokinetics of imipramine and its major active and conjugated metabolites in depressed patients. J Clin Psychopharmacol 1988; 8: 48-53

633 Suzuki A, Otani K, Ishida $M$ et al. Increased plasma concentrations of bromperidol and its reduced metabolite with levomepromazine, but not with thioridazine. Ther Drug Monit 1997; 19: 261-264

634 Suzuki Y, Fukui N, Sawamura K et al. Concentration-response relationship for fluvoxamine using remission as an endpoint: a receiver operating characteristics curve analysis in major depression. J Clin Psychopharmacol 2008; 28: 325-328

635 Svirbely JR, Speicher CE. The importance of request and report forms in the interpretation of therapeutic drug monitoring data. Ther Drug Monit 1980; 2: 211-216

636 Sweet RA, Pollock BG, Kirshner $M$ et al. Pharmacokinetics of singleand multiple-dose bupropion in elderly patients with depression. J Clin Pharmacol 1995; 35: 876-884

637 Sweet RA, Pollock BG, Mulsant BH et al. Pharmacologic profile of perphenazine's metabolites. J Clin Psychopharmacol 2000; 20: 181-187

638 Szegedi A, Jansen WT, van Willigenburg AP et al. Early improvement in the first 2 weeks as a predictor of treatment outcome in patients with major depressive disorder: a meta-analysis including 6562 patients. J Clin Psychiatry 2009; 70: 344-353

639 Takano A, Suhara T, Ichimiya T et al. Time course of in vivo 5-HTT transporter occupancy by fluvoxamine. J Clin Psychopharmacol 2006; 26: 188-191

640 Takano A, Suzuki K, Kosaka J et al. A dose-finding study of duloxetine based on serotonin transporter occupancy. Psychopharmacology 2006; 185: 395-399

641 Tan L, Yu JT, Sun YP et al. The influence of cytochrome oxidase CYP2A6, CYP2B6, and CYP2C9 polymorphisms on the plasma concentrations of valproic acid in epileptic patients. Clin Neurol Neurosurg 2010; 112: 320-323

642 Tanaka O, Kondo T, Otani K et al. Single oral dose kinetics of zotepine and its relationship to prolactin response and side effects. Ther Drug Monit 1998; 20: 117-119

643 Tanaka E, Kurata N, Yasuhara H. How useful is the "cocktail approach" for evaluating human hepatic drug metabolizing capacity using cytochrome P450 phenotyping probes in vivo? J Clin Pharm Ther 2003; 28: $157-165$

644 Tasker TCG, Kaye CM, Zussman BD et al. Paroxetine plasma levels: lack of correlation with efficacy or adverse events. Acta Psychiatr Scand 1989; 80 (350): 152-155

645 Tateishi T, Watanabe M, Kumai $T$ et al. CYP3A is responsible for $\mathrm{N}$-dealkylation of haloperidol and bromperidol and oxidation of their reduced forms by human liver microsomes. Life Sci 2000; 67: 2913-2920

646 Taylor D. Antidepressant drugs and cardiovascular pathology: a clinical overview of effectiveness and safety. Acta Psychiatr Scand 2008; 118: 434-442

647 Taylor D. Psychopharmacology and adverse effects of antipsychotic long-acting injections: a review. Br J Psychiatry Suppl 2009; 52: S13-S19

648 Thanacoody RH, Daly AK, Reilly JG et al. Factors affecting drug concentrations and QT interval during thioridazine therapy. Clin Pharmacol Ther 2007; 82: 555-565

649 The Scottish Schizophrenia Research Group. The Scottish first episode Schizophrenia study II. Treatment: pimozide versus flupenthixol. $\mathrm{Br}$ J Psychiatry 1987; 150: 334-338

650 Thieme $D$, Rolf $B$, Sachs $H$ et al. Correlation of inter-individual variations of amitriptyline metabolism examined in hairs with CYP2C19 and CYP2D6 polymorphisms. Int J Legal Med 2008; 122: 149-155 
651 Timmer CJ, Sitsen JM, Delbressine LP. Clinical pharmacokinetics of mirtazapine. Clin Pharmacokinet 2000; 38: 461-474

652 Tiseo PJ, Rogers SL, Friedhoff LT. Pharmacokinetic and pharmacodynamic profile of donepezil $\mathrm{HCl}$ following evening administration. $\mathrm{Br}$ J Clin Pharmacol 1998; 46 (Suppl 1): 13-18

653 Titier K, Canal M, Déridet E et al. Determination of myocardium to plasma concentration ratios of five antipsychotic drugs: comparison with their ability to induce arrhythmia and sudden death in clinical practice. Toxicol Appl Pharmacol 2004; 199: 52-60

654 Toennes SW, Maurer HH. Microsoft Excel in pharmacokinetics - an easy way to solve kinetic problems in clinical toxicology, legal medicine or doping control. In: Sachs H, Bernhard W, Jeger A (eds.). Proceedings of the $34^{\text {th }}$ International TIAFT Meeting, Interlaken. 11-15 August 1996. Leipzig: Molina, 1997; 201-204

655 Tokairin T, Fukasawa T, Yasui-Furukori $N$ et al. Inhibition of the metabolism of brotizolam by erythromycin in humans: in vivo evidence for the involvement of CYP3A4 in brotizolam metabolism. Br J Clin Pharmacol 2005; 60: 172-175

656 Tokunaga H, Kudo K, Imamura T et al. Plasma concentrations of antipsychotic drugs in psychiatric inpatients. Nippon Hoigaku Zasshi 1997; 51: 417-422

657 Tompson DJ, Vearer D. Steady-state pharmacokinetic properties of a 24-hour prolonged-release formulation of ropinirole: results of two randomized studies in patients with Parkinson's disease. Clin Ther 2007; 29: 2654-2666

658 Topiwala A, Fazel S. The pharmacological management of violence in schizophrenia: a structured review. Expert Rev Neurother 2011; 11: 53-63

659 Tornio A, Neuvonen PJ, Backman JT. The CYP2C8 inhibitor gemfibrozil does not increase the plasma concentrations of zopiclone. Eur J Clin Pharmacol 2006; 62: 645-651

660 Touw DJ, Neef C, Thomson AH et al. Cost-effectiveness of therapeutic drug monitoring: a systematic review. Ther Drug Monit 2005; 27: $10-17$

661 Trivedi MH, Rush AJ, Gaynes BN et al. Maximizing the adequacy of medication treatment in controlled trials and clinical practice: $\operatorname{STAR}\left({ }^{*}\right)$ D measurement-based care. Neuropsychopharmacol 2007; 32: $2479-2489$

662 Tsai MH, Lin KM, Hsiao MC et al. Genetic polymorphisms of cytochrome P450 enzymes influence metabolism of the antidepressant escitalopram and treatment response. Pharmacogenomics 2010; 11 : 537-546

663 Tuerck D, Wang Y, Maboudian $M$ et al. Similar bioavailability of dexmethylphenidate extended (bimodal) release, dexmethyl-phenidate immediate release and racemic methylphenidate extended (bimodal) release formulations in man. Int J Clin Pharmacol Ther 2007; 45: 662-668

664 Turbott J, Norman TR, Burrows GD et al. Pharmacokinetics of nortriptyline in elderly volunteers. Commun Psychopharmacol 1980; 4: 225-231

665 Turpeinen M, Koivuviita N, Tolonen A et al. Effect of renal impairment on the pharmacokinetics of bupropion and its metabolites. Br J Clin Pharmacol 2007; 64: 165-173

666 Uchida H, Mamo DC, Mulsant BH et al. Increased antipsychotic sensitivity in elderly patients: evidence and mechanisms. J Clin Psychiatry 2009; 70: 397-405

667 Uhr M, Steckler T, Yassouridis A et al. Penetration of amitriptyline, but not of fluoxetine, into brain is enhanced in mice with blood-brain barrier deficiency due to mdr1a P-glycoprotein gene disruption. Neuropsychopharmacology 2000; 22: 380-387

668 Uhr M, Tontsch A, Namendorf $C$ et al. Polymorphisms in the drug transporter gene $\mathrm{ABCB} 1$ predict antidepressant treatment response in depression. Neuron 2008; 57: 203-239

669 Ujiie Y, Fukasawa T, Yasui-Furukori $N$ et al. Rifampicin markedly decreases plasma concentration and hypnotic effect of brotizolam. Ther Drug Monit 2006; 28: 299-302

670 Ulrich S, Baumann B, Wolf $R$ et al. Therapeutic drug monitoring of clozapine and relapse - a retrospective study of routine clinical data. Int J Clin Pharmacol Ther 2003; 41: 3-13

671 Ulrich S, Hiemke C, Laux G et al. TDM group of the Arbeitsgemeinschaft Neuropsychopharmakologie und Pharmakopsychiatrie (AGNP). Value and actuality of the prescription information for therapeutic drug monitoring of psychopharmaceuticals: a comparison with the medico-scientific evidence. Pharmacopsychiatry 2007; 40: 121-127

672 Ulrich S, Läuter J. Comprehensive survey of the relationship between serum concentration and therapeutic effect of amitriptyline in depression. Clin Pharmacokinet 2002; 41: 853-876
673 Ulrich S, Sandmann U, Genz A. Serum concentrations of haloperidol pyridinium metabolites and the relationship with tardive dyskinesia and parkinsonism: a cross-section study in psychiatric patients. Pharmacopsychiatry 2005; 38: 171-177

674 Ulrich S, Wurthmann C, Brosz $M$ et al. The relationship between serum concentration and therapeutic effect of haloperidol in patients with acute schizophrenia. Clin Pharmacokinet 1998; 34: 227-263

675 Valdes R Jr, Payne DA, Linder MW (eds.). Laboratory medicine practice guidelines and recommendations for laboratory analysis and application of pharmacogenetics to clinical practice. Washington, DC: National Academy of Clinical Biochemistry, 2010

676 Van der Weide J, Steijns LS, van Weelden MJ. The effect of smoking and cytochrome P450 CYP1A2 genetic polymorphism on clozapine clearance and dose requirement. Pharmacogenetics 2003; 13: 169-172

677 Van der Weide J, van Baalen-Benedek EH, Kootstra-Ros JE. Metabolic ratios of psychotropics as indication of cytochrome P450 2D6/2C19 genotype. Ther Drug Monit 2005; 27: 478-483

678 Van der Zwaag C, McGee M, McEvoy JP et al. Response of patients with treatment-refractory schizophrenia to clozapine within three serum level ranges. Am J Psychiatry 1996; 153: 1579-1584

679 Van Gorp F, Whyte IM, Isbister GK. Clinical and ECG effects of Escitalopram overdose. Ann Emerg Med 2009; 54: 4-408

680 Van Putten T, Marder SR, Wirshing WC et al. Neuroleptic plasma levels. Schizophr Bull 1991; 17: 197-216

681 Varsaldi F, Miglio G, Scordo MG et al. Impact of the CYP2D6 polymorphism on steady-state plasma concentrations and clinical outcome of donepezil in Alzheimer's disease patients. Eur J Clin Pharmacol 2006; 62: 721-726

682 Vasudev K, Das S, Goswami U et al. Pharmacokinetics of valproic acid in patients with bipolar disorder. J Psychopharmacol 2001; 15: $187-190$

683 Vasudev K, Goswami U, Kohli K. Carbamazepine and valproate monotherapy: feasibility, relative safety and efficacy, and therapeutic drug monitoring in manic disorder. Psychopharmacology (Berl) 2000; 150: 15-23

684 Veefkind AH, Haffmans PMJ, Hoencamp E. Venlafaxine serum levels and CYP2D6 genotype. Ther Drug Monit 2000; 22: 202-208

685 Velligan DI, Lam YW, Glahn DC et al. Defining and assessing adherence to oral antipsychotics: a review of the literature. Schizophr Bull 2006; 32: 724-742

686 Venkatakrishnan K, Culm KE, Ehrenberg BL et al. Kinetics and dynamics of intravenous adinazolam, N-desmethyl adinazolam, and alprazolam in healthy volunteers. J Clin Pharmacol 2005; 45: 529-537

687 Venkatakrishnan K, von Moltke LL, Greenblatt DJ. Nortriptyline E-10hydroxylation in vitro is mediated by human CYP2D6 (high affinity) and CYP3A4 (low affinity): implications for interactions with enzyme-inducing drugs. J Clin Pharmacol 1999; 39: 567-577

688 Vernaleken I, Fellows C, Janouschek $H$ et al. Striatal and extrastriatal D2/D3-receptor-binding properties of ziprasidone: a positron emission tomography study with [18F]Fallypride and [11C]raclopride (D2/D3-receptor occupancy of ziprasidone). J Clin Psychopharmacol 2008; 28: 608-617

689 Vernaleken I, Janouschek H, Raptis $M$ et al. Dopamine D2/3 receptor occupancy by quetiapine in striatal and extrastriatal areas. Int J Neuropsychopharmacol 2010; 13: 951-960

690 Vernaleken I, Siessmeier T, Buchholz HG et al. High striatal occupancy of $\mathrm{D} 2$-like dopamine receptors by amisulpride in the brain of patients with schizophrenia. Int J Neuropsychopharmacol 2004; 7: 421-430

691 Ververs FF, Voorbij HA, Zwarts P et al. Effect of cytochrome P450 2D6 genotype on maternal paroxetine plasma concentrations during pregnancy. Clin Pharmacokinet 2009; 48: 677-683

692 Viala A, Ba B, Durand A et al. Comparative study of the pharmacokinetics of zuclopenthixol decanoate and fluphenazine decanoate. Psychopharmacology (Berl) 1988; 94: 293-297

693 Vine W, Bowers $L D$. Cyclosporine: structure, pharmacokinetics, and therapeutic drug monitoring. Crit Rev Clin Lab Sci 1987; 25: 275-311

694 Viola MS, Bercellini MA, Saidon P et al. Pharmacokinetic variability of oxcarbazepine in epileptic patients. Medicina (B Aires) 2000; 60: 914-918

695 Vogel F, Gansmüller R, Leiblein $T$ et al. The use of ziprasidone in clinical practice: Analysis of pharmacokinetic and pharmacodynamic aspects from data of a drug monitoring survey. Eur Psychiatry 2009; 24: 143-148

696 Voineskos AN, Wilson AA, Boovariwala A et al. Serotonin transporter occupancy of high-dose selective serotonin reuptake inhibitors during major depressive disorder measured with [11C]DASB positron emission tomography. Psychopharmacology (Berl) 2007; 193: 539-545 
697 Von Moltke LL, Greenblatt DJ, Giancarlo GM et al. Escitalopram (S-citalopram) and its metabolites in vitro: cytochromes mediating biotransformation, inhibitory effects, and comparison to R-citalopram. Drug Metab Dispos 2001; 29: 1102-1109

698 Von Moltke LL, Greenblatt DJ, Granda BW et al. Zolpidem metabolism in vitro: responsible cytochromes, chemical inhibitors, and in vivo correlations. Br J Clin Pharmacol 1999; 48: 89-97

699 Vormfelde SV, Bitsch A, Meineke I et al. Non-response to maprotiline caused by ultra-rapid metabolism that is different from CYP2D6? Eur J Clin Pharmacol 1997; 52: 387-390

700 Vuille F, Amey M, Baumann P. Use of plasma level monitoring of antidepressants in clinical practice. Towards an analysis of clinical utility. Pharmacopsychiatry 1991; 24: 190-195

701 Waade RB, Christensen H, Rudberg I et al. Influence of comedication on serum concentrations of aripiprazole and dehydroaripiprazole. Ther Drug Monit 2009; 31: 233-238

702 Waldschmitt C, Vogel F, Maurer C et al. Measurement of duloxetine in blood using high-performance liquid chromatography with spectrophotometric detection and column switching. Ther Drug Monit 2007; 29: 767-772

703 Waldschmitt C, Vogel F, Pfuhlmann B et al. Duloxetine serum concentrations and clinical effects. Data from a therapeutic drug monitoring (TDM) survey Pharmacopsychiatry 2009; 42: 189-193

704 Wan J, Xia H, He $\mathrm{N}$ et al. The elimination of diazepam in Chinese subjects is dependent on the mephenytoin oxidation phenotype. $\mathrm{Br}$ J Clin Pharmacol 1996; 42: 471-474

705 Wang JH, Liu ZQ, Wang W et al. Pharmacokinetics of sertraline in relation to genetic polymorphism of CYP2C19. Clin Pharmacol Ther 2001; 70: 42-47

706 Ward E, Musa MN, Bailey LG. Clinical pharmacokinetics of lithium. J Clin Pharmacol 1994; 34: 280-285

707 Weber J, McCormack PL. Asenapine CNS. Drugs 2009; 23: 781-792

708 Weiden PJ, Kozma C, Grogg A et al. Partial compliance and risk of rehospitalization among California Medicaid patients with schizophrenia. Psychiatr Serv 2004; 55: 886-891

709 Weigmann H, Bierbrauer J, Härtter S et al. Automated determination of clozapine and major metabolites in serum and urine. Ther Drug Monit 1997; 19: 480-488

710 Weigmann $H$, Härtter S, Hiemke C. Automated determination of clomipramine and its major metabolites in human and rat serum by high-performance liquid chromatography with on-line columnswitching. J Chromatogr B Biomed Sci Appl 1998; 710: 227-233

711 Weigmann H, Härtter S, Maehrlein S et al. Simultaneous determination of olanzapine, clozapine and demethylated metabolites in serum by on-line column-switching high-performance liquid chromatography. J Chromatogr B Biomed Sci Appl 2001; 759: 63-71

712 Weiss U, Marksteiner J, Kemmler $G$ et al. Effects of age and sex on olanzapine plasma concentrations. J Clin Psychopharmacol 2005; 25: 570-574

713 Wen B, Ma L, Zhu M. Bioactivation of the tricyclic antidepressant amitriptyline and its metabolite nortriptyline to arene oxide intermediates in human liver microsomes and recombinant P450s. Chem Biol Interact 2008; 173: 59-67

714 Wen $B$, Zhou M. Metabolic activation of the phenothiazine antipsychotics chlorpromazine and thioridazine to electrophilic iminoquinone species in human liver microsomes and recombinant P450s. Chem Biol Interact 2009; 181: 220-226

715 White NC, Litovitz T, Clancy C. Suicidal antidepressant overdoses: a comparative analysis by antidepressant type. J Med Toxicol 2008; 4: $238-250$

716 Wienkers LC, Allievi C, Hauer MJ et al. Cytochrome P-450-mediated metabolism of the individual enantiomers of the antidepressant agent reboxetine in human liver microsomes. Drug Metab Dispos 1999; 27: 1334-1340

717 Wiesel FA, Alfredsson G, Ehrnebo $M$ et al. The pharmacokinetics of intravenous and oral sulpiride in healthy human subjects. Eur J Clin Pharmacol 1980; 17: 385-391

718 Wille SM, Cooreman SG, Neels HM et al. Relevant issues in the monitoring and the toxicology of antidepressants. Crit Rev Clin Lab Sci 2008; 45: 25-89

719 Willmore LJ, Abelson MB, Ben-Menachem E et al. Vigabatrin: 2008 update. Epilepsia 2009; 50: 163-173

720 Wilson JF. Survey of reference ranges and clinical measurements for psychoactive drugs in serum. Ther Drug Monit 2003; 25: 243-247

721 Wilting I, Heerdink ER, Mersch PP et al. Association between lithium serum level, mood state, and patient-reported adverse drug reactions during long-term lithium treatment: a naturalistic follow-up study. Bipolar Disord 2009; 11: 434-440
722 Wincor MZ, Munjack DJ, Palmer R. Alprazolam levels and response in panic disorder: preliminary results. J Clin Psychopharmacol 1991; 11: 48-51

723 Winter HR, Earley WR, Hamer-Maansson JE et al. Steady-state pharmacokinetic, safety, and tolerability profiles of quetiapine, Norquetiapine, and other quetiapine metabolites in pediatric and adult patients with psychotic disorders. J Child Adolesc Psychopharmacol 2008; 18: 81-98

724 Wójcikowski J, Boksa J, Daniel WA. Main contribution of the cytochrome P450 isoenzyme 1A2 (CYP1A2) to N-demethylation and 5 -sulfoxidation of the phenothiazine neuroleptic chlorpromazine in human liver - a comparison with other phenothiazines. Biochem Pharmacol 2010; 80: 1252-1259

725 Wójcikowski J, Daniel WA. Perazine at therapeutic drug concentrations inhibits human cytochrome P450 isoenzyme 1A2 (CYP1A2) and caffeine metabolism - an in vitro study. Pharmacol Rep 2009; 61: 851-858

726 Wójcikowski J, Pichard-Garcia L, Maurel P et al. Contribution of human cytochrome p-450 isoforms to the metabolism of the simplest phenothiazine neuroleptic promazine. Br J Pharmacol 2003; 138: $1465-1474$

727 Wolff K, Hay AW, Rasitrick D et al. Steady-state pharmacokinetics of methadone in opioid addicts. Eur J Clin Pharmacol 1993; 44: 189-194

728 Wong SL, Granneman GR. Modeling of sertindole pharmacokinetic dispositions in healthy volunteers in short term dose-escalation studies. J Pharmaceut Sci 1998; 87: 1629-1631

729 Wong SL, Menacherry S, Mulford D et al. Pharmacokinetics of sertindole and dehydrosertindole in volunteers with normal or impaired renal function. Eur J Clin Pharmacol 1997; 52: 223-227

730 Wright CE, Sisson TL, Ichhpurani AK et al. Steady-state pharmacokinetic properties of pramipexole in healthy volunteers. J Clin Pharmacol 1997; 37: 520-525

731 Wynalda MA, Wienkers LC. Assessment of potential interactions between dopamine receptor agonists and various human cytochrome P450 enzymes using a simple in vitro inhibition screen. Drug Metab Dispos 1997; 25: 1211-1214

732 Xiang Q, Zhao X, Zhou Y et al. Effect of CYP2D6, CYP3A5, and MDR1 genetic polymorphisms on the pharmacokinetics of risperidone and its active moiety. J Clin Pharmacol 2010; 50: 659-666

$733 \mathrm{Xu} \mathrm{P}, \mathrm{Li} \mathrm{HD}$, Zhang BK et al. Pharmacokinetics and tolerability of modafinil tablets in Chinese subjects. J Clin Pharm Ther 2008; 33: 429-437

734 Yao C, Raoufinia A, Gold $M$ et al. Steady-state pharmacokinetics of galantamine are not affected by addition of memantine in healthy subjects. J Clin Pharmacol 2005; 45: 519-528

735 Yasui-Furukori N, Kondo T, Ishida $M$ et al. The characteristics of sideeffects of bromperidol in schizophrenic patients. Psychiatry Clin Neurosci 2002; 56: 103-106

736 Yasui-Furukori N, Saito M, Nakagami T et al. Association between multidrug resistance 1 (MDR1) gene polymorphisms and therapeutic response to bromperidol in schizophrenic patients: a preliminary study. Prog Neuropsychopharmacol Biol Psychiatry 2006; 30: 286-291

737 Yasui-Furukori N, Saito M, Nakagami T et al. Clinical response to risperidone in relation to plasma drug concentrations in acutely exacerbated schizophrenic patients. J Psychopharmacol 2010; 24: 987-994

738 Yeung PK, Hubbard JW, Korschinski ED et al. Pharmacokinetics of chlorpromazine and key metabolites. Eur J Clin Pharmacol 1993; 45: 563-569

739 Yin OQ, Wing YK, Cheung Y et al. Phenotype-genotype relationship and clinical effects of citalopram in Chinese patients. J Clin Psychopharmacol 2006; 26: 367-372

740 Yu DK, Dimmitt DC, Lanman RC et al. Pharmacokinetics of dothiepin in humans: a single dose dose-proportionality study. J Pharm Sci 1986; 75: 582-585

741 Zernig G, Hiemke C, Havemann-Reinecke $U$ et al. Empfehlungen für die gutachterliche Bewertung von Medikamentenspiegeln in der Psychiatrie im gerichtsanhängigen Schadensfall. Psychopharmakotherapie 2009; 16: 57-64

742 Zernig G, Lechner T, Kramer-Reinstadler $K$ et al. What the clinician still has to be reminded of. Ther Drug Monit 2004; 26: 582

743 Zernig G, Ng K, Hiemke C et al. Therapeutic drug monitoring-based clozapine dosing recommendations. Ther Drug Monit 2007; 29: 130-131 
744 Zhao $Q$ Iyer GR, Verhaeghe $T$ et al. Pharmacokinetics and safety of galantamine in subjects with hepatic impairment and healthy volunteers. J Clin Pharmacol 2002; 42: 428-436

745 Zhou SF. Polymorphism of human cytochrome P450 2D6 and its clinical significance: Part I. Clin Pharmacokinet 2009; 48: 689-723

746 Zhou SF. Polymorphism of human cytochrome P450 2D6 and its clinical significance: Part II. Clin Pharmacokinet 2009; 48: 761-804

747 Zhou SF, Liu JP, Chowbay B. Polymorphism of human cytochrome P450 enzymes and its clinical impact. Drug Metab Rev 2009; 41: 89-295
748 Zimmerman NP, Hickie IB, McGorry PD. Guidelines for youth depression: time to incorporate new perspectives. Med J Aust 2010; 193: 557

749 Zullino DF, Delessert D, Eap CB et al. Tobacco and cannabis smoking cessation can lead to intoxication with clozapine or olanzapine. Int Clin Psychopharmacol 2002; 17: 141-143 